Energy Division

\title{
Research Update, Existing Buildings Research, $1989-1991$
}

\author{
J. M. MacDonald \\ M. P. Ternes \\ W. R. Mixon \\ T. R. Sharp \\ J. O. Kolb \\ R. C. Diamond* \\ R. Judkoff ${ }^{\dagger}$ \\ K. E. Wilkes \\ R. P. Mazzucchi ${ }^{\S}$ \\ * - Lawrence Berkeley Laboratory \\ $\dagger_{-}$National Renewable Energy Laboratory \\ $\S$-Pacific Northwest Laboratory
}

February 1993

Prepared for the

\section{Existing Buildings Research Program}

Office of Building Energy Research

Prepared by the

OAK RIDGE NATIONAL LABORATORY

Oak Ridge, Tennessee 37831

Managed by

MARTIN MARIETTA ENERGY SYSTEMS, INC.

for the

U.S. DEPARTMENT OF ENERGY

under Contract No. DE-AC05-84OR21400 


\section{Contents}

LIST OF TABLES $\ldots \ldots \ldots \ldots \ldots \ldots \ldots \ldots \ldots \ldots \ldots \ldots \ldots \ldots \ldots$

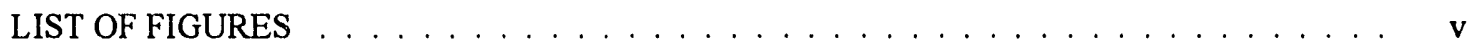

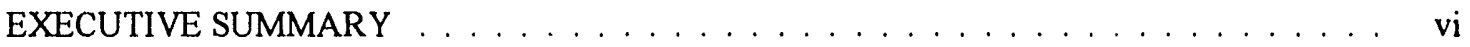

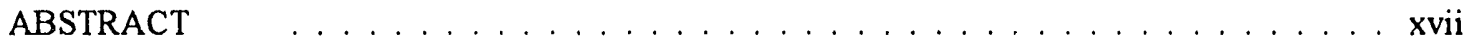

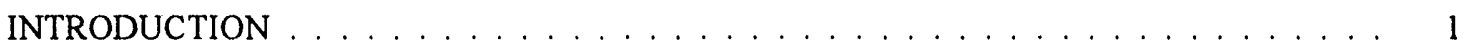

IMPORTANCE OF EXISTING BUILDINGS $\ldots \ldots \ldots \ldots \ldots \ldots$

Global Warming . . . . . . . . . . . . . . . . . . . . . . 4

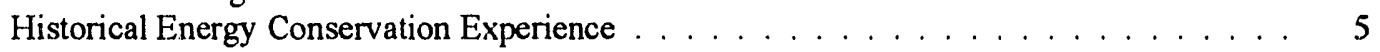

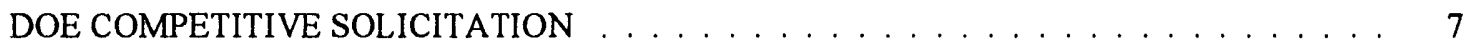

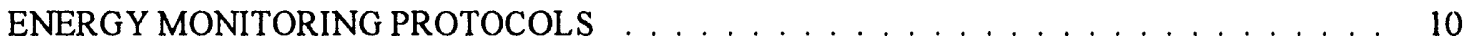

Need for Monitoring Protocols . . . . . . . . . . . . . . . . . . . . . 10

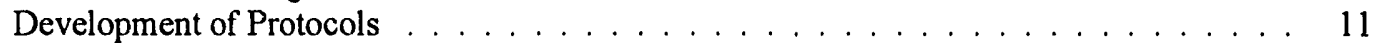

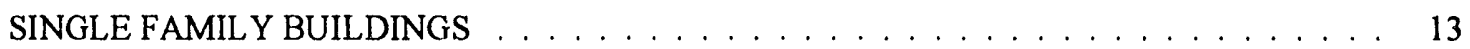

Retrofit Performance Demonstrations . . . . . . . . . . . . . . . . . . 13

New York . . . . . . . . . . . . . . . . . . . . . . . 13

North Carolina . . . . . . . . . . . . . . . . . . . 19

Minnesota . . . . . . . . . . . . . . . . . . . . . 20

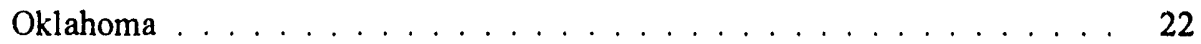

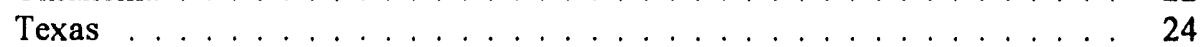

Development of Improved Tools . . . . . . . . . . . . . . . . . . . . . . . . . 26

Motor current signature diagnostics for air conditioners . . . . . . . . . . . 26

Duct systems . . . . . . . . . . . . . . . . . . . . . 26

Mobile Home Research . . . . . . . . . . . . . . . . . . . . . . . . . . . . . 30

Radiant Barrier Research . . . . . . . . . . . . . . . . . . . . . 33

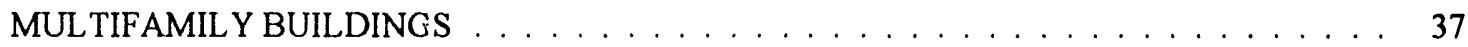

Retrofit Performance Demonstrations . . . . . . . . . . . . . . . . . . . . 37

Burlington, Vermont . . . . . . . . . . . . . . . . . . 37

New York . . . . . . . . . . . . . . . . . . . . . . . 38

Development of Improved Tools . . . . . . . . . . . . . . . . . . . . . . . . . 38

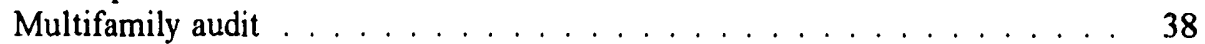

Multifamily diagnostics . . . . . . . . . . . . . . . . . . 38

Retrofit modeling . . . . . . . . . . . . . . . . . . . . 39

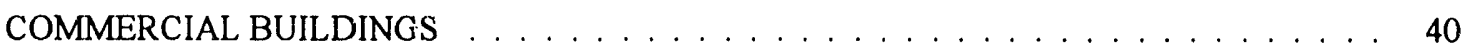

Retrofit Performance Demonstrations . . . . . . . . . . . . . . . . . . . . . . 40

Tennessee . . . . . . . . . . . . . . . . . . . . . 40

Massachusetts ........................ . . 43

District of Columbia . . . . . . . . . . . . . . . . . . . . . . . . 44

Development of Improved Tools . . . . . . . . . . . . . . . . . . . . . . . . . . . . 44

Monitoring guidelines . . . . . . . . . . . . . . . . . . 44

Analysis methods . . . . . . . . . . . . . . . . . . 45

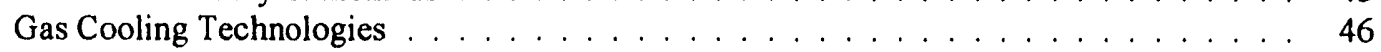

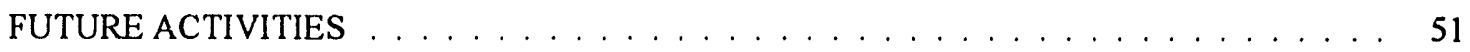

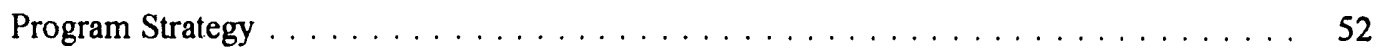

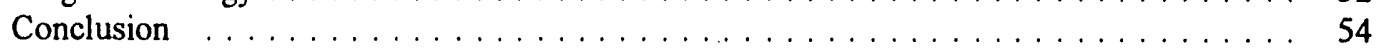

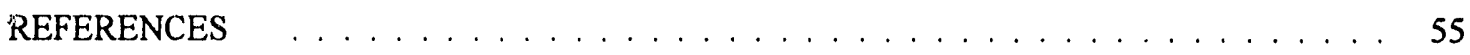

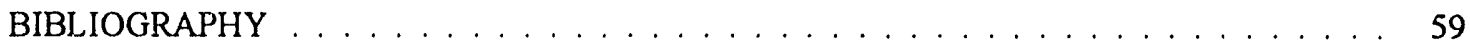




\section{List of Tables}

Page

Table NY1 Summary of adjusted savings for the audit houses $\ldots \ldots \ldots \ldots \ldots$

Table NY2 Comparison of current results with those of previous studies $\ldots \ldots \ldots$

Table MN1 Economic analysis of average first year savings based on modeled performance of heated basements . . . . . . . . . . . . . . . 21

Table RBl Present value savings for radiant barrier attached to bottoms of rafters . . . 36

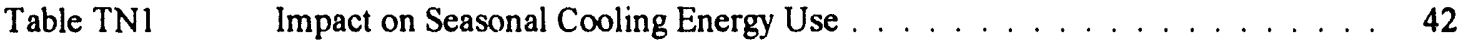




\section{List of Figures}

Figure NY1 Comparison of adjusted to predicted space-heating energy savings

for each audit house . . . . . . . . . . . . . . . . 15

Figure NY2 Installation frequency of energy conservation measures in

the 36 audit houses . . . . . . . . . . . . . . . . . . 16

Figure NY3 Histogram of adjusted space-heating energy savings for the

32 audit houses . . . . . . . . . . . . . . . . . . . . . . 17

Figure NY4 Histogram of actual installation costs for the 32 audit houses . . . . . . . 17

Figure NY5 Comparison of indoor temperature changes for the field test houses . . . . 18

Figure OK1 Histogram of normalized pre-weatherization air-conditioning

electricity consumption . . . . . . . . . . . . . . . . 23

Figure OK2 Average normalized pre- and post-weatherization air-conditioning

Figure TXl Box plots of pre- and post-retrofit air conditioner size and EER . . . . . 25

Figure $\mathrm{MCl} \quad \mathrm{MCS}$ startup fraction indicates refrigerant charge $\ldots \ldots \ldots \ldots$

Figure $\mathrm{MH1} \quad \mathrm{A}$ truck moves a mobile home into the environmental enclosure (warehouse) . 30

Figure MH2 Measured cumulative overall building loss coefficient (BLC) for

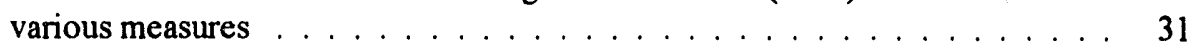

Figure MH3 Measured reductions in BLC for each mobile home configuration . . . . . 31

Figure MH4 Increase in measured efficiency of furnace/duct systems $\ldots \ldots \ldots \ldots$

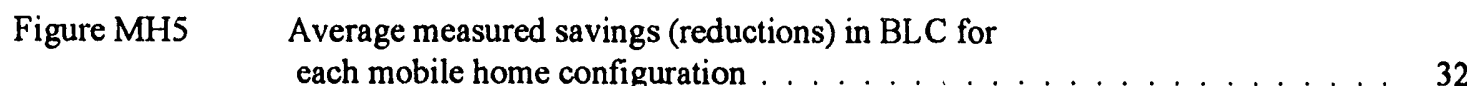

Figure MH6 Mobile home construction details were studied closely $\ldots \ldots \ldots \ldots 32$

$\begin{array}{ll}\text { Figure } \mathrm{RB1} & \text { Image showing clean radiant barrier (dark square) } \\ \text { against dusted barrier (grey) } \ldots \ldots \ldots \ldots \ldots \ldots \ldots \ldots & \ldots \ldots \ldots \ldots\end{array}$

Figure RB2 Comparison of model predictions with ceiling heat fluxes in a full-size house . 34

Figure $\mathrm{TN} 1 \quad$ Outside view of the bank $\ldots \ldots \ldots \ldots \ldots \ldots \ldots$

Figure TN2 Hourly heating energy use before and after the retrofit $\ldots \ldots \ldots \ldots 41$

Figure TN3 Retrofit impact on cooling energy use on weekends . . . . . . . . . . 42

Figure TN4 The bank air conditioning is provided by typical pad-mounted

$\begin{array}{ll}\text { Figure } \mathrm{GCl} & \text { Total cooling coil load profile for reference building } \\ & \text { with VAV system in Chicago } \ldots \ldots \ldots \ldots \ldots \ldots\end{array}$

Figure $\mathrm{GC2} \quad$ Chiller load duration curves $\ldots \ldots \ldots \ldots \ldots \ldots$

Figure GC3 Internal rate of return (IRR) values for replacing electric centrifugal chillers with engine driven chiller options,

$200,000 \mathrm{ft}^{2}$ office building with VAV system, Chicago . . . . . . . . . 49

Figure $\mathrm{F} 1 \quad$ Customer categories of the Existing Buildings program $\ldots \ldots \ldots \ldots \ldots$ 


\section{EXECUTIVE SUMMARY}

Although research and development efforts directed toward improving the energy efficiency of new buildings are important for increasing the efficiency of the buildings sector, improvements to existing buildings will always be critical because buildings are used typically for periods of over 50 years. The Existing: Buildings Research program of the Office of Building Technologies within the Conservation and Renewable Energy Program of the U.S. Department of Energy has continued over the pasi several years to advance capabilities in the United States for improving the delivery of energy efficiency technologies to buildings. The importance of energy savings for existing buildings is highlighted by the buildings energy conservation record over the period 1972-19\$6, where available data indicate that improvements to existing buildings have led to a contribution five times as large as that from new buildings to the increase in energy efficiency of the buildings sector (see $\mathrm{pp} \mathrm{5-6).} \mathrm{Continued} \mathrm{improvement} \mathrm{in} \mathrm{buildings}$ sector energy efficiency may require increased emphasis on existing buildings.

Energy technologies are continually evolving and are introduced somewhat continuously. Since buildings typically have lives longer than 50 years and improved building energy efficiency technologies do not come in batches, existing buildings must continually be improved to achieve accelerated progress in energy efficiency in the buildings sector. Introduction of improved technologies will occur over an unacceptably long time if existing buildings are not a major thrust of any national energy efficiency improvement program directed at buildings.

Global climate change, especially global warming, has become a major issue related to energy use. Existing buildings account for about $35 \%$ of the total energy use in the United States and about $10 \%$ of total global energy use. Since the contributions to global warming are approximated by energy use, existing buildings in the United States have a potentially important impact on global warming issues.

The Existing Buildings Research program has contributed to significant improvements in energy efficiency of existing buildings by development of improvements to retrofit technologies, by coordinating and conducting research studies on the use of energy efficiency technologies (to reduce barriers and increase use), and by continually evaluating changes in technologies that could improve and maintain buildings energy efficiency. This Research Update summarizes these contributions for the years 1989-1991.

-

The program seeks to support the increase in energy efficiency of the existing building stock by focusing on four technical objectives:

- Provide reliable data on retrofit performance and the means of collecting such data and maintain the national capability for analyzing and updating retrofit performance data

- Evaluate technologies for retrofit energy savings potential and assist in the development of attractive retrofit technologies 
- Measure and analyze the influence of human and other factors on the effectiveness of retrofits and post-retrofit operations and maintenance

- Make the results of research on existing buildings widely available to the building efficiency industry through participation with national networks and other technology transfer activities

Research is conducted on single family, multifamily, and commercial (including institutional) buildings. The program also conducts activities across sectors to further the technical objectives. The summary of results will be presented first by major cross-cutting activity and then by building sector.

\section{DOE COMPETITIVE SOLICITATION}

In 1989, DOE issued a broad competitive solicitation to develop cooperative, cost-shared projects in order to promote collaboration between the buildings industry and the DOE National Laboratories. The solicitation offered financial as well as technical assistance. The areas of research interest listed in the solicitation were:

- Development of educational programs and delivery systems which increase energy efficiency awareness and achievement of energy savings.

- Field monitoring of the efficacy of single or combined retrofit measures.

- Development of tools or methods to diagnose energy use in buildings, building equipment, or operations and maintenance.

- Development of non-proprietary models that accurately predict building energy use and savings due to retrofit measures.

- Innovative and effective methods of technology transfer.

- Documentation of energy savings in existing buildings.

The response was excellent. There were 104 proposals received from 80 organizations, and the research topics proposed confirmed our previous determination of the types of research and information that are needed to overcome barriers to retrofit actions. Ten proposals were accepted, and the work on most of these began in 1991.

\section{ENERGY MONITORING PROTOCOLS}

Energy (and power) monitoring in buildings is conducted for utility planning, assessing the efficiency of building energy systems (new building performance, baseline performance, evaluation of retrofits), systems development (HVAC, lighting, controls, etc.), tracking performance, assessing public policy, and diagnosing specific problems in buildings. While the range of 
issues raised for these various purposes is diverse, a common challenge is obtaining accurate, reliable, and cost-effective performance data that meets information needs.

Protocols consist of experimental plans, specifications, and procedures for various field monitoring activities that are generally useful to others as models and examples of accepted practice. The focus is on methods and procedures for monitoring, as opposed to the selection and use of hardware. In general, monitoring protocols are being advanced to serve as examples of good practice, to improve communication of the experimental design of specific projects, to achieve more uniformity in the development and documentation of monitoring projects, and to improve communication by use of a classification system.

The Existing Buildings program has participated in the development of monitoring protocols and made major contributions over several years. Protocols have been developed specifically for monitoring energy savings in field studies of energy retrofits in single family, multifamily, and commercial buildings. Participation in the ASHRAE Technical Committee 9.6 Subcommittee on Building Energy Monitoring has made a significant contribution to the completion of a chapter on this topic for the ASHRAE Handbook (1991 Applications volume). Within ASTM, a new standard for monitoring energy use in residential buildings has been approved, Standard Practice for Specifying Data for Evaluation of Energy Used in Residential Buildings, E 1410, and is now available. A standard guide for designing energy monitoring projects in commercial buildings is in the balloting stage now. The Existing Buildings program has made significant contributions to energy monitoring procedures, and important knowledge is being added to the publications of national standards organizations.

\section{DEVELOPMENT OF IMPROVED TOOLS}

A large percentage of existing building air conditioners, heat pumps, and chillers operate at low efficiency and reduced capacity due to a variety of problems. One common problem is improper refrigerant charge, caused either by leaks in the system or improper charging when installed. For one system tested at ORNL, a $26 \%$ reduction in refrigerant charge caused a $23 \%$ loss of efficiency and a $31 \%$ loss of capacity.

The program has been studying whether measurement of electric current outside the compressor can be used as a diagnostic tool to identify equipment with low refrigerant charge. One electric current measurement parameter has been found that indicates refrigerant charge and is insensitive to variations of temperature, voltage, and evaporator air flow. Tests to date are encouraging and continue to support the technical feasibility of developing a simple diagnostic tool to indicate low refrigerant charge in air conditioners.

Ducted forced-air heating systems are an important thermal distribution system in buildings. Duct systems were examined in a study in the Pacific Northwest. Field data on duct losses was sparse prior to this project. The economics of retrofitting ducts after construction was not well understood. The objective of this project was to assess the energy impact and economics of duct losses and to test techniques for measuring and locating duct leakage. 
The study showed that, for comparable homes, ducted homes have 12-26\% more air leakage than homes without duct systems and heating energy use per square foot of heated area of ducted houses is $13-40 \%$ higher than for unducted houses. The studies also indicated that duct leakage is highly variable. Ten percent of the houses showed no significant leakage while $10 \%$ showed severe leakage. On average, duct leakage reduced heating system efficiency by $12 \%$. Using present techniques, about one quarter of the duct leakage could be located and repaired. Estimates of energy savings from duct repairs averaged $375 \mathrm{kWh} / \mathrm{year}$, which led to a simple payback of about four years.

A flexible, public domain methodology was developed for estimating financial indicators for alternative HVAC equipment in commercial buildings. It is based on simulation of the building hourly energy use, and it allows for many economic parameters, among which are detaiied utility rate structures, energy escalation rates, inflation rates, and loan expenses. The methodology can also be applied to single family and commercial buildings, and technologies other than HVAC technologies can also be analyzed.

All the programs used in the methodology are public domain routines. In this investigation, personal computers were used or could be used to run all the programs. These programs are flexible and can be changed relatively easily.

\section{SINGLE FAMILY FIELD DEMONSTRATIONS}

Energy consumption data on a variety of single family energy retrofit projects have been collected over the years, and many have reported considerable scatter in the effectiveness of retrofits. This scatter leads to uncertainty about reasonable approaches to improving energy efficiency through retrofits, and the uncertainty leads to distrust by consumers about energy retrofits. The single family research program has conducted research, development, and demonstration efforts in a number of areas to begin to address the uncertainties about energy retrofits in single family buildings. These activities have supported widespread and growing improvements in public and private sector skills for putting energy retrofits in place in the single family building stock.

A cost-shared, cooperative field test was performed in 89 houses in Buffalo, New York, to verify the energy savings and program improvements achieved from use of an advanced residential energy conservation measure (ECM) selection technique in conservation programs. The technique is a commercially available, proprietary audit program that is based on a prototype developed originally under the Existing Buildings program.

The study results showed that use of a measure selection technique to select unique ECMs for individual houses resulted in a significant cost-effective level of energy savings. The average adjusted savings of the houses studied was 257 therms/year: 252 therms/year from space-heating energy savings and 5 therms/year from water-heating energy savings. Adjusted space-heating energy savings was $25 \%$ of the average pre-weatherization space-heating energy consumption ( 1022 therms/year), adjusted water-heating energy savings was $2 \%$ of the average pre-weatherization water-heating energy consumption ( 272 therms/year), and the total adjusted 
energy savings was $17 \%$ of the average pre-weatherization house gas consumption. The overall benefit-to-cost ratio for the ECMs installed in the houses was 1.24 assuming just installation costs (no administration cost), current residential fuel costs $(\$ 0.579 /$ therm), a discount rate of 0.05 , and no fuel escalation (same assumptions as made in the measure selection technique). A weatherization program would be cost effective at an administration cost less than $\$ 335 /$ house.

A field test is being conducted in North Carolina to examine a newly-developed, single-family weatherization audit which incorporates new weatherization measures and techniques and expanded capabilities over existing audits used in most state weatherization programs. The field test is part of an overall effort to improve the energy savings and cost-effectiveness of weatherization programs nationwide. This field test is currently in progress, and results are expected in 1992 .

Another cooperative, cost-shared field test was performed in 81 occupied low-income, single-family houses in the Tulsa, Oklahoma area. The objectives of the field test were to determine the space-cooling electricity consumption of low-income houses equipped with window air-conditioners, the reduction in consumption due to ECMs installed under Oklahoma's Weatherization Assistance Program (WAP), and the additional reduction due to two ECMs designed to reduce space-cooling electricity consumption: attic radiant barriers and replacement of low-efficiency window air conditioners with high-efficiency units.

To study air-conditioning electricity consumption and savings, new field measurement and analysis methods were developed. The electricity consumption of each individual air conditioner, indoor temperature of each house, and outdoor temperature were measured to obtain weekly energy consumption totals and average weekly temperature. Pre-weatherization measurements were made from June to September 1988. Post-weatherization measurements were made the following cooling season (May to September 1989). The study results show that programs directed at reducing space-cooling electricity consumption will more likely be cost effective if targeted at clients with high air-conditioning electricity consumption and/or if costs can be minimized. Current air-conditioning electricity consumption sets an upper limit on potential program savings. Under this field test, consumption of the 81 houses averaged 1664 $\mathrm{kWh} /$ year (\$119/year). Individual house consumptions were quite variable, with $10 \%$ of the tested houses using less than $250 \mathrm{kWh} /$ year and $10 \%$ more than $3000 \mathrm{kWh} /$ year.

Replacing low-efficiency air conditioners with high-efficiency units produced measurable savings, with increased savings and cost-effectiveness achieved in houses with high initial air-conditioning electricity consumption. An average reduction in air-conditioning electricity consumption of $535 \mathrm{kWh} /$ year ( $\$ 38 /$ year and $28 \%$ of pre-weatherization consumption) was obtained from replacement of one air conditioner per house at a cost of $\$ 947$ house. For approximately the same cost (\$999/house), savings doubled to $1068 \mathrm{kWh} /$ year $(\$ 76 /$ year and $34 \%$ of pre-weatherization consumption) in houses with initial air-conditioning electricity consumption greater than $2500 \mathrm{kWh} / \mathrm{year}$.

Replacement of residential central air conditioners with high-efficiency units was examined in a field test in Austin, Texas. The objective of this study was to cletermine the energy use and 
electric demand impacts of replacing older, low-efficiency air conditioners with (smaller, where possible) high-efficiency units. Electric energy performance data was collected on twelve houses during two cooling seasons (pre-retrofit in 1987 and post-retrofit in 1988).

The air conditioner retrofits in this project reduced the annual air conditioner electric consumption and peak demand by an average of $38 \%$. Normalized average demand reductions were $1.1 \mathrm{~W} / \mathrm{sq} \mathrm{ft}$ of conditioned area, and normalized average annual energy savings were 1.4 $\mathrm{kWh} / \mathrm{sq} \mathrm{ft}$. Air conditioner power demand at individual sites was a well-defined function of outdocr air temperature for both pre- and post-retrofit periods. As an aggregate for all sites, air conditioner energy consumption was a strongly linear function of outdoor temperature.

The air conditioner retrofits in Austin are effective in reducing annual air conditioner electric consumption and peak electric demand. Cost-effectiveness of the replacements was not expected to be good, since dollar savings are not quite large enough (in the range of $\$ 150-200 / y r$ ) to justify replacement of functioning units. The results from this study were expected to be used when considering development of a conservation program targeted at increasing the efficiency and reducing the size of units installed when an air conditioner is being replaced for other reasons (such as a unit that can no longer be repaired cost effectively).

Foundation insulation was examined in a field test in Minnesota. The objective was to evaluate the effectiveness of foundation insulation in reducing basement conductive heat loss. Ten houses received interior insulation and ten received exterior insulation retrofits. Fiberglass insulated stud walls were used for eight of the interior retrofits and extruded polystyrene was used for two. All ten exterior retrofits were done using extruded polystyrene. For various reasons, such as change of owner/occupant, five houses were deleted from the final analysis.

On the average, the houses in the study achieved only about one-third of the whole-house energy savings that were predicted by a two-dimensional finite difference model. Savings may have been overpredicted by the model, since it assumed a constant and uniform basement air temperature and did not include effects of basement air stratification on whole-house energy use.

Model calculations indicated that, in order for foundation insulation retrofits to achieve payback periods of ten years or less, they must be applied to intentionally heated space. The accuracy of the model for these results was verified by comparing model results to measured data obtained from a uniformly heated below grade test module.

\section{MOBILE HOME RESEARCH}

A controlled environmental enclosure has been developed to allow testing of weatherization measures for pre-1976 vintage (pre-HUD-Standard) mobile homes under controlled conditions. Pre-HUD-Standard mobile homes use from 1.25 to 2 times the energy per square foot of comparable site-built houses. Their unique construction makes them difficult to weatherize effectively using the measures and techniques developed for site-constructed dwellings. 
Eight mobile homes have been tested. Each test usually takes only one or two nights, so it has been possible to combine testing with training workshops. The trainees install a measure one day and find out how effective their work has been the next. To date a number of weatherization measures have been tested, including: air sealing and duct repair (using blower door and tracer gas), furnace tune-ups, interior storm panels, window repairs and replacements, blown-in insulation in the belly (fiberglass and cellulose), insulation wrap of the belly, skirting and insulated skirting, blown-in insulation in the roof (fiberglass and cellulose), roof cap insulation, and wall insulation.

In general, for colder climates the most cost effective measures include: blower-door-directed air sealing and duct repair, furnace tune-up, interior storm panels, and blown insulation in the roof and the belly. The blown insulation may result in moisture damage in some climates and should probably be researched further before it is widely applied.

Tests to date have shown skirting, insulated skirting, roof cap insulation, and insulation wrap of the belly to be less cost effective. The research also indicates that window and door replacements should only be used when repair would be more expensive than replacement. Even for jalousie and awning windows, money is better spent on interior storm panels than on window replacement. Some additional testing was performed with wind emulation, which appeared to confirm these conclusions.

\section{RADIANT BARRIER RESEARCH}

A special research effort has been conducted to examine a new retrofit measure for single family buildings. The new measure is radiant barriers, which are installed in attics of single family houses to improve thermal performance. Computer models were developed for residential attics with or without radiant barriers. A model for the thermal performance of attics was coupled with the DOE-2.1C model to estimate annual energy savings due to radiant barriers. The model was extended to allow estimates of the amount of moisture that would accumulate on the underside of a horizontal radiant barrier on an annual basis. Both models were partially validated by comparing their predictions with measured values of ceiling heat flow, house energy use loads, and moisture condensation. Both models were used to estimate annual energy savings and moisture accumulation for a wide range of climatic conditions.

The estimates of annual energy savings were used as a basis for an Attic Radiant Barrier Fact Sheet that was published by DOE in 1991. The intent of this Fact Sheet is to provide consumers with a source of unbiased information on which to make decisions about installing radiant barriers. The Fact Sheet tells what radiant barriers are, how they work, how they differ from conventional attic insulation, what their characteristics are, how much they cost, and what effect they will have on cooling and heating bills. The annual energy savings estimates are shown as present value savings ( $\$$ per square foot of ceiling area), which allows the consumer to compare directly with the cost for installation to determine whether or not installation of a radiant barrier 
is cost effective. In general, the estimated savings are higher for warmer climates and higher when the radiant barrier is added to lower levels of conventional attic insulation.

\section{MULTIFAMILY FIELD DEMONSTRATIONS}

A field test involving retrofits of 335 multifamily units is being conducted in Burlington, Vermont. The project was conceived and is being carried out by a local non-profit housing organization (Northgate Housing) and the local electric utility (Burlington Electric Department). The apartments have been converted from electric-baseboard heating to gas-fired hydronic systems, with additional retrofits to the building shell and equipment. The retrofits in the buildings will be modeled using an energy simulation program to estimate the contribution of the individual retrofit measures where possible. The utility bills will also be analyzed to determine the overall energy savings. Results from this project should be available in 1992.

Another multifamily field test is being planned to evaluate replacement of central boilers and installation of new windows in 30 apartment buildings in New York City. The space-heating energy consumption will be monitored for two years to examine the persistence of savings.

\section{COMMERCIAL FIELD DEMONSTRATIONS}

A field evaluation of a smart thermostat and related temperature control improvements was conducted in a 4,000 sq $\mathrm{ft}$ commercial bank building in Knoxville, Tennessee. The field study had three objectives: to demonstrate the energy savings and demand impacts of the installed measures, to develop a better understanding of how to measure and analyze baseline and improved performance from measured energy use data in small commercial buildings, and to improve knowledge of the data requirements necessary to characterize the energy performance of commercial buildings. Timed setback-setup control was added to the primary heating and cooling systems in the building and timed on/off control to two secondary systems. The upgrades on the three systems were achieved with minimal replacement of existing controls.

Hourly electricity and gas consumption and hourly outdoor temperatures are available for this building for the period of June 17, 1987 to August 30,1988. Data analyses indicated that the measures were highly effective. Heating energy savings were substantial for both weekdays and weekends. The control changes provided a $33 \%$ reduction in winter heating energy use. The new control strategy reduced cooling energy requirements by $21 \%$. Unlike heating energy savings, cooling energy savings occurred mostly on weekends, with essentially no savings on weekdays. The retrofit was installed by a contractor at a cost of $\$ 600$ in 1988 . Total energy savings provided a simple payback of less than one year on the controls upgrade.

A project is being conducted with an electric utility in Massachusetts that is conducting an energy conservation program for small commercial customers. The project is set up to provide: analytical review of estimates of energy savings benefits, development of improved savings estimates where needed, identification of additional energy saving measures for use in the 
program, planning of field tests to verify savings from measures, evaluation of program benefits and analysis of energy savings results from field tests, and development of improved methods for providing energy services so these services can move closer to "real time." An evaluation of program energy-saving impacts for the approximately 1,000 buildings served by the program from March through September 1990 will be completed during 1992.

The research work on the energy savings potential of energy management controls in the small bank in Tennessee highlighted the potential benefits of this type of technology - which many commercial buildings now use but many also do not. A field test of improved controls in medium to large commercial buildings in the general location of the District of Columbia is presently being planned. The objective of the project is to provide credible results on the field performance of these new technologies.

\section{FUTURE ACTIVITIES}

The new National Energy Strategy (NES) identifies more effective techniques for retrofitting existing residential buildings as an important area of ongoing research that has produced useful results and will continue to receive support. For commercial buildings the NES states a goal of supporting industry, utilities, and government agencies in developing and implementing effective [retrofit] programs. Increasing the energy efficiency of the buildings sector is an important part of the NES.

The Existing Buildings Research program provides a fundamental resource for national efforts to improve the efficiency of the buildings sector of our economy. In addition tc conducting R\&D on new technologies needed to specifically address special needs for energy retrofits in buildings, this program bridges the huge gap between technology R\&D and technology use. Within this gap is the large array of activities associated with deployment of technologies within buildings. For deployment to be successful, the technology must meet a need and the barriers to deployment described in the In+roduction must be overcome.

To support continued technology deployment, the program will continue to support improvements to program implementation through field test studies. Wider application of current technologies is important. Field tests will only ie conducted in cases where other organizations provide significant cost-sharing, indicating an important need for the results. To the extent possible, we will attempt to conduct demonstrations in all climate areas of the country.

New technologies for improved retrofit capabilities and diagnosis of retrofit opportunities will receive increased attention. Advanced diagnostics are also needed to make identification and installation of retrofits a lower portion of total installation costs. Advanced methods for tracking and analyzing energy use and savings will continue to be applied and refined.

If the energy efficiency of the buildings sector in this country is to be dramatically improved over the next 30 years, we must improve the use of energy efficiency technologies. Improved delivery of measures, improved understanding of how buildings actually perform in the field, 
and methods for improving operations and maintenance of buildings and energy equipment are all examples of ways to improve the deployment (transfer) of technologies. The Existing Buildings Research program works to meet these needs. Much has been learned about technology deployment in buildings in the first five years of the program, and our future plans will be directed at continuing the improvements and making a real contribution to the energy efficiency future of the United States. 


\title{
Research Update, Existing Buildings Research, 1989-1991
}

\author{
J. M. MacDonald, ORNL \\ M. P. Ternes, ORNL \\ W. R. Mixon, ORNL \\ T. R. Sharp, ORNL \\ J. O. Kolb, ORNL \\ R. C. Diamond, LBL \\ R. Judkoff, NREL \\ K. E. Wilkes, ORNL \\ R. P. Mazzucchi, PNL
}

\begin{abstract}
This Research Update presents the status of the Existing Buildings Research program of the Office of Building Technologies of the U.S. Department of Energy for the period 1989-1991. This program covers research on energy efficiency improvements for the residential and commercial buildings in this country. The Existing Buildings Research program has contributed to significant improvements in energy efficiency of existing buildings by development of improvements to retrofit technologies, by coordinating and conducting research studies on the use of energy efficiency technologies (to reduce barriers and increase use), and by continually evaluating changes in technologies that could improve and maintain buildings energy efficiency. If the energy efficiency of the buildings sector in this country is to be dramatically improved over the next 30 years, we must improve the use of energy efficiency technologies. Improved delivery of measures, improved understanding of how buildings actually perform in the field, and methods for improving operations and maintenance of buildings and energy equipment are all examples of ways to improve the deployment (transfer) of technologies. Much has been learned about technology deployment in buildings in the first five years of the program, and our future plans will be directed at continuing the improvements and making a real contribution to the energy efficiency future of the United States.
\end{abstract}




\section{INTRODUCTION}

The Existing Building Research program of the Office of Building Technologies within the Conservation and Renewable Energy Program of the U.S. Dept of Energy has continued over the past several years to advance capabilities in the United States for improving the delivery of energy efficiency technologies to consumers' buildings. This Research Update provides a summary of program activities for 1989-1991. (See MacDonald 1988a for a summary of previous work.) Improving energy efficiency of existing buildings through retrofit measures remains one of the major opportunities for increasing the resiliency of our economy, ameliorating potential environmental difficulties, and extending the lifetimes of our energy resources.

Although efforts directed toward improving buildings as they are built (new buildings) are important for improving the efficiency of the buildings sector, improvements to existing buildings will always be critical because buildings are used typically for periods of over 50 years. Thus, introduction of improved technologies will occur over an unacceptably long time if existing buildings do not have retrofit improvements installed. For example, the housing stock standing in 1990 will represent about $75 \%$ of the total housing stock standing 20 years later, so if no improvements are made to the existing stock, a large portion of the stock cannot contribute to expected improvements. Existing buildings are an important part of the U.S. infrastructure. They represent a major energy and economic investment-with perhaps the longest holding periods of any capital stock - that must be maintained and improved over time.

Our previous estimates of potential energy savings possible from retrofits indicate 5 quads/yr (quad $=10^{15}$ Btu) or more might be saved in existing buildings (MacDonald 1988), and our field experience indicates these estimates are probably reasonable. Advances in technologies are expected to increase this savings potential. In the recent draft conservation and electric power plan (NWPPC 1990, p 24) for the Pacific Northwest, acquisition of 1,350 MW of conservation resources is proposed, which at an average load factor of $30 \%$ for a whole year translates to about 0.04 quads/yr. This energy savings for one fuel-electricity-in a region of the country having low electricity costs is impressive. Electricity consumption in this region is about $5 \%$ of total electrical energy use for the country. Efforts to improve the efficiency of existing buildings have been extensive in this region, yet the proposed acquisition of conservation resources from existing buildings is $400 \mathrm{MW}$ out of the 1,350 total (30\%). Significant improvements to the existing building stock are still possible and desirable.

The entire country, including the buildings sector, has made major gains in energy efficiency. One estimate showed efficiency improvement savings of 32 quads/yr in 1986 over the year 1972 , if historical trends had held constant (DOE 1989, p 5). Of these estimated 32 quads of savings, $50 \%$ of the savings were estimated to occur in the buildings sector, which includes residential, commercial, and institutional buildings. Another indicator of improved efficiency is the change in energy consumption relative to the change in gross national product (GNP). From 1972 to 1989 , total energy use increased only $14 \%$ while GNP increased $59 \%$ (EIA 1990a, p 25). Somc impressive efficiency gains have been made since the time of the Arab Oil Embargo of 1973. 
Given that improving the energy efficiency of our economy is important, other comparisons suggest that improving the efficiency of our buildings infrastructure should be pursued still more vigorously. The industial sector had been the largest consumer of energy since 1949, when the other two sectors of the exoncmy--buildings and transportation-each consumed about $60 \%$ as much energy. However, ty 1972 buildings consumed about $80 \%$ as much energy as industry. And from 1986-1989, buildings used about the same as or a little more energy than the industrial sector, while the transportation sector used about $75 \%$ as much (EIA 1990a, p 13).

Energy expenditures show a different picture. In recent history, the industrial sector has had the lowest expenditures, while the transportation sector has had the highest. However, expenditures for energy in the buildings sector increased from $84 \%$ of transportation expenditures in 1975 to $120-130 \%$ of those for transportation from 1986-1988, making the buildings sector the highest (EIA 1990b,p 17). The buildings sector has moved toward increased energy use relative to the industrial sector and increar id expenditures relative to the iransportation sector, indicating relative gruwth in this part of the economy or relative weakness in efficiency improvement compared to the other two scctors (also see MacDonald 1988, p 3). Thus, a higher relative improvement in buildings energy efficiency appears needed as the buildings sector contributes a growing impact on energy use and expenditures relative to the other two sectors.

Warnings of an "efficiency plateau" have surfaced, where, around the world, the recent evidence of a reversal or stoppage of increases in average heating efficiency of homes and the slowdown in improvements in appliance efficiency are cited as indicators of the buildings sector contribution to such a plateau. Schipper and Ketoff $(1989, \mathrm{p} 541)$ indicate their assessment that the plateau "reflects consumer indifference, not the exhausting of cost-effective energy saving investments." The Existing Buildings Research program recognizes that improving the energy performance of buildings requires continuous innovation, where innovation means both the development and use of energy saving technologies. Innovation requires that new technologies be developed and available and that these technologies be used. Enabling the development and use of retrofit technologies is the central challenge of the program.

Many energy saving technologies (investments) are available at reasonably attractive investment returns, and significant energy savings potential remains. However, the markets are cluttered with imperfections that limit the use of the technologies. These imperfections, or barriers, have been discussed a number of times (see Carlsmith 1990, Sect. V, for discussion and previous references). The key barriers addressed through efforts of the Existing Buildings Research program are:

- Investment risk - Retrofit investments are risky because energy savings are less than expected on the average and difficult to predict for individual buildings. Risk aversion is an important decision criterion for consumers. The program interacts with organizations all over the country to improve the understanding of actual energy performance of retrofits and reduce variations in expected savings for specific measures or groups of measures. 
- Lack of expertise - The buildings industry and consumers generally lack the knowledge and inclination to deal with energy technology selection and installation. Significant expertise is needed to deal with all technologies and their interactions and potential pitfalls. Providing the needed expertise or supplementing available expertise is often very important to increasing the success of retrofit programs. The program provides significant resources to address lack of expertise and to build expertise within intermediary groups.

- Change over time - Building occupants and uses change over îme, and maintaining high efficiency involves not only keeping equipment and systems running properly but also tracking the influence of changes in occupants and uses of buildings. The development of improved energy use tracking systems is an important part of the program.

- New technologies - The retrofit market is characterized by the constant introduction of new technologies to be evaluated. Evaluation of new technologies is a critical task that must be ongoing if new technologies are continually developed, and evaluation of new technologies is central to the program.

The Existing Buildings Research program has contributed to significant improvements in energy efficiency of existing buildings by development of improvements to retrofit technologies, by coordinating and conducting research studies on the use of energy efficiency technologies (to reduce barriers and increase use), and by continually evaluating changes in technologies that could improve and maintain buildings energy efficiency. The Office of Building Technologies of the U.S. Department of Energy (DOE) conducts research, development, and demonstration projects to achieve four technical objectives:

- Provide reliable data on retrofit performance and the means of collecting such data and maintain the national capability for analyzing and updating retrofit performance data

- Evaluate technologies for retrofit energy savings potential and assist in the development of attractive retrofit technologies

- Measure and analyze the influence of human and other factors on the effectiveness of retrofits and post-retrofit operations and maintenance

- Make the results of research on existing buildings widely available to the building efficiency industry through participation with national networks and other technology transfer activities

For more information on the specific program areas, contact the following:

Ernest Freeman

U.S. Department of Energy CE-421

1000 Independence Avenue S.W.

Washington, D.C. 20585

202/586-9192
William Mixon

Oak Ridge National Laboratory

P.O. Box 2008, Bldg. 3147

Oak Ridge, Tennessee 37831-6070 615/576-7323 


\section{IMPORTANCE OF EXISTING BUILDINGS}

Buildings built before 1991 will comprise a significant portion of the total building stock in the years 2010 and 2030. The actual percentage of housing units or commercial floor space depends on both the amount of pre-1991 building stock removed from the total stock and on the new building stock constructed.

The need for new construction depends to some degree on the building stock being removed, since a significant portion of new construction replaces old building stock that is obsolete. For example, in the decade of the 1990's approximately 0.4 to 0.5 million housing units built before 1991 will be removed from the housing stock each year. Total new construction will probably range from 1 to 1.5 million units each year, so replacement of the old stock that was removed represents over $25 \%$ (and sometimes closer to half) of new construction year to year.

The uncertainties in the real estate market in 1991 may reflect a continuing change from the 1970 's toward the relative decline of the 1980's in housing construction. Mankiw (1989) warns of a continuing decline in the need for new housing units. Our analysis of the Mankiw results and data from other sources indicates that annual construction of 1.2 to 1.3 million housing units/yr may be typical for the 1990's, which is less than the average of 1.4 million housing units/yr completed in the decade of the 1980's ( 1.7 million units/yr in the 1970's). Further declines in the future may also be in store. Declines in new construction-and possibly increased renovation of existing stock-mean increasing importance for existing buildings.

The commercial market (which includes commercial and institutional buildings) has significant problems resulting from overbuilding in the 1980's, and construction of new commercial buildings may be impacted for a long time. Real estate analysts expect the recovery from this overbuilding to be long and painful. The time to return to the $5 \%$ vacancy rate considered "natural" by the real estate industry may be as long as 14 years (Wall Street Journal 1990). The uncertainties in the commercial market are greater, but the pre-1991 commercial stock is expected to represent a significant portion of the total commercial stock in the year 2030 .

\section{GLOBAL WARMING}

Global climate change, especially global warming, has become a major issue for many countries. Significant debate is underway about the validity of global warming (Schneider 1989, Breton 1990). Decades of research may be required to resolve the scientific uncertainties, which cause scientific consensus to "[crumble] over the value question of whether present information is sufficient to generate a societal response stronger than more scientific research on the problems" (Schneider 1989, p 778).

Estimates of carbon equivalent emission reductions for the United States suggest that, through various energy efficiency and other initiatives, $\mathrm{CO}_{2}$ [equivalent] emissions could be kept at 1988 levels through the year 2010 solely by implementing programs that are estimated to have net 
cost savings for the nation. However, the potential reduction is expected to be limited by significant problems with implementation of those programs (Breton 1990). Significant international potential for emissions reductions through energy efficiency initiatives are also suggested (Schwengels 1990).

The buildings sector in the United States (all existing residential, commercial, and institutional buildings) is important in the consideration of global warming, because the United States accounts for about one quarter of world energy use and greenhouse gas (GHG-those gases which contribute to potential global warming) emissions. Existing buildings account for about $35 \%$ of total energy use and GHG emissions in the I'nited States, which means existing buildings in the United States account for almost $10 \%$ of total global energy use and GHG emissions. (GHG emissions approximately track energy use.)

However, buildings represent an energy-consuming part of the infrastructure of an economy that changes more slowly than the other two sectors: industry and transportation. Thus, effective efforts in this sector to introduce higher energy efficiency will have to consider methods to improve the efficiency of existing buildings because of the slow rate of change in the stock.

\section{HISTORICAL ENERGY CONSERVATION EXPERIENCE}

A significant report of trends in energy conservation in the United States was released recently by the U.S. Dept of Energy (DOE 1989). Savings due to efficiency improvement were estimated for the whole economy at 31.8 quads/yr (quad $=10^{15} \mathrm{Btu}$ ) in 1986 , using 1972 as the base year. if historical trends had held constant (i.e., efficiencies were frozen at 1972 levels). Fifty percent of the savings ( 15.9 quads/yr) were estimated to occur in the buildings sector.

This report is significant because it builds on skills developed over the decade of the 1980's for evaluating energy use and energy conservation improvements by sector. Thus, the report represents the most informed attempt to examine historical conservation achievements and explain the factors affecting these achievements.

The analysis of residential buildings, where total savings in 1986 relative to 1972 were 10.9 quads/yr, showed that perhaps $30-40 \%$ of the residential energy conservation savings resulted from retrofits. For commercial and institutional buildings (savings of 5.0 quads/yr), the analysis was less detailed (since fewer data are available) and indicated that retrofits may have accounted for over $90 \%$ of the savings. These results suggest that savings from energy retrofits amounted to more than 8 quads/yr (about $50 \%$ of the 15.9 quads/yr total improvement) and that retrofit savirgs were about equal in both the commercial and residential subsectors.

'These same results suggest savings from new buildings (both residential and commercial) amounted to 1.8 quads/yr over this period (about $10 \%$ of the total). The remaining improvement (40\%) leading to the total of 15.9 quads/yr resulted from other changes estimated in the residential stock (in energy use per unit per year), which included behavioral changes, changes in migration/regional growth, increased wood use, and reductions in household size. 
Comparison of the energy savings from retrofits to the savings for new buildings underscores the critical importance of improvements to the existing building stock in obtaining real energy efficiency gains for the U.S. economy.

Thus, the contribution of energy savings in existing buildings to the improvement of the energy efficiency of the buildings sector over the period 1972-1986 is estimated to be five times as much as for new buildings. The high relative savings for existing buildings highlights the importance of existing buildings to national energy efficiency. The available data indicate that improvements to existing buildings have been more important historically.

Recent estimates of potential energy savings performed during development of the National Energy Strategy suggest that about 15 quads/yr of energy could be saved through increased building energy efficiency by the year 2030 (BNL 1991, p 3-17). Based on historical experience, a significant fraction of any potential savings will likely come from improvements in existing buildings. We estimate that about one-third of this savings in the year 2030 will result from improvements to existing buildings. In addition, if increased buildings efficiency is needed in the short term (less than 15 years), major emphasis on existing buildings will be necessary. Efficiency benefits for the nation resulting from improvements to new buildings take a long time to grow to substantial levels.

Because buildings are in use for long lives of 50 years or more, the nature of the stock is slow to change. However, energy technologies are continually evolving and are introduced somewhat continuously over timeframes much less than 50 years. Since improved building energy efficiency technologies do not come in batches, existing buildings must continually be improved to achieve accelerated progress in energy efficiency in the buildings sector. Introduction of improved technologies will occur over an unacceptably long time if existing buildings are not a major thrust of any national energy efficiency improvement program directed at buildings. 


\section{DOE COMPETITIVE SOLICITATION}

In 1989, DOE issued a broad competitive solicitation to develop cooperative, cost-shared projects that would further the technical objectives of the program. In order to promote collaboration between the buildings industry and the DOE National Laboratories, the solicitation offered financial assistance as well as technical assistance of National Laboratory staff for project design, implementation, evaluation, and/or dissemination of results. The areas of research interest listed in the solicitation were as follows:

- Development of educational programs and delivery systems which increase energy efficiency awareness and achievement of energy savings.

- Field monitoring of the efficacy of single or combined retrofit measures.

- Development of toois or methods to diagnose energy use in buildings, building equipment, or operations and maintenance.

- Development of non-proprietary models that accurately predict building energy use and savings due to retrofit measures.

- Innovative and effective methods of technology transfer.

- Documentation of energy savings in existing buildings.

The response was excellent. There were 104 proposals received from 80 organizations, and the research topics proposed confirmed our previous determination of the types of research and information that are needed to overcome barriers to retrofit actions. Ten proposals were accepted, and the work on most of these is beginning in 1991. The ten proposals are summarized below:

\section{Establishing a Model for Retrofitting HUD Affordable Housing Projects, Burlington Electric Department.}

The savings, costs, and other benefits of a comprehensive energy efficiency retrofit of 53 buildings containing 335 units of affordable housing will be evaluated with technical assistance of LBL. More than $\$ 4$ million of a total renovation budget of $\$ 6.5$ million was for energy cost saving measures to ensure the continued affordability of this housing. Retrofit measures will include replacement space and water heating and distribution systems, building insulation, infiltration barriers, replacement doors and windows, and foundation insulation.

\section{Persistence of Window and Heating System Retrofits in Multifamily Buildings, New York Sate Energy Office.}

The persistence of savings will be analyzed for a period of about 20 months for window and heating system retrofit measures in 30 multifamily buildings. Energy use will be determined from weekly readings of individual meters to be installed on the heating system of each building and conditions that impact persistence will be determined using inspections, attitude surveys, training, and comparisons with a control group. 


\section{Monitoring of Conservation Retrofits in Single Family Buildings,} Florida Solar Energy Center.

The actual energy savings and impact on peak electric demand and load profiles of individual retrofit measures in ten houses will be determined by monitoring before and after the retrofit according to the DOE single family monitoring protocol. The retrofit measures include infiltration reduction, window treatments, attic insulation, air conditioner replacement with high efficiency unit, and duct system sealing. Both cooling and heating season data will be collected, and all data will be delivered to ORNL.

\section{Use of Energy Management and Control Systems for Performance Monitoring of Retrofit Projects, Texas A\&M University.}

The project is to evaluate and field test the use of energy management and control systems (EMCS) for remote performance monitoring of conservation and load management measures in non-residential buildings to be retrofit in the Texas LoanSTAR Program. Technical issues include the monitoring capabilities of EMCS, open-protocol communication requirements, case study performance evaluations, and guidelines for EMCS based monitoring. Technical support is provided by LBL.

\section{Commercial Buildings Monitoring and Retrofit Program, Central Vermont Public Service Corp.}

The predictability of retrofit energy efficiency measures in small commercial buildings will be improved through a program incorporating survey, monitoring, and retrofit of selected buildings. Buildings in their service area will be characterized and segmented using existing records of customer energy use and DOE monitoring protocols, and several test buildings will be selected for installation of retrofit measures with pre- and post-retrofit monitoring to determine savings. Results will help target specific retrofit measures to building characteristics and provide a basis for a utility marketing program.

\section{Modify and Enhance PSIC's Builder Guidelines for Existing Building Applications, Passive Solar Industries Council (PSIC).}

An existing energy design and analysis tool entitled "Passive Solar Design Strategies: Guidelines for Home Builders" will be modified for use in retrofit and remodeling applications. The new Retrofit Guidelines are to be a user-friendly design tool for selecting the best mix of conservation, renewable, and natural cooling techniques that are apprupriate for a wide range of locations. 


\section{An Innovative Educational Program for Residential Energy Efíiciency, Cornell University.}

An innovative conservation education program of households to be conducted through Comell Cooperative Extension will be developed, implemented, and evaluated. Social-psychological principles will be used to encourage simple changes in habits and home management or simple technical options that will produce energy savings. The study will involve 250 households in an education group and 250 in a control group, with surveys before and one year after an energy conservation workshop.

\section{A Study of the Persistence of Energy Savings in Single-Family Residences in Wisconsin, Wisconsin Energy Conservation Corporation (WECC).}

The persistence of savings will be analyzed for energy efficiency retrofit measures on single-family, gas heated residences over a three to six year period after retrofit. Retrofit measures will include heating system replacements and modification, thermal envelope measures such as attic and wall insulation, infiltration reduction, and water heater measures. Cooperation of Wisconsin utilities will provide energy billing data on a large number of homes, and ORNL will provide technical support for analysis.

\section{Waste Heat Recovery in Restaurants: Design Optimization and Field Verification, Sud Associates, P.A.}

A field evaluation of technologies to recover waste heat from restaurant refrigeration equipment for preheating hot water will be conducted at two sites to measure the actual energy savings and cost. Results will provide restaurant owners/operators with the objective data needed to assess expected savings for their particular application. Technical assistance with experimental design and interpretation of results is provided by ORNL.

Improving Energy Efficiency by Design, American Consulting Engineers Council.

An information package will be developed for engineering firms to show that energy services can be successfully and profitably sold to owners and developers. The package will include the advantages that can be gained from additional energy analysis to support energy efficient design and an effective method of marketing the concept. 


\section{ENERGY MONITORING PROTOCOLS}

Energy (and power) monitoring in buildings is conducted for a variety of purposes. Some of these are: utility planning, assessing the efficiency of building energy systems (new building performance, baseline performance, evaluation of retrofits), systems development (HVAC, lighting, controls, etc.), tracking performance, assessing public policy, and diagnosing specific problems in buildings. The Existing Buildings program is one of the leaders in planning and managing analysis projects involving field measurement of buildings energy use (building energy monitoring). Monitoring and analysis can aid the promotion of effective technologies by providing more reliable data on the expected benefits of energy efficiency improvements and demonstrating how improved monitoring and performance tracking methods help maintain efficient performance (long term benefits).

\section{NEED FOR MONITORING PROTOCOLS}

Field performance monitoring of building energy systems is increasingly employed to obtain data required for making decisions about energy and power use in commercial and related buildings. Data from field monitoring studies are used by a diverse community including energy suppliers, energy end-users, building systems designers, public and private research organizations, equipment manufacturers, and public officials involved with the regulation of residential and commercial building energy efficiency. While the range of issues these various constituencies face is diverse, a common challenge is obtaining accurate, reliable, and cost-effective performance data that meets information needs.

Much of the literature on building performance monitoring can be generally characterized as case study reports which emphasize the data and findings for a particular project. The results from these studies generally provide little potential benefit for other buildings because differences between buildings cloud comparisons. Protocols serve to promote comparability of projects, which can lead to increased knowledge by more practitioners.

In recent years field performance monitoring has developed into a specialized discipline, evidenced by the first National Workshop on Field Data Acquisition for Building and Equipment Energy Use Monitoring at Dallas, Texas, in October 1985. The proceedings from this workshop (including Hughes and Clark, 1986; Mazzucchi, 1986) provide an excellent overview of the state of field performance monitoring at that time, significant issues facing the monitoring community, and future directions. Field performance monitoring has been subject to introspection and criticism by its practitioners. Recurring themes in this criticism include the need for detailed planning and the importance of establishing the relationship between the data collected and the objectives of the monitoring project (EPRI 1983, Hughes 1986). Project planning is often too hardware oriented, with insufficient emphasis on data analysis and development of data products that meet the project's goals and objectives. Monitoring projects have also been criticized for gathering excessive data for which there is no clear use. The development and use 
of protocols based on tested and accepted practices for planning and implementing field monitoring projects are expected to help alleviate such shortcomings.

Protocols consist of experimental plans, specifications, and procedures for various field monitoring activities that are generally useful to others as models and examples of accepted practice. The focus is on methods and procedures for monitoring, as opposed to the selection and use of hardware. In general, monitoring protocols are being advanced to serve as examples of good practice, to improve communication of the experimental design of specific projects, to achieve more uniformity in the development and documentation of monitoring projects, and to improve communication by use of a classification system.

Protocols provide uniform guidelines and offer additional benefits if followed by a variety of different user groups. Field data are expensive to obtain and analysis expensive to perform, and such project results should be available to others for study or use with a reasonable level of effort for adaptation. Since guidelines are designed to ensure more consistent and comparable procedures, definitions, and data, those performing similar monitoring projects should be able to use other data sets with the knowledge that information collected is reasonably consistent and complete. Such exchanges of data will allow all involved to either increase their database or to collect only necessary (i.e., less) data.

\section{DEVELOPMENT OF PROTOCOLS}

A procedure for uniform development and documentation of monitoring protocols has been proposed to improve communication and understanding of any particular protocol (Misuriello, 1987). The procedure includes the following major elements:

1. A classification system that broadly groups various types of monitoring activities and associated protocols based on similarities of goals, experimental approach, and data requirements.

2. A guide specification which provides a consistent format for communicating the methodological requirements of protocols for particular monitoring projects. This format addresses procedures for stating the goals and objectives of the monitoring and research questions to be addressed, specification of data products, specification of data analysis procedures and algorithms, specification of data points to be monitored, special concerns of hardware selection, and procedures for quality control.

3. Standard terminology and definitions that further specify the monitoring protocol requirements. This includes definitions of measured quantities such as energy end-uses and published standards of measuring and testing procedures incorporated by reference. 
The Existing Buildings program has participated in the development of monitoring protocols and made major contributions over several years. Protocols have been developed specifically for monitoring energy savings in field studies of energy retrofits in single family (Ternes 1987), multifamily (Szydlowski 1989), an. commercial (MacDonald 1989a) buildings. Participation in the ASHRAE Technical Committee 9.6 Subcommittee on Building Energy Monitoring has made a significant contribution to the completion of a chapter on this topic for the $A S H R A E$ Handbook (1991 Applications volume). Within ASTM, a new standard for monitoring energy use in residential buildings has been approved, Standard Practice for Specifying Data for Evaluation of Energy Used in Residential Buildings, E 1410. A standard guide for designing energy monitoring projects in commercial buildings is in the balloting stage within ASTM now. The Existing Buildings program has made significant contributions to energy monitoring procedures, and important knowledge is being added to the publications of national standards organizations. 


\section{SINGLE FAMILY BUILDINGS}

Energy consumption data on a variety of single family energy retrofit projects have been collected over the years, and many have reported considerable scatter in the effectiveness of retrofits. This scatter leads to uncertainty about reasonable approaches to improving energy efficiency through retrofits, and the uncertainty leads to distrust by consumers about energy retrofits. The single family research program has conducted research, development, and demonstration efforts in a number of areas to begin to address the uncertainties about energy retrofits in single family buildings. These activities have supported widespread and growing improvements in public and private sector skills for putting energy retrofits in place in the single family building stock.

\section{RETROFIT PERFORMANCE DEMONSTRATIONS}

\section{NEW YORK}

A cost-shared, cooperative field test was performed in 89 houses in Buffalo, New York, to verify the energy savings and program improvements achieved from use of an advanced residential energy conservation measure (ECM) selection technique in conservation programs (Ternes 1991a). The technique was also tested to provide input into determining whether utility investments in residential gas end-use conservation are cost effective.

The Gak Ridge National Laboratory (ORNL) previously developed a selection technique and tested it in the State of Wisconsin's Low-Income Weatherization Assistance Program in 1985. This work was summarized by MacDonald (1988a) in the previous Research Update. Results showed that the technique more than doubled the annual energy savings per dollar expenditure of the program as compared with the priority system formerly used in 1982. Following this previous study, the technique was modified by the Wisconsin Energy Conservation Corporation for the State of Wisconsin to improve the accuracy of the energy savings predictions and include additional ECMs (including water-heating system ECMs).

The technique is now a commercially available, proprietary audit program and runs on a personal computer. The technique focuses on reducing space- and water-heating energy consumption. Under the technique, each house is analyzed individually to identify all ECMs that are cost effective in the building envelope, space-heating system, and water-heating system. Information on each house is collected through house surveys, discussions with the occupants, examinations of previous billing data, and diagnostic testing (measuring house air-leakage rates using a blower door and space-heating system efficiencies through a flue gas analysis). The benefit-to-cost ratio (BCR) for each ECM is determined using this information and other economic data, allowing the cost-effective ECMs $(B C R>1.0)$ to be selected once interactions between ECMs are taken into account. Because cost-effective ECMs are selected uniquely for each house, inefficient houses that can benefit most from weatherization receive more ECMs and greater amounts of money are spent on them. 
The field test was a cooperative effort among four organizations. The Alliance to Save Energy helped initiated the project by bringing together the principal participants and provided managerial support throughout the project. The State of New York (Department of Public Service) also helped organize the project and provided managerial support throughout the project. National Fuel Gas Distribution Corporation performed the majority of the field work, which included selecting the houses, installing instrumentation, collecting data, auditing the houses, and performing the weatherizations. ORNL designed the study, managed the data, and executed the analysis.

The 89 houses were divided into two groups: 45 houses received a mix of ECMs as selected by the measure selection technique (audit houses) and 44 served as a control group. Space-heating gas consumption, water-heating gas consumption, and indoor temperature of each house were measured at weekly intervals in addition to outdoor temperature. Pre-weatherization data were collected for all houses during one winter season (January to April 1988). ECMs were installed in the audit houses between August and November 1988. Post-weatherization data were collected for all houses during the following winter season (December 1988 to April 1989). Regression analysis of pre- and post-weatherization data were used to estimate annual spaceheating energy consumptions and savings normalized to historical outdoor temperatures and a constant $68 \mathrm{~F}$ indoor temperature (approximately the same indoor temperature assumed in the selection technique). A simpler technique was used to estimate annual water-heating energy savings. Savings for the audit houses were also adjusted using the savings estimated for the control houses to account for factors affecting the space- and water-heating energy consumptions that could not be considered directly.

The study results showed that use of a measure selection technique to select unique ECMs for individual houses resulted in a significant cost-effective level of energy savings. Energy savings results are summarized in Table NY1. The average adjusted savings of the audit houses was

\begin{tabular}{|l|c|c|c|c|c|}
\hline \multicolumn{5}{|c|}{ Table NY1 - Summary of adjusted savings for the audit houses } \\
\hline & $\begin{array}{c}\text { Annual pre- } \\
\text { weatherization } \\
\text { energy use } \\
\text { (therms/yr) }\end{array}$ & $\begin{array}{c}\text { Annual energy savings } \\
\text { (therms/yr) } \\
\text { Adjusted }\end{array}$ & $\begin{array}{c}\text { Percent } \\
\text { savings }\end{array}$ & $\begin{array}{c}\text { Percent of } \\
\text { predicted }\end{array}$ \\
\hline Space-heating & 1022 & 252 & 298 & $25 \%$ & $85 \%$ \\
\hline Water-heating & 272 & 5 & 30 & $2 \%$ & $17 \%$ \\
\hline Other gas use & 182 & & & & \\
\hline Total & 1476 & 257 & 328 & $17 \%$ & $78 \%$ \\
\hline
\end{tabular}

257 therms/year: 252 therms/year from space-heating energy savings and 5 therms/year from water-heating energy savings. Adjusted space-heating energy savings was $25 \%$ of the average pre-weatherization space-heating energy consumption (1022 therms/year), adjusted water-heating energy savings was $2 \%$ of the average pre-weatherization water-heating energy consumption ( 272 therms/year), and the total adjusted energy savings was $17 \%$ of the average pre-weatherization house gas consumption. The overall BCR for the ECMs installed in the audit houses was 
1.24 assuming just installation costs (no administration cost), current residential fuel costs $(\$ 0.579 /$ therm), a discount rate of 0.05 , and no fuel escalation (same assumptions as made in the measure selection technique). A weatherization program would be cost effective at an administration cost less than $\$ 335 /$ house.

The measure selection technique predicted space-heating energy savings and total installation costs with reasonable accuracy, indicating that its recommendations are justified (ECMs were correctly recommended in individual houses and concentration of ECMs in selected houses was justified). As shown in Table NY 1, the average adjusted space-heating energy savings achieved in the audit houses was predicted relatively accurately by the selection technique (within $85 \%$ ). Although not statistically accurate for individual houses, the selection technique's prediction of spaceheating energy savings is reasonably accurate for most houses. Figure NY1 shows that houses are generally grouped around a line representing equality between predicted and adjusted savings. Agreement between predicted and adjusted savings was especially good for houses in which few ECMs were installed (low predicted savings). Changing the balance point temperature used to predict space-heating energy savings of envelope ECMs from $60^{\circ} \mathrm{F}$ to $57^{\circ} \mathrm{F}$ eliminates the difference between average predicted and measured savings. The selection technique was not very accurate in

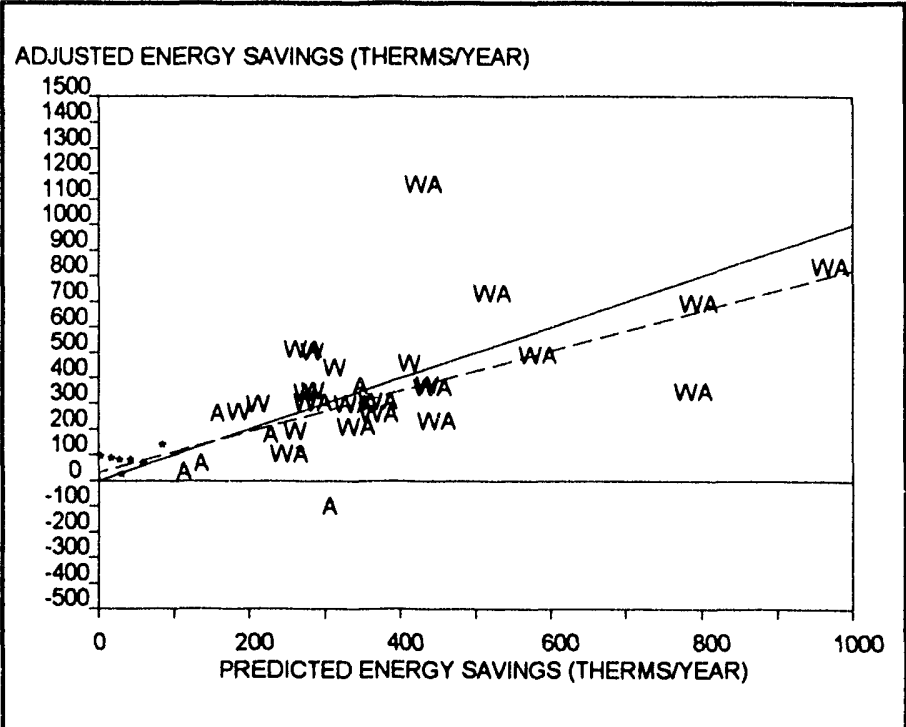

Figure NY1-Comparison of adjusted to predicted space-heating energy savings for each audit house ' $A$ ' - indicates house in which attic insulation with a predicted savings greater than 75 therms/yr was installed

' $W$ ' - indicates house in which wall insulation with a predicted savings greater than 75 therms/yr was installed

'WA' - both attic and wall insulation installed (each meets the savings criterion individually)

"*' - neither was installed

Solid line - adjusted and predicted savings are equal

Dashed line - least squares regression fit for the actual data

predicting water-heating energy

savings. However, the study was not designed to specifically measure small water-heating energy savings. Additionally, anticipated water-heating energy savings were much less than anticipated space-heating energy savings. The average cost for performing the ECMs in the houses was estimated quite reliably by the selection technique (within $2 \%$ ).

The effectiveness of the selection technique in achieving energy savings for lower expenditures improved from the 1985 study in Wisconsin (see Table NY2). Under this field test, 18.5 therms/year were saved for every $\$ 100$ spent on ECMs as compared to 15.9 therms/year measured in the previous study and 5.4 therms/year measured in 1983 for the Wisconsin Weatherization Assistance Program that used a simple priority list to select measures. Although 


\begin{tabular}{|l|c|c|c|}
\hline \multicolumn{3}{|c|}{ Table NY2-Comparison of current results with those of previous studies } \\
\hline & $\begin{array}{c}\text { New York } \\
\text { feld test }\end{array}$ & $\begin{array}{c}\text { Wisconsin } \\
\text { field test (1985) }\end{array}$ & $\begin{array}{c}1983 \text { WECC } \\
\text { study* }\end{array}$ \\
\hline $\begin{array}{l}\text { Pre-weatherization space-heating } \\
\text { energy consumption }\end{array}$ & 1022 therms & 1071 therms & \\
\hline Annual energy savings & 257 therms & 207 therms & 105 therms \\
\hline Percent of predicted savings & $78 \%$ & $83 \%$ & \\
\hline $\begin{array}{l}\text { Expenditures (energy conservation } \\
\text { measures only) }\end{array}$ & $\$ 1387$ house & $\$ 1303$ house & $\$ 1950 /$ house
\end{tabular}

this improvement could certainly be due to differences between the experiments in housing characteristics and climate, improvements made to the technique are also likely contributors (especially limiting recommended ECMs to those with predicted BCRs greater than 1.0).

A wide variety of ECMs were selected by the technique (Fig. NY2). Only 11 of 21 ECMs considered by the selection technique were installed. Three water-heating system ECMs (pipe

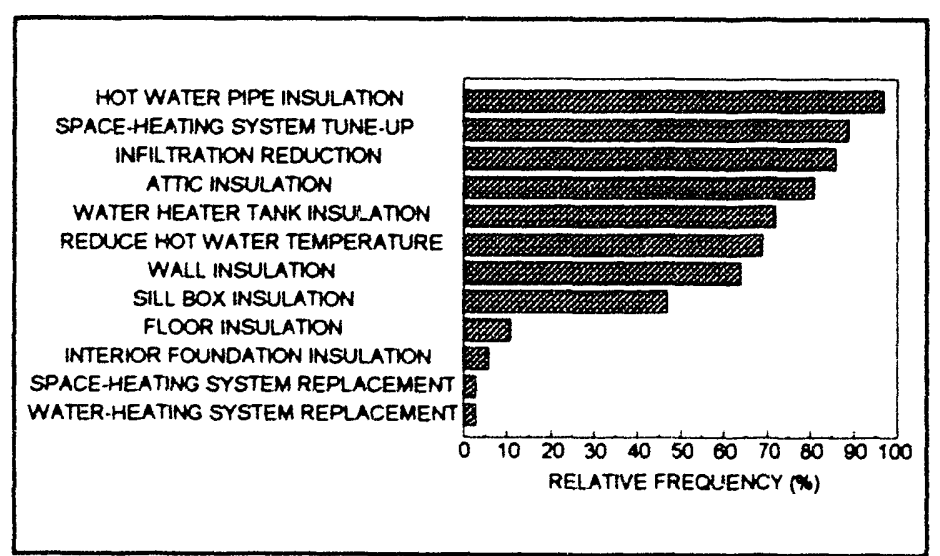

Figure NY2 - Installation frequency of energy conservation measures in the 36 audit houses in New York

A new water heater was not considered a measure but was installed in one house as a repair item. insulation, insulating blanket, and temperature reduction), infiltration reduction, and attic, wall, and sill box insulation were frequently performed. Space-heating system tune-ups were routinely performed to ensure that the system s were operating safely and to avoid liability issues, although energy savings were still expected. Floor insulation, foundation insulation, and space-heating system replacement were ECMs infrequently performed. ECMs that were never performed included storm windows, intermittent ignition devices, and vent dampers. If a clock

thermostat with $5^{\circ} \mathrm{F}$ setback had been an option considered by the selection technique, it would have been selected in only one house. 
The selection technique, designed to concentrate ECMs in houses that would most benefit from them, produced a wide variation in energy savings and expenditures among houses. On average, the space-heating energy savings was largest in houses with higher preweatherization space-heating energy consumption and that received greater expenditures for ECMs. Adjusted space-heating energy savings ranged from -136 to 1120 therms/year (Fig. NY3) and adjusted water-heating energy savings ranged from -98 to 172 therms/year. The amount of money spent on each house averaged $\$ 1453$ for 36 houses ( $\$ 1387$ for 32 houses with energy savings that could be analyzed)

\section{Number of homes}

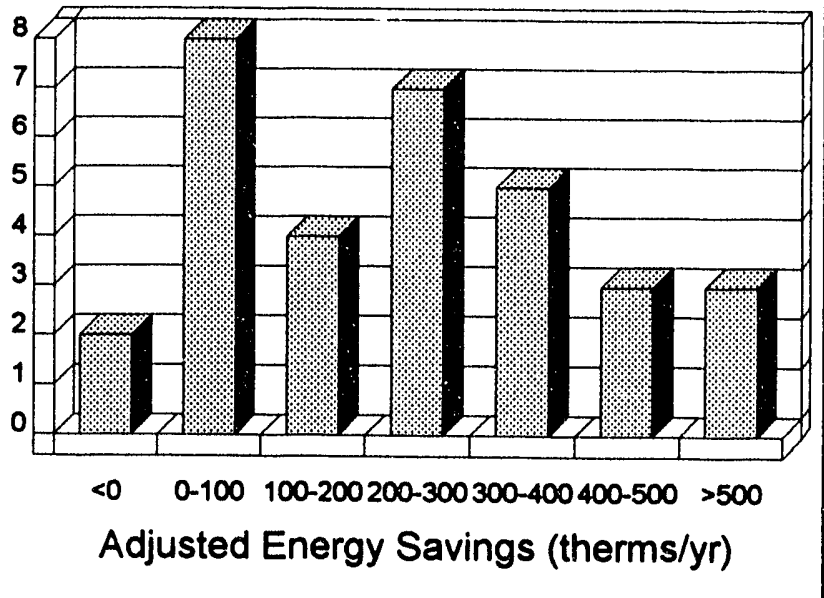

Figure NY3-Histogram of adjusted space-heating energy savings for the $\mathbf{3 2}$ audit houses but varied over a large range: less than $\$ 500$ /house was spent in five houses and more than $\$ 2000 /$ house was spent in 11 houses (see Fig. NY4). Expenditures were predominately for wall and attic insulation: an average of $\$ 750$ and $\$ 400$, respectively, was spent in each house for these measures, while less than $\$ 75$ was spent (on average) on each of the remaining measures.

An infiltration reduction procedure, designed to increase energy savings at reduced costs by using a blower door to locate major house leaks and to determine when

\section{Number of homes}

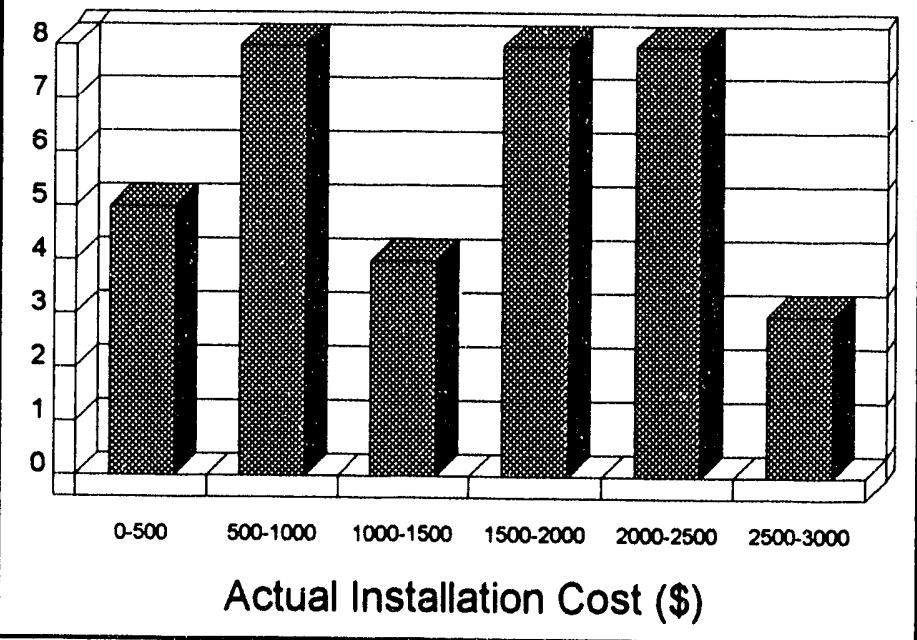

Figure NY4-Histogram of actual installation costs for the $\mathbf{3 2}$ audit houses infiltration work was no longer cost effective, did produce significant cost reductions. Work was not performed in $19 \%$ of the houses because their air-leakage flow rates were already sufficiently low (less than $1500-1800$ CFM 50 , where CFM50 is $\mathrm{ft}^{3} / \mathrm{min}$ of air at $50 \mathrm{~Pa}$ ). By requiring infiltration reduction work to be performed at a BCR of 2.0 , expenditures were limited to an average of $\$ 73 /$ house (excluding a $\$ 70 /$ house set up cost). Better trained and more experienced crews may spend more than this to achieve greater reductions. Greater expenditures and reductions would also result if the BCR for the work was lowered. 
Average indoor temperature changes following weatherization were small, indicating that a significant take-back effect had not occurred. Conclusions drawn from previous ORNL experiments reported by MacDonald (1988a) in the previous Research Update, that indoor temperature and its change does not contribute significantly to lower than expected savings observed in weatherization programs but that they do contribute to the variation in measured savings observed in individual houses, were confirmed. The average temperature maintained in the audit houses was about that expected (68$70^{\circ} \mathrm{F}$ ). As shown in Fig. NY5, the average change in indoor temperature for the

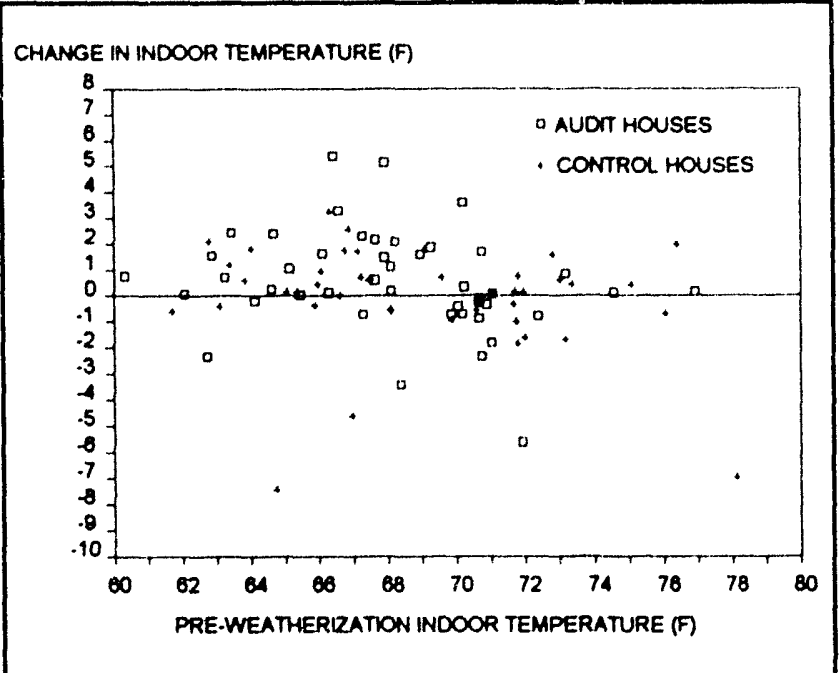

Figure NY5-Comparison of indoor temperature changes for the field test houses The temperature change is the average post-weatherization temperature minus the average pre-weatherization temperature. audit houses was near zero $\left(+0.5^{\circ} \mathrm{F}\right)$ and about equal to that observed, on average, in the control houses $\left(-01^{\circ} \mathrm{F}\right)$. Indoor temperatures maintained in individual houses and changes in temperature following weatherization are unique for each house, however.

Recommendations regarding future development and implementation of similar measure selection techniques were developed from the results from this study and the previous study performed in Wisconsin. These recommendations were directed at making techniques easier to use and to increase savings and cost effectiveness. The recommendations proved very useful in the development of a new approved audit procedure developed by ORNL for the DOE Weatherization Assistance Program. Several major recommendations are listed below.

1. Infiltration reduction work should be performed in parallel with the measure selection technique (preferably following the infiltration reduction procedure used in this study).

2. Low-cost ECMs (such as most water-heating system ECMs) should be performed in parallel with the measure selection technique rather than including them in the audit. These measures should be selected using simple criteria. These measures can normally be performed in the time needed to collect and input information into an audit to make a recommendation.

3. ECMs requiring occupant use and control (such as thermostat setbacks of the space-heating or water-heating systems) should be included in a client education package that is also performed in parallel with the measure selection technique.

4. In a sufficiently small geographic area where there is consistency in housing stock, climate, installation costs, and other relevant parameters, application of the measure selection technique to every house in a pilot test may indicate that a simpler technique could produce near equivalent results. This occurs because the consistency allows patterns to develop regarding correct 
installations. This is more likely to occur if envelope and water-heating system ECMs only are performed because of the importance of interactions of savings between measures when space-heating system ECMs are included.

\section{NORTH CAROLINA}

The North Carolina Field Test is part of an overall effort to improve the energy savings and cost-effectiveness of weatherization programs nationwide. It is designed to evaluate the first application of a newly-developed, single-family weatherization audit which incorporates new weatherization measures and techniques and expanded capabilities over existing audits used in most state weatherization programs (contact William Mixon for more information, page 3 ). The test is expected to both technically evaluate the new audit and to provide user experience which can be used to improve the audit and its implementation requirements prior to its expansion for national use.

The North Carolina Field Test is a cooperative effort supported by the U.S. Department of Energy's Weatherization Assistance Program, Existing Building Research Program, and Atlanta Support Office; the State of North Carolina Department of Economic and Community Devel. opment; and the North Carolina Alternative Energy Corporation. The Alliance to Save Energy, the Oak Ridge National Laboratory, and three weatherization subgrantees in North Carolina are also participants in the evaluation.

The field test design allows side-by-side performance testing of the new, computerized audit and North Carolina's current weatherization audit. A key feature of the new audit, as contrasted to a set list of priorities, is that its computerized selection technique actually evaluates the expected performance of each potential measure for an individual house. The program then ranks the recommended measures in the order that they should be installed based on their benefit-to-cost ratio. These features allow an individual house to receive the measures it needs most and provides a house-specific priority list that can be used when weatherization funds are limited. The audit also considers measures specifically directed at reducing cooling energy in addition to heating energy reductions.

One-hundred twenty houses were identified and equally divided into two weatherization groups and a control group. A variety of heating system types are represented in the sample including space heaters, wall and floor furnaces, and central furnaces. Represented heating fuels are kerosene, natural gas, propane, and fuel oil. Whole-house electricity, water heating, space heating, and cooling energy use were measured weekly at each house. Individual house indoor temperatures and outdoor weather conditions at centralized weather stations were measured hourly.

The two weatherization approaches installed attic and floor insulations in nearly equivalent quantities, and storm windows and wall insulation in drastically different quantities. The field test data collection was completed in 1991, and data analysis will continue in 1992. A comprehensive final report on the project will also be prepared in 1992. 


\section{MINNESOTA}

Foundation insulation is typically one of the last and most costly retrofits added to an existing single family house. A previous study (Quaid, 1988) found average space heat energy savings of 19.2 percent due to foundation insulation in fifteen otherwise well insulated houses in Minneapolis, Minnesota. Quaid's study, however, did not control for air sealing coincident with the retrofit, and relied on self-reported data with regard to basement heating.

A field study of foundation insulation was conducted in Minnesota to further examine foundation insulation (Robinson 1991). This field study was conducted by Robinson Technical Services. The objective of this study was to measure the savings due only to retrofit foundation insulation. The study was designed to evaluate the effectiveness of foundation insulation in reducing basement conductive heat loss. The study design controlled for foundation air leakage and intentional basement heating.

Since foundation insulation is a permanent retrofit, a before-after experimental method was used with ten houses receiving interior insulation and ten receiving exterior insulation retrofits. Fiberglass insulated stud walls were used for eight of the interior retrofits and extruded polystyrene was used for two. All ten exterior retrofits were done using extruded polystyrene. For various reasons, such as change of owner/occupant, five houses were deleted from the final analysis.

To control for basement heating, basement supply and return registers were closed or sealed and foundations were air sealed during the study. None of the basements was heated for comfort or used as daily living space.

Houses were visited quarterly to check homeowner meter readings, to service thermographs located in the basement and near the thermostat, and to observe any changes in basement usage. Homeowner read weekly data were collected on 18 houses for the duration of the study. Two houses were submetered using data acquisition systems.

Retrofit performance was evaluated by comparing the total energy input within the envelope before and after the retrofit. A linear two-parameter model (normalized thermal load model) of total load versus the outside temperature was used for this analysis.

The average energy savings for the interior and exterior retrofits were 92 and 24 therm/yr, respectively. These savings were 7.9 and 3.0 percent of the pre-retrofit space heat energy use. Aggregate payback periods for the interior retrofits with and without a finished wall were 42 and 23 years, respectively, with minimum values of 23 and 12 years. The average costs for these retrofits were $\$ 2130$ and $\$ 1173$ with and without a finished wall, respectively. The aggregate payback period for the exterior retrofits was 129 years, with a minimum of 37 years. The average exterior retrofit cost was $\$ 1675$. 
On the average, the houses in the study achieved only about one-third of the whole-house energy savings that were predicted by a two-dimensional finite difference model. Savings may have been overpredicted by the model, since it assumed a constant and uniform basement air temperature and did not include effects of basement air stratification on whole-house energy use.

Model calculations indicated that, in order for foundation insulation retrofits to achieve payback periods of ten years or less, they must be applied to intentionally heated spaces (Table MN1). The accuracy of the model for these results was verified by comparing model results to measured data obtained from a uniformly heated below grade test module.

\begin{tabular}{|c|c|c|c|c|c|c|c|c|c|}
\hline \multicolumn{10}{|c|}{$\begin{array}{l}\text { Table MN1 - Economic analysis of average first year savings } \\
\text { based on modeled performance of heated basements }\end{array}$} \\
\hline & \multirow{2}{*}{$\begin{array}{c}\text { First year } \\
\text { savings } \\
(\$ / y r)\end{array}$} & \multicolumn{2}{|c|}{$\begin{array}{l}\text { Cost of } \\
\text { Retrofit } \\
\text { (\$) }\end{array}$} & \multicolumn{2}{|c|}{$\begin{array}{c}\text { Cost of } \\
\text { Conserved } \\
\text { Energy (\$/therm) }\end{array}$} & \multicolumn{2}{|c|}{$\begin{array}{l}\text { Simple Payback } \\
(y r)\end{array}$} & \multicolumn{2}{|c|}{$\begin{array}{l}\text { Benefit-to-Cost } \\
\text { Ratio }\end{array}$} \\
\hline & & $\begin{array}{l}\text { With } \\
\text { Finish }\end{array}$ & $\begin{array}{l}\text { Without } \\
\text { Finish }\end{array}$ & $\begin{array}{l}\text { With } \\
\text { Finish }\end{array}$ & $\begin{array}{l}\text { Without } \\
\text { Finish }\end{array}$ & $\begin{array}{l}\text { With } \\
\text { Finish }\end{array}$ & $\begin{array}{l}\text { Without } \\
\text { Finish }\end{array}$ & $\begin{array}{l}\text { With } \\
\text { Finish }\end{array}$ & $\begin{array}{l}\text { Without } \\
\text { Finish }\end{array}$ \\
\hline Interior & 272 & 2130 & 1173 & 0.28 & 0.15 & 7.8 & 4.3 & 1.96 & 3.67 \\
\hline Exterior & 162 & 1675 & & 0.37 & & 10.3 & & 1.49 & \\
\hline Both & $22: 3$ & 1948 & & 0.31 & & 8.5 & & 1.77 & \\
\hline
\end{tabular}

Regression analysis of savings as a function of the area insulated showed that the addition of a single savings loss parameter to the analysis, where the loss parameter is related to house configuration, yielded regression models for both the interior and exterior insulation cases that explained 80 percent or more of the observed savings. The loss parameters were the height of the house and the reciprocal of the depth of the insulation below grade for the interior and exterior insulation cases, respectively.

Insulation applied in an uncontrolled basement produces highly variable results, and has the principal effect of increasing the temperature and comfort of the basement, rather than producing cost-effective whole-house energy savings. Using these same retrofit and energy costs, modeled energy savings indicated conditioned basements can be insulated to enhance com fort and to obtain cost-effective energy savings.

Based on the results of this study, additional research is indicated to find alternative strategies to reduce the energy use of unconditioned or uninhabited basements. The regression results in this study indicate that interzone coupling and retrofit induced losses (which included increased 
basement temperatures) appear to be very important, but these factors are poorly understood. Therefore, the effect of air stratification and internal air movement on the effectiveness of foundation insulation needs further examination.

\section{OKLAHOMA}

A cooperative, cost-shared field test was performed in 81 occupied low-income, single-family houses in the Tulsa, Oklahoma area (Temes 1991b) The objectives of the field test were to determine the space-cooling electricity consumption of low-income houses equipped with window air-conditioners, the reduction in consumption due to energy conservation measures (ECMs) installed under Oklahoma's Weatherization Assistance Program (WAP), and the additional reduction due to two ECMs designed to reduce space-cooling electricity consumption: attic radiant barriers and replacement of low-efficiency window air conditioners with high-efficiency units.

The 81 houses were divided into a control group and three treatment groups: ECMs performed under Oklahoma's WAP, WAP ECMs plus a truss-mounted attic radiant barrier, and WAP ECMs plus a high efficiency air conditioner to replace a less efficient unit. A standard set of ECMs (selected specifically to reduce space-heating energy consumption) is installed in each low-income house serviced by the Oklahoma WAP: caulking and weatherstripping is performed first, attic insulation levels are increased to a thermal resistance of $R-19$ using blown cellulose insulation, and storm windows are repaired or installed. The attic radiant barrier used in the field test consisted of a material with two low-emissivity surfaces and was attached to the underside of the roof rafters and on the gabled ends of the attic. In each house receiving a replacement air conditioner, one window air conditioner with an Energy Efficiency Ratio (EER) less than or equal to 7.0 was replaced by a high-efficiency unit (EER greater than or equal to 9.0) having about the same capacity as the original unit. In houses with two existing units meeting this criterion, the unit with the greatest pre-weatherization electricity consumption was replaced. All units older than four years were assumed to be eligible for replacement because actual EER ratings were not available.

The field test was a cooperative effort involving six organizations. The Alliance to Save Energy helped initiate the project by bringing together the principal participants and provided managerial support throughout the project. The State of Oklahoma (Department of Commerce) funded Wa-Ro-Ma Tri-County Community Action Foundation through the WAP to perform most of the field related tasks which included identifying houses, installing instrumentation, collecting data, and performing all weatherization activities. Public Service Company of Oklahoma assisted in instrumentation installation and data collection, and also provided managerial support throughout the project. The Oak Ridge National Laboratory designed the study, managed the data, and executed the analysis. The Reflective Insulation Manufacturers Association donated radiant-barrier material and provided training for installation of the material.

To study air-conditioning electricity consumption and savings, new field measurement and analysis methods were developed. The electricity consumption of each individual air conditioner, indoor temperature of each house, and outdoor temperature were measured at weekly 
intervals. Pre-weatherization measurements were made from June to September 1988. Postweatherization measurements were made the following cooling season (May to September 1989). Data for each house were examined individually to identify data appropriate for two air-conditioning electricity consumption-temperature regions: a transitional region, where consumption is non-zero but not a function of outdoor temperature or outdoor-indoor temperature difference, and a linear region. Regression analysis of pre- and post-weatherization data falling within the linear region were used with a simpler analysis of transitional region data to estimate annual air-conditioning electricity consumption and savings normalized to historical outdoor temperatures and pre-weatherization indoor temperatures.

The study results show that programs directed at reducing space-cooling electricity consumption will more likely be cost effective if targeted at clients with high air-conditioning electricity consumption and/or if costs can be minimized. Current air-conditioning electricity consumption sets an upper limit on potential program savings. Under this field test, consumption of the 81 houses averaged $1664 \mathrm{kWh} /$ year (\$119/year). As shown in Fig. OK1, individual house consumptions were quite variable, with $10 \%$ of the tested houses using less than $250 \mathrm{kWh} /$ year and $10 \%$ more than $3000 \mathrm{kWh} /$ year.

Replacing low-efficiency air conditioners with high-efficiency units produced measurable savings, with increased savings and cost-effectiveness achieved in houses with high initial air-conditioning electricity consumption. An average reduction in air-conditioning electricity consumption of $535 \mathrm{kWh} /$ year (\$38/year and $28 \%$ of pre-weatherization consumption) was obtained from replacement

Relative Frequency (\%)

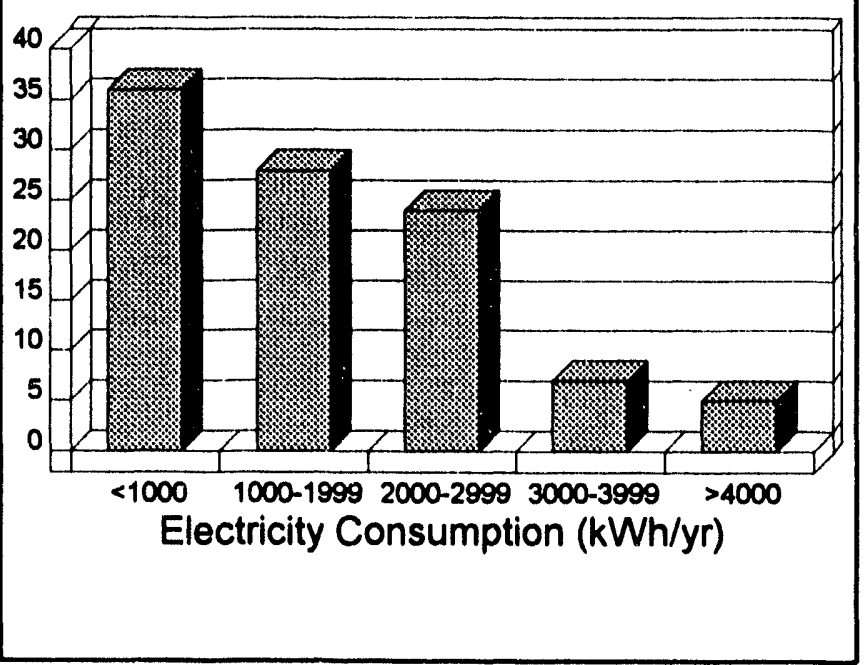

Figure OK1-Histogram of nomalized pre-weatherization air-conditioning electricity consumption of one air conditioner per house at a cost of $\$ 947 /$ house. Average pre- and post-weatherization consumptions are shown in Fig. OK2. For approximately the same cost ( $\$ 999 /$ house), savings doubled to $1068 \mathrm{kWh} /$ year (\$76/year and $34 \%$ of pre-weatherization consumption) in houses with initial air-conditioning electricity consumption greater than $2500 \mathrm{kWh} /$ year.

Air-conditioning electricity savings produced by ECMs installed under Oklahoma's WAP or by combining a truss-mounted attic radiant barrier with these ECMs could not be detected under the field test (see Fig. OK2). ECMs installed under Oklahoma's WAP (chosen based on effectiveness at reducing space-heating energy consumption) should continue to be justified based on their space-i,eating energy savings potential only. Attic radiant barriers should not be 


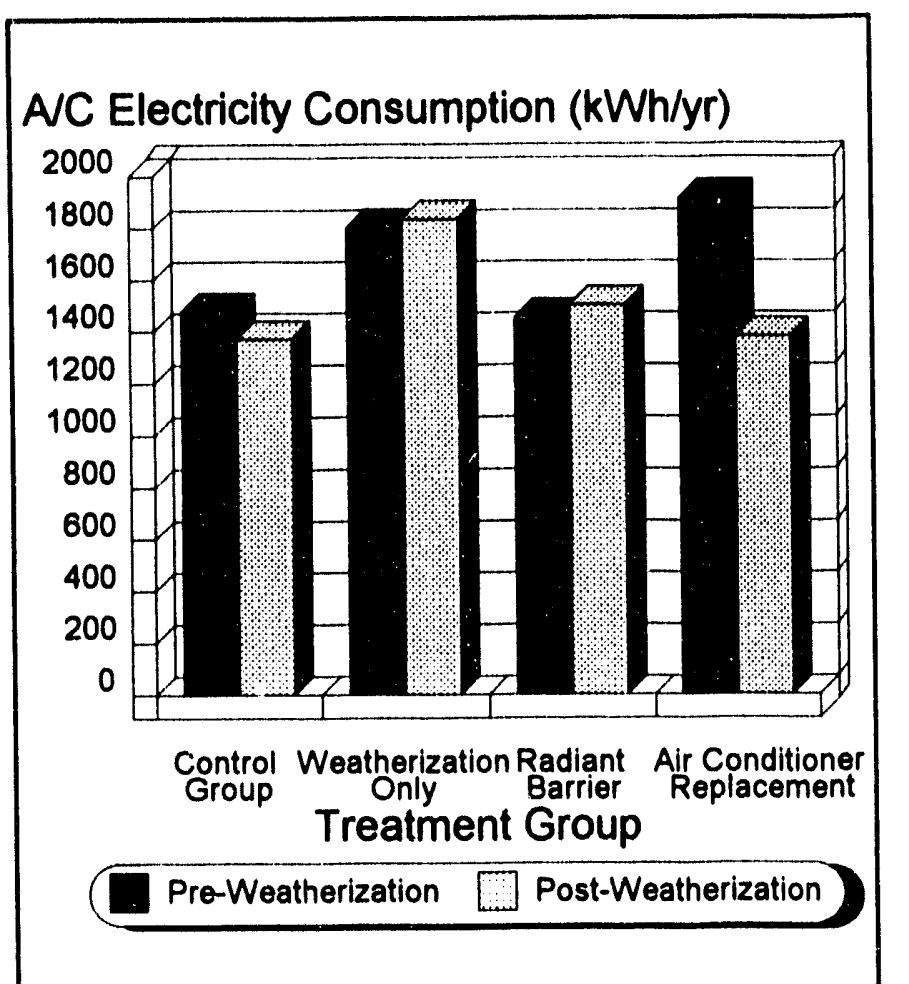

Figure OK2 Average normalized pre- and

pos:-weatherization air-conditioning

electricity consumption for the four groups

of field test houses included in the program if alternatives with verified savings are available and/or until further testing demonstrates energy savings. Recommendations regarding attic radiant barriers are based on the measured air-conditioning electricity savings only. Comfort improvements, especially in the portions of the houses that were not air conditioned, could not be addressed from this study.

It must be emphasized that these results are limited to air-conditioning electricity savings. Further, these results are most pertinent to the Oklahoma WAP and other low-income programs dealing with houses, occupants, and slimate similar to that encountered in the field test (e.g., houses cooled by one or two air conditioners, occupied by low-income families, and located in a climate similar to that of Tulsa, Oklahoma).

\section{TEXAS}

Replacement of residential central air conditioners with high-efficiency units was examined in a field test in Austin, Texas (Bums 1991). This field test was conducted by The Fleming Group in cooperation with the City of Austin. The objective of this study was to determine the energy use and electric demand impacts of replacing older, low-efficiency air conditioners with high-efficiency units. In this project, an analysis approach to predict the effect of such a retrofit was also developed.

Electric energy performance data was collected on twelve houses during two cooling seasons (pre-retrofit and post-retrofit). Existing low-efficiency units were monitored during the 1987 cooling season and were replaced during the 1987-88 heating season with new, smaller-sized, high-efficiency units (Fig. TX1 shows the distributions of pre- and post-retrofit units) that were monitored during the 1988 cooling season.

The air conditioner retrofits in this project reduced both the annual air conditioner electric consumption and the peak demand by an average of about $40 \%$. Normalized average demand reductions were $1.1 \mathrm{~W} / \mathrm{sq} \mathrm{ft}$ of conditioned area, and normalized average annual energy savings were $1.4 \mathrm{kWh} / \mathrm{sq} \mathrm{ft}$. 


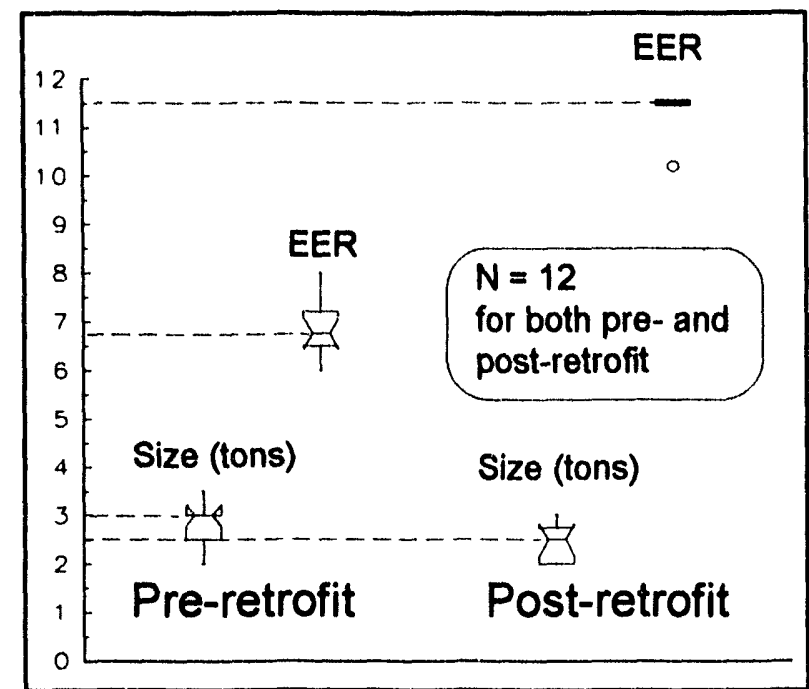

Figure TX1-Box plots of pre- and post-retrofit air conditioner size and EER Those familiar with box plots will understand the quartile distributions shown. The key information in this plot is that the mean change in size was from about 3 to 2.5 tons and that the EER increased from about 6.7 to 11.5 (all new units had an EER of 11.5 except one unit at 10.2).
Air conditioner power demand at :ndividual sites was a well-defined function of outdoor air temperature for both pre- and post-retrofit periods. As an aggregate for all sites, air conditioner energy consumption was a strongly linear function of outdoor temperature. The most successful relationship that emerged was daily air conditioner electric consumption as a function of daily average outdoor temperature.

Analysis of the retrofit effect using PRISM yielded an estimated $30 \%$ reduction in the annual cooling energy consumption. This compares with the $38 \%$ reduction in annual cooling energy consumption estimated with direct monitoring.

The air conditioner retrofits in Austin are effective in reducing annual air conditioner electric consumption and peak electric demand. Cost-effectiveness of the replacements was not expected to be good, since dollar savings are not quite large enough (in the range of $\$ 150-200 / y r$ ) to justify replacement of functioning units. The results from this study were expected to be used when considering development of a conservation program targeted at increasing the efficiency and reducing the size of units installed when an air conditioner is being replaced for other reasons (such as a unit that can no longer be repaired cost effectively). When an air conditioner is being replaced for other reasons, only the incremental cost of the new unit is considered in the cost-benefit analysis, and the replacements studied here would be highly cost effective based only on the incremental cost. 


\section{DEVELOPMENT OF IMPROVED TOOLS}

\section{MOTOR CURRENT SIGNATURE DIAGNOSTICS FOR AIR CONDITIONERS}

A large percentage of existing building air conditioners, heat pumps, and chillers operate at low efficiency and reduced capacity due to a variety of problems. One common problem is improper refrigerant charge, caused either by leaks in the system or improper charging when installed. For one system tested at ORNL, a $26 \%$ reduction in refrigerant charge caused a $23 \%$ loss of efficiency and a $31 \%$ loss of capacity.

An exiloratory study has been completed by ORNL to determine if motor current signature (MCS) cin be used as a diagnostic tool to identify equipment with low refrigerant charge. The MCS refers to the high frequency noise signals or other variations in the electric current of the motor that can be detected with simple, non-intrusive clamp-on sensors. The initial test (Miller 1991) showed that at least three different parameters could be determined from the MCS that varied with refrigerant charge when a test heat pump was operated at closely controlled conditions. A followup test used a much smaller through-the-wall air conditioner to examine the sensitivity of these MCS parameters to field conditions, such as variations in indoor and outdoor temperature, line voltage, and evaporator air flow. One of the parameters, which was determined from transient current flow during startup was found to be insensitive to variations of temferature, voltage, and evaporator blockage. As shown in Figure $\mathrm{MCl}$, when measured values of this parameter were divided by the value at optimum refrigerant charge (to provide a dimensionless value from zero to one) and plotted against the refrigerant charge fraction (fraction of full charge), all test data for the two very different units fell on the same line. Tests

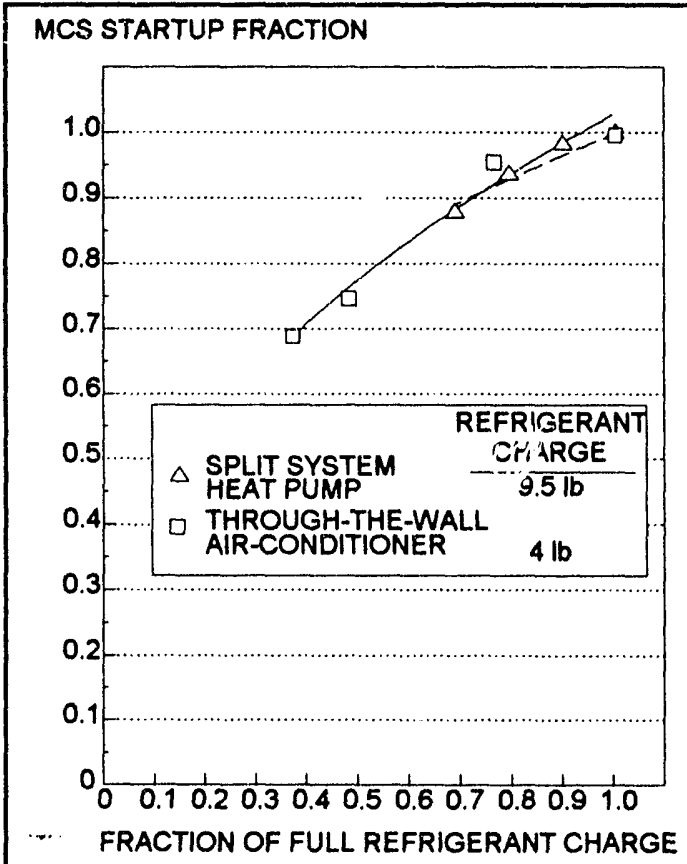

Figure MC1-MCS startup fraction indicates refrigerant charge The MCS startup fraction is the value of the MCS startup parameter divided by the value of the MCS startup parameter at full refrigerant charge. to date are encouraging and continue to support the technical feasibility of developing a simple diagnostic tool to indicate low refrigerant charge in air conditioners.

\section{DUCT SYSTEMS}

Thermal-energy distribution systems are an important part of the systems providing heating and cooling to conditioned building spaces. In the U.S., we estimate approximately 4 quads of primary energy annually passes through thermal distribution systems in buildings. Based upon 
an assumed efficiency of $75 \%$ for existing systems, an improvement in the efficiency of those systems to about $87 \%$ ( $50 \%$ reduction in losses) represents an annual savings of more than 0.5 quads of primary energy, or an annual cost savings of over 4 billion dollars. Moreover, the electrical demand load shape due to inefficient distribution systems is even more peaked than general cooling demand (due to the increased fractional on-times caused by inefficiencies during peak periods), which implies that distribution system efficiency improvements can provide even larger savings in peak electricity demand.

Since ducted forced-air heating systems are an important thermal distribution system in buildings, the Existing Buildings Research program funded Lambert Engineering to conduct field studies of duct systems in the Pacific Northwest. Field data on duct losses was sparse prior to this project, and the economics of sealing ducts as a retrofit was not well understood. The objective of this project was to assess the energy impact and economics of duct losses and to test techniques for measuring and locating duct leakage.

The project examined the energy impact of ducted heating systems in two studies. The first study (Robison 1989a) was a statistical analysis of 400 homes constructed to the Model Conservation Standard (MCS) of the Bonneville Power Authority (Bonneville) and 400 "current practice" homes as a control group in the Bonneville Residential Standards Demonstration Program (RSDP). The groups are comparable and serve as "test-reference" samples. Data used were from blower door tests - 4 Pascal Specific Leakage A rea and 50 Pascal Air Exchange Rate -and the Specific Heat Loss Factor determined from monitored energy use. The second study (Robison 1989b) was a field investigation of 20 RSDP houses with ducted heating systems using blower door and tracer gas tests.

The major results of the "test-reference" statistical study were:

1) Ducted homes have $12-26 \%$ more air leakage;

2) Heating energy use/sq $\mathrm{ft}$ of heated area of ducted houses is $13-40 \%$ higher than for unducted houses;

3) Duct losses were higher in current practice houses than in the more energy-efficient MCS houses.

The field investigation results are summarized as follows.

1) Duct leakage is highly variable. Ten percent of the houses showed no significant leakage while $10 \%$ showed severe leakage.

2) On average, duct leakage reduced heating system efficiency by $12 \%$.

3) The presence of heating ducts increased the apparent leakiness of houses by about $10 \%$ based on blower door tests (4 Pa ELA and $50 \mathrm{~Pa}$ air exchange rate).

4) Tracer gas tests showed that fan-driven losses dominate infiltration while the furnace fan operates, causing an increase of about 0.5 air changes/hour.

5) Flow hood tests showed that return ducts leaked twice as much as supply ducts during fan operation. 
6) Interaction of fan-driven and natural infiltration appeared to be more consistent with linear addition of air flows rather than addition of flows in quadrature.

7) About one quarter of the duct leakage could be located and repaired.

8) Estimates of energy savings from duct repairs averaged $375 \mathrm{kWh} /$ year, which led to a simple payback of about four years.

Duct-related energy losses are significant in recent vintage houses with ducted heating systems. Duct leakage should be eliminated during construction as much as possible because repairability is difficult after construction. Ducts should also be located in heated spaces as much as possible. Duct leakage repair can be an economically attractive retrofit, especially for weatherization programs where fixed costs are spread over other retrofit measures.

These field studies showed that additional work is needed on diagnostic techniques and models to improve the predictability of duct leakage. Whole house blower door testing does not appear to provide an adequate testing technique. Direct testing of isolated ducts with a "flow-hood" appears to provide a higher precision level of results.

Since the time of this study, other significant research on ducts has been conducted for several organizations. Ongoing work in Florida has led to important improvements in understanding the influence of duct leakage on pressure differences in houses in Florida. Savings of air conditioner energy use of $18 \%$ have been reported for homes in Florida resulting from duct repair (Cummings 1990). The nature of duct impacts on air tightness or leakiness measurements in homes in California has been studied (Wilcox 1990). Duct leakage was one of the significant problems discovered in a study of causes of high air conditioning costs in Califormia (Proctor 1991). Duct systems have been receiving much additional research attention in recent years.

In response to the need for improved knowledge on ducted distribution systems, the Existing Buildings Research program initiated a three-year research program focused on improving the efficiency of thermal energy distribution systems in 1990. This program is co-sponsored by the California Institute for Energy Efficiency. The duct system program is managed and conducted by Lawrence Berkeley Laboratory (LBL).

The first year of duct research included: 1) a telephone survey of HVAC contractors, 2) the development and use of a two-day air-distribution diagnostic measurement protocol, and 3) the development of an integrated air-flow/thermal-performance simulation tool. The focus of the work is California residences, which is essentially a focus on crawlspace and slab-on-grade houses. In these types of houses, the distribution system typically passes through unconditioned spaces (attics or crawlspaces), and these configurations are common throughout most of the U.S. sunbelt.

Some of the more salient indications for California from the HVAC-contractor survey were:

1) The vast majority of new duct systems are installed in attics,

2) The vast majority of ducts installed are R-4 insulated flexible plastic,

3) Approximately three quarters of the ducts are sealed with cloth duct-tape only, and 
4) More than half of the contractors said they would be interested in being paid to make post-installation performance checks, and are capable of installing water/refrigerant distribution or conditioned-space air distribution systems.

The objectives of the field diagnostic measurement program are to provide high-quality data for characterizing the California residential air-distribution stock (including its retrofit poten- iial), defensible input data for performance-simulation efforts, and refined measurement tools for use in larger-scale projects.

The two-day diagnostic measurement protocol developed includes measurements of:

1) Supply and return-duct leakage to outside by three independent techniques,

2) Supply and return-duct pressures and overall building air infiltration with and without distribution-fan operation,

3) Interzonal and envelope pressure differences created by distribution-fan operation with interior doors closed, including measurements of the driving flows,

4) Temperature variations between the supply plenum and several registers to characterize the duct conduction losses,

5) Crawlspace and attic temperature changes due to system operation,

6) Documentation of house and equipment conditions, including duct-system leakage sites.

To accomplish these measurements within a two-day period while minimizing instrumentation- and operator-induced uncertainties, a prompting, automated data acquisition system was developed for this purpose. This system was successfully used in six houses in 1990 and 30 houses in 1991.

To obtain credible estimates of air distribution system performance, an hourly simulation tool was developed. This tool is based on a multi-zone flow simulation (MOVECOMP) for a residential air distribution system in a typical Califomia house, coupled to a thermal simulation of the same house (DOE-2). The long-term objectives of developing this tool are to provide the capability for:

1) Simulating annual energy, peak-load and ventilation implications of residential air distribution, and

2) Simulating the effectiveness of alternative distribution technologies and retrofit options.

The air-flow simulation portion of this tool is up and running, and will be combined with the thermal simulation model and applied in the coming year. The coming year will also see the initiation of research to develop novel duct-sealing technologies and complete retrofit protocols. 


\section{MOBILE HOME RESEARCH}

A controlled environmental enclosure has been developed to allow testing of weatherization measures for pre-1976 vintage (pre-HUD-Standard) mobile homes under controlled conditions (Judkoff 1990). Pre-HUD-Standard mobile homes use from 1.25 to 2 times the energy per square foot of comparable site-built houses. Their unique construction makes them difficult to weatherize effectively using the measures and techniques developed for site-constructed dwellings.

In addition to the Existing Buildings Program, this work was supported by the National Weatherization Assistance Program (DOE/WAP), the seven states comprising Weatherization Region VIII, the Colorado Division of Housing, and the DOE Denver Support Office. The Solar Energy Research Institute designed the testing program and equipment and managed the experimental data collection, data management, and analysis of results.

A study conducted by Meridian Corporation for DOE indicated that weatherization of mobile homes resulted in simple paybacks (cost of weatherization divided by first year cost savings) of about 21 years. Site-built houses weatherized yielded a simple payback of about 11 years (CSR 1989). Because of the apparent problems with weatherizing mobile homes, a testing program was started to provide some hard data on the thermal effectiveness of various weatherization techniques.

Under this program, a mobile home is moved into the environmental enclosure (converted warehouse, Fig. $\mathrm{MH}$ ) and tested in its initial condition to determine the heat losses from infiltration and conduction, and to determine the delivered heat efficiency of the furnace and duct system. A single weatherization measure is then installed and the testing is repeated to determine the change in conductive and infiltration losses and delivered heat efficiency due to that measure. This process is repeated until the individual effects of an entire set of weatherization measures have been determined.

Eight mobile homes have been tested. Each test usually takes only one or two nights, so it has been possible to combine testing with training workshops. The trainees install a

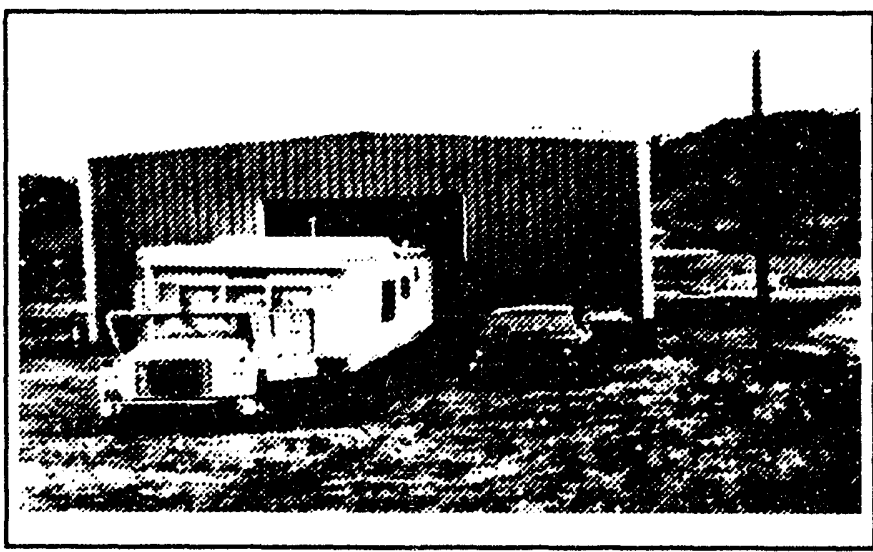

Figure MH1 A truck moves a mobile home into the environmental enclosure (warehouse) measure one day and find out how effective their work has been the next. To date a number of weatherization measures have been tested, including: 
- Air sealing and duct repair (using blower door and tracer gas)

- Furnace tune-ups

- Interior storm panels

- Window repairs and replacements

- Blown-in insulation in the belly (fiberglass and cellulose)

- Insulation wrap of the belly

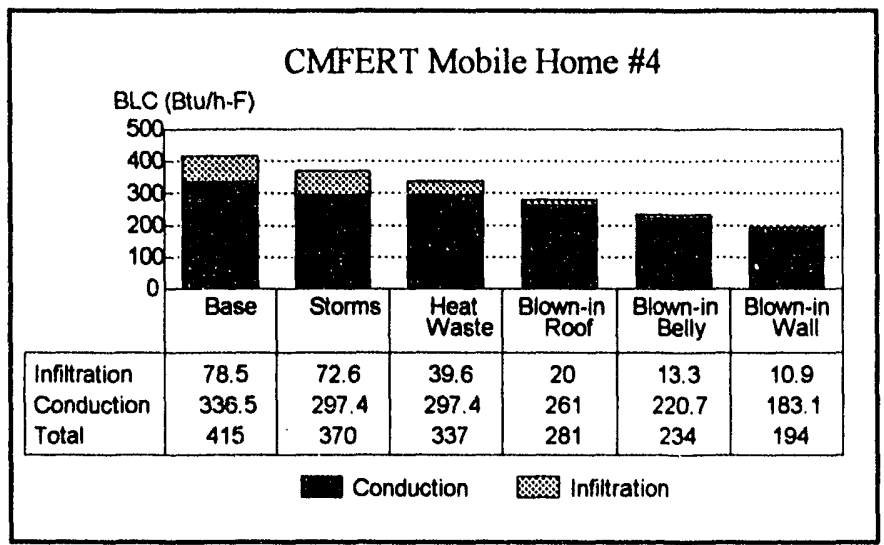

Figure MH2-Measured cumulative overall building loss coefficient (BLC) for various measures

- Skirting and insulated skirting

- Blown-in insulation in the roof (fiberglass and cellulose)

- Roof cap insulation

- Wall insulation

Figure MH2 shows the cumulative building heat loss coefficient associated with a series of weatherization measures installed on mobile home \#4. The bottom and top portion of each bar represent the conductive and infiltration portions of the heat loss respectively. The installation of all

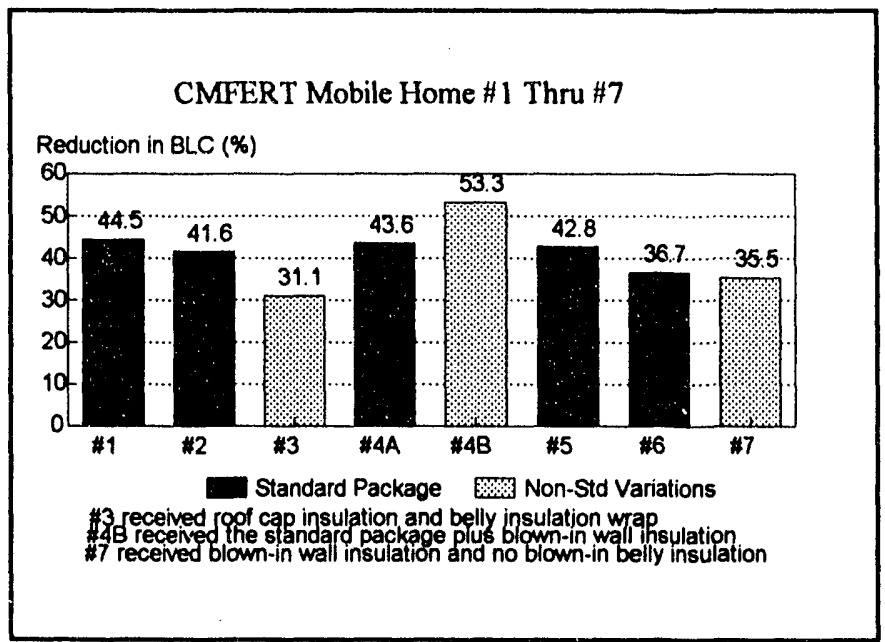

Figure MH3 - Measured reductions in BLC for each mobile home configuration weatherization measures resulted in a 44 percent reduction in the heat loss coefficient due to blower door directed air sealing, duct repair, furnace tune-up, interior storm panels, blown-in insulation in the belly, and blown-in insulation in the roof. A new wall blowing method was developed that reduced the heat loss coefficient by an additional $9 \%$.

Figure MH3 shows the overall percent reduction in heat loss coefficient for each of the mobile homes that were tested.

Figure MH4 shows the increase in delivered heat efficiency due to weatherization of five of the mobile homes. Sealing holes in the ducts, belly blow, and furnace tune up all increase efficiency. 
Units \#2, \#3 and \#4 showed larger efficiency increases than unit $\# 1$ and \#5 primarily because they began with larger leaks in their duct system.

Figure MH5 shows the average percent reduction in heat loss coefficient due to each measure based on all eight homes tested.

In general, for colder climates the most cost effective measures include: blower-door-directed air sealing and duct repair, furnace tune-up, interior storm panels, belly blow(floor insulation), and roof blow. The roof blow and belly insulation may result in moisture damage if used in humid climates, and these measures should probably be researched further before being widely applied.

The blower door has shown itself to be an essential tool in the weatherization of mobile homes. Not only does it help crews to tighten the units more effectively, but it also prevents overtightening which can be especially dangerous in low-volume buildings. The ASHRAE standard air exchange rate of $15 \mathrm{CFM} /$ person should be followed.

Tests to date have shown skirting, insulated skirting, roof cap insulation, and insulation wrap of the belly to be less cost effective. The research also indicates that window and door replacements should only be used when repair would be more expensive than replacement. Even for jalousie and awning windows, money is better spent on interior storm panels than on

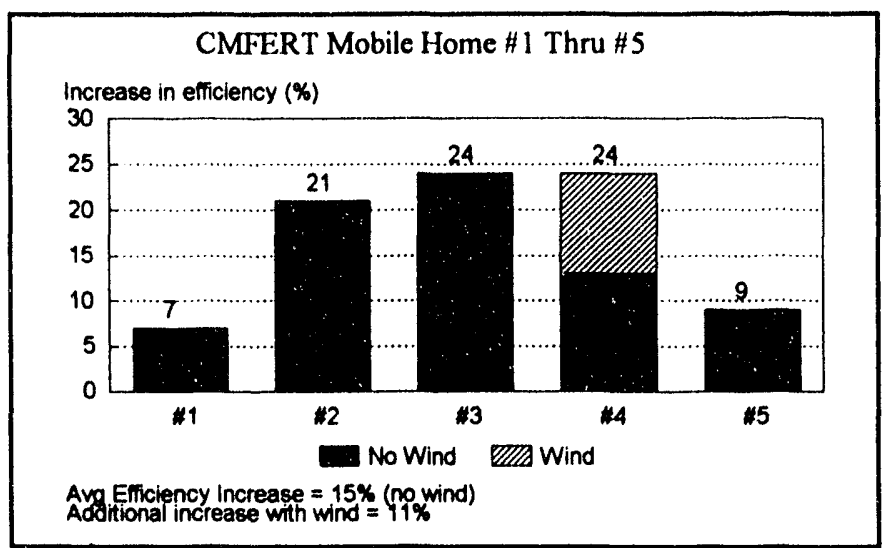

Figure MH4-lncrease in measured efficiency of furnace/duct systems

CMFERT Mobile Home \# 1 Thru \#7

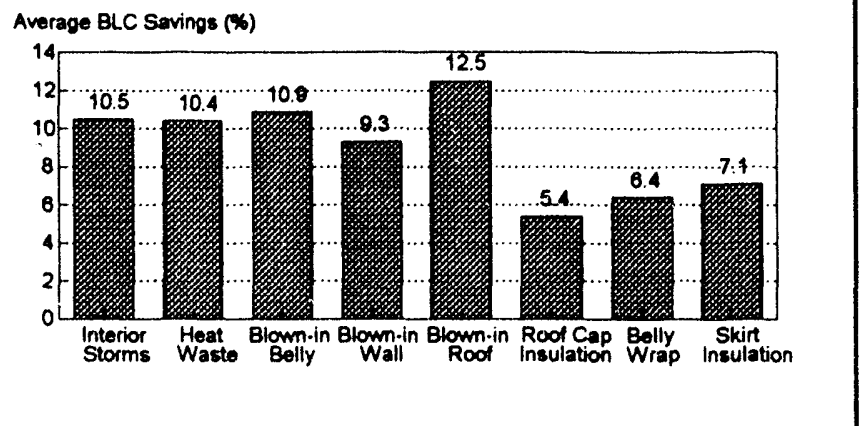

Figure MH5-Average measured savings (reductions) in BLC for each mobile home configuration

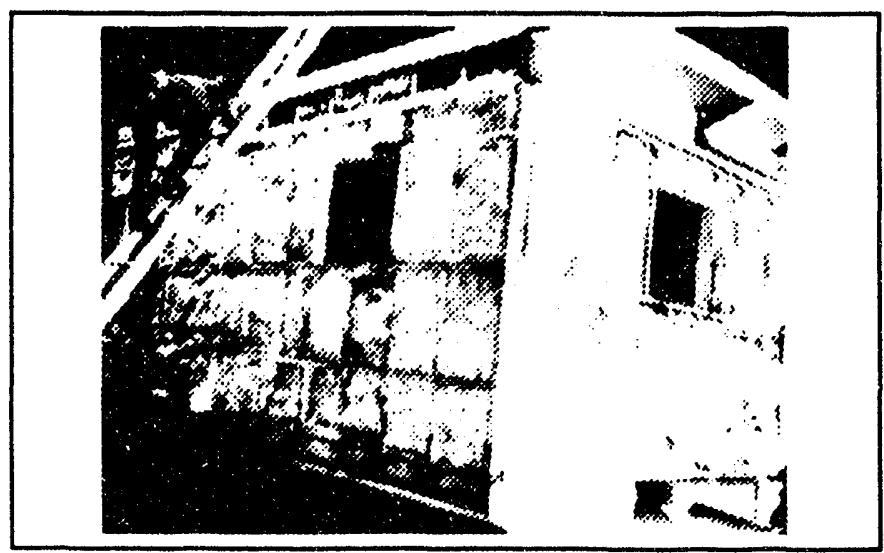

Figure MH6 - Mobile home consitruction details were studied closely 
window replacement. Some additional testing was performed with wind emulation (Judkoff 1991), which appeared to confirm these conclusions.

Finally, the research indicated that cost effective energy savings are possible if weatherization measures are adapted to the unique construction details in mobile homes.

During the course of this project much was learned about how to better weatherize pre-HUDStandard mobile homes in cold and relatively dry climates. Questions remain concerning how to properly weatherize mobile homes in cold-moist, hot-moist, and hot-dry climates. For example, whether roof blows, belly insulation, or air tightening will lead to long-term condensation problems in moist climates. Further research on these issues could avoid potential problems and allow greater savings in these climates.

Much of what has been learned by studying pre-HUD-Standard mobile homes is also applicable to newer manufactured housing. However, some additional research is required to develop an appropriate weatherization package for these homes.

\section{RADIANT BARRIER RESEARCH}

A special research effort has been conducted to examine a new retrofit measure for single family buildings. The new measure is radiant barriers, which are installed in attics of single family houses to improve thermal performance. Under joint sponsorship of the Department of Energy, the Tennessee Valley Authority, Electric Power Research Institute, and the Reflective Insulation Manufacturers Association, the Oak Ridge National Laboratory has led the investigation. This research has consisted of both experiments (Levins 1989, 1990) and simulation modeling (Cook 1989, Wilkes 1988, 1989, 1990, 1991a, 1991b).

The experiments were described in the previous Research Update (MacDonald 1988a) and were conducted using three nearly identical unoccupied ranch-style houses in Karns, Tennessee (midway between Knoxville and Oak Ridge). Early experiments had been conducted with radiant barriers laid directly on top of the attic insulation (the horizontal configuration) and with the radiant barrier attached to the bottoms of the rafters (the truss configuration). These experiments showed that the horizontal configuration performed better than the truss configurations, that percentage savings was larger for the summer cooling season than for the winter heating season, and that savings due to radiant barriers were larger when they were used in combination with lower levels of conventional insulation (such as R-11 and R-19) than when they were used with higher levels (such as R-30).

Although the experiments have shown the horizontal configuration to give the better performance, this application has two potential drawbacks, moisture condensation and dust accumulation, which were addressed by further experiments. During the winter of 1987-1988, an experiment was conducted at the Karns houses to observe the effects of moisture condensation on the underside of a perforated horizontal radiant barrier. Even though the houses were 
operated at high relative humidities (45 and $55 \%$ at $70^{\circ} \mathrm{F}$ ), there did not appear to be any structural, wet insulation, or stained ceiling problems. However, such problems might occur in climates colder than that of the Knoxville area.

During the summer of 1988, an experiment was conducted at the Karns houses to observe the effects of dust accumulation on the performance of horizontal radiant barriers. Artificial dusting (Fig. RB I) was used to change the radiant barrier emittance from 0.05 to either 0.125 or 0.185 . The experiments showed that even a dusty radiant barrier produces a lower cooling load than no radiant barrier. However, as the dust level was increased, the cooling load savings decreased. With emittances of 0.125 and 0.185 , the load savings were 78 and $49 \%$ of the cooling load savings for a clean

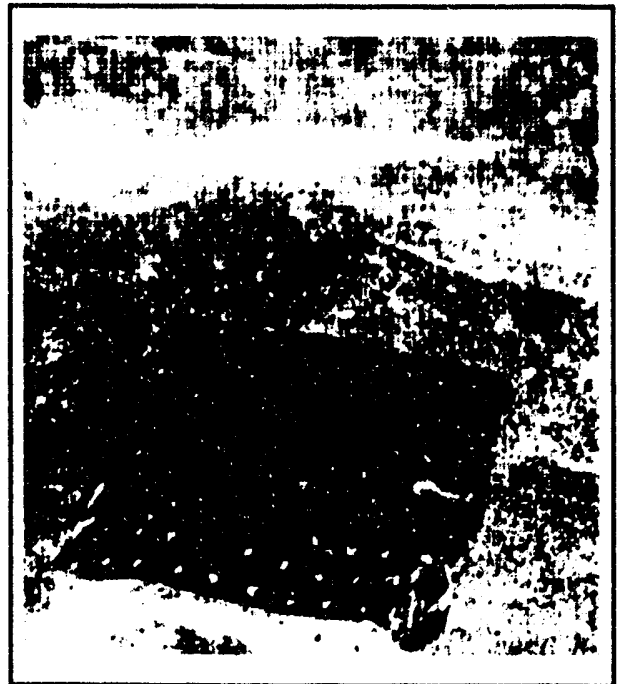

Figure RB1-lmage showing clean radiant barrier (dark square) against dusted barrier (grey). horizontal radiant barrier.

In order to generalize the results of radiant barrier experiments, computer models were developed for residential attics with or without radiant barriers. A model for the thermal performance of attics was coupled with the DOE-2.1C model to estimate annual energy savings due to radiant barriers. The model was extended to allow estimates of the amount of moisture that would accumulate on the underside of a horizontal radiant barrier on an annual basis. Both models were partially validated by comparing their predictions with measured values of ceiling heat flow from a number of experiments (Fig. RB2 shows one such comparison), and with house loads and moisture condensation from the Karns house experiments. Both models were used to estimate annual energy savings and moisture accumulation for a wide range of climatic conditions.

The estimates of annual energy savings were used as a basis for an Attic Radiant Barrier Fact Sheet that was published by DOE in 1991. The intent of this Fact Sheet is to provide consum-

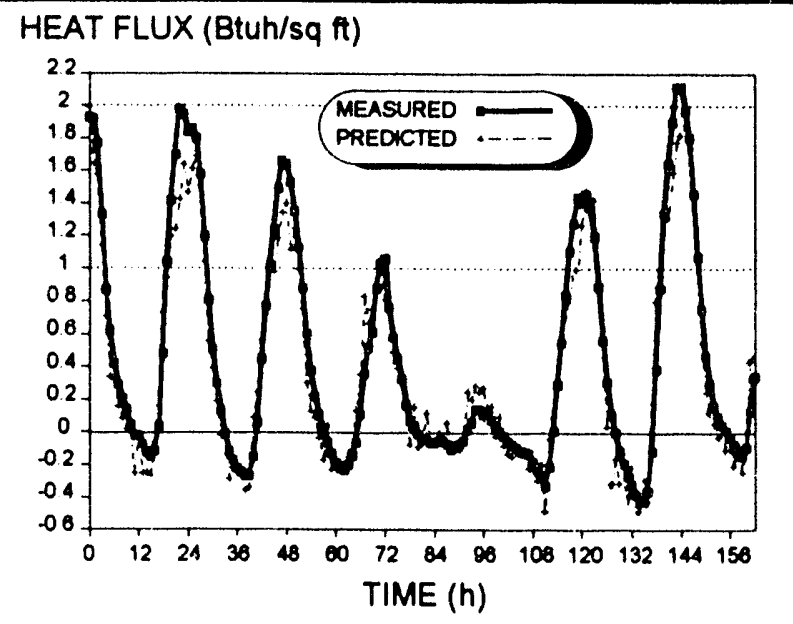

Figure RB2-Comparison of model predictions with ceiling heat fluxes in a full-size house Positive heat fluxes are from attic into house. ers with a source of unbiased information on which to make decisions about installing radiant barriers. The Fact Sheet was developed with the assistance of an industry Radiant Barrier Systems Technical Panel, which consisted of members from ORNL, DOE, the Reflective Insulation Manufacturers Association, the Mineral 
Insulation Manufacturers Association, the Tennessee Valley Authority, the Electric Power Research Institute, and the Florida Solar Energy Center. The Fact Sheet tells what radiant barriers are, how they work, how they differ from conventional attic insulation, what their characteristics are, how much they cost, and what effect they will have on cooling and heating bills. The annual energy savings estimates are presented in terms of a present value savings (\$ per square foot of ceiling area, Table RB 1), giving numbers that the consumer can compare directly with the cost for installation to determine whether or not installation of a radiant barrier is cost effective. In general, the estimated savings are higher for warmer climates and higher when the radiant barrier is added to lower levels of conventional attic insulation.

During development of the Fact Sheet, three areas were identified where additional research is needed. First is the performance of radiant barriers under winter conditions. Field experiments in climates much colder than that of the Knoxville area are needed to provide better validation of the models for savings during the heating season. Second, the available experimental data on the effects of dust accumulation on energy savings are not entirely consistent. Experiments under well-controlled laboratory conditions are needed to provide better validation of the model predictions of the effects of emittance changes on energy savings. Also, more field data are needed to define better the variation of emittance with time as dust accumulates. Finally, most models and experiments have been concemed with the effect of radiant barriers on reducing the heat flow through the ceiling. In addition to this, truss radiant barriers can reduce the temperature of the air in the attic space and hence can reduce heat gains to air-conditioning ducts that are often run through attic spaces. Additional modeling of the effects on duct heat gains are needed, and experiments are needed to validate the model predictions. 


\begin{tabular}{|c|c|c|c|c|}
\hline \multicolumn{5}{|c|}{$\begin{array}{l}\text { TABLE RB1-Present Value Savings for Radiant Barrier Attached to Bottoms of Rafters } \\
\text { (Note: R-11, R-19, R-30, and R-38 refer to the existing level of conventional insulation.) }\end{array}$} \\
\hline \multirow[b]{2}{*}{ City } & \multicolumn{4}{|c|}{$\begin{array}{l}\text { Present Value Savings, } \\
\text { Dollars per Square Foot of Attic Floor }\end{array}$} \\
\hline & $\mathrm{R}-11$ & R-19 & R-30 & R-38 \\
\hline Albany, NY & $0.17-0.19$ & $0.08-0.09$ & $0.04-0.05$ & $0.03-0.04$ \\
\hline Albuquerque, NM & $0.24-0.27$ & $0.12-0.15$ & $0.08-0.10$ & $0.06-0.08$ \\
\hline Atlanta, GA & $0.21-0.25$ & $0.10-0.13$ & $0.06-0.08$ & $0.05-0.07$ \\
\hline Bismarck, ND & $0.18-0.20$ & $0.09-0.10$ & $0.05-0.06$ & $0.04-0.05$ \\
\hline Chicago, IL & $0.17-0.19$ & $0.08-0.10$ & $0.05-0.06$ & $0.04-0.05$ \\
\hline Denver, Co & $0.19-0.22$ & $0.10-0.12$ & $0.06-0.08$ & $0.05-0.07$ \\
\hline El Toro, CA & $0.19-0.22$ & $0.10-0.12$ & $0.06-0.08$ & $0.05-0.07$ \\
\hline Houston, TX & $0.23-0.28$ & $0.12-0.15$ & $0.07-0.10$ & $0.05-0.08$ \\
\hline Knoxville, TN & $0.22-0.25$ & $0.11-0.13$ & $0.07-0.09$ & $0.05-0.07$ \\
\hline Las Vegas, NV & $0.30-0.36$ & $0.15-0.19$ & $0.09-0.12$ & $0.07-0.10$ \\
\hline Los Angeles, CA & $0.11-0.12$ & $0.06-0.07$ & $0.04-0.05$ & $0.03-0.04$ \\
\hline Memphis, TN & $0.23-0.27$ & $0.11-0.14$ & $0.07-0.09$ & $0.06-0.08$ \\
\hline Miami, FL & $0.28-0.36$ & $0.15-0.20$ & $0.09-0.13$ & $0.07-0.10$ \\
\hline Minneapolis, MN & $0.18-0.19$ & $0.08-0.10$ & $0.05-0.06$ & $0.03-0.04$ \\
\hline Orlando, FL & $0.26-0.32$ & $0.13-0.17$ & $0.08-0.12$ & $0.07-0.10$ \\
\hline Phoenix, AZ & $0.36-0.43$ & $0.17-0.23$ & $0.10-0.14$ & $0.08-0.12$ \\
\hline Portland, ME & $0.14-0.15$ & $0.06-0.06$ & $0.03-0.04$ & $0.03-0.03$ \\
\hline Portland, OR & $0.14-0.16$ & $0.07-0.08$ & $0.04-0.05$ & $0.03-0.04$ \\
\hline Raleigh, NC & $0.20-0.24$ & $0.10-0.12$ & $0.06-0.08$ & $0.05-0.07$ \\
\hline Riverside, CA & $0.27-0.37$ & $0.13-0.17$ & $0.07-0.10$ & $0.06-0.08$ \\
\hline Sacramento, CA & $0.23-0.26$ & $0.12-0.14$ & $0.07-0.10$ & $0.06-0.08$ \\
\hline Salt Lake City, UT & $0.21-0.24$ & $0.10-0.12$ & $0.06-0.08$ & $0.05-0.07$ \\
\hline St. Louis, MO & $0.21-0.24$ & $0.10-0.13$ & $0.06-0.08$ & $0.05-0.07$ \\
\hline Seattle, WA & $0.11-0.12$ & $0.05-0.05$ & $0.03-0.03$ & $0.02-0.02$ \\
\hline Topeka, KS & $0.22-0.26$ & $0.11-0.13$ & $0.07-0.09$ & $0.05-0.07$ \\
\hline Waco, TX & $0.26-0.31$ & $0.13-0.17$ & $0.08-0.11$ & $0.06-0.09$ \\
\hline Washington, D.C. & $0.20-0.23$ & $0.09-0.12$ & $0.06-0.07$ & $0.05-0.06$ \\
\hline \multicolumn{5}{|c|}{$\begin{array}{l}\text { NOTE: First value applies to houses with no air-conditioning ducts in attics. Second value } \\
\text { applies to houses with air-conditioning ducts in attics. } \\
\text { Values in table are based on a radiant barrier with an emissivity of } 0.05 \text { or less and a } 25 \text { year } \\
\text { life. }\end{array}$} \\
\hline
\end{tabular}




\section{MULTIFAMILY BUILDINGS}

Of the three buildings sectors, single-family, multifamily, and commercial, multifamily has had the least level of activity, and presents some of the greatest challenges. Over one quarter of the U.S. housing stock is in multifamily buildings. While we know something about the performance of retrofits in single-family houses, we still have much to learn about the interactions and performance of retrofits in multifamily buildings. The measured savings from retrofits in multifamily buildings are typically $25-50 \%$ less than the predicted savings, with a large spread around the mean. The Existing Buildings Research program is working to reduce these uncertainties.

Field tests were previously conducted in Chicago and St. Paul, Minnesota, which provided a large source of data on the energy use characteristics of these buildings. These data are currently being used to develop improved tools for estimating and evaluating the performance of retrofits. Field tests that the program is currently working on are described below.

\section{RETROFIT PERFORMANCE DEMONSTRATIONS}

Two proposals selected for the DOE Competitive Solicitation (see section on DOE Competitive Solicitation) involved field tests of retrofits in multifamily buildings. The Lawrence Berkeley Laboratory (LBL) provides technical assistance on these projects and the Existing Buildings program benefits from use of project results.

\section{BURLINGTON, VERMONT}

A field test involving retrofits of 335 multifamily units is being conducted in Burlington, Vermont. The project was conceived and is being carried out by a local non-profit housing organization (Northgate Housing) and the local electric utility (Burlington Electric Department). The apartments have been converted from electric-baseboard heating to gas-fired hydronic systems, with additional retrofits to the building shell and equipment.

The idea driving this project is that if the units could be made energy-efficient, then the lower utility bills would allow tenants to pay their bills more easily. The retrofit work (new hydronic space heaters, new siding, windows, insulation) has been completed. Blower door tests were made of the pre-retrofit and post-retrofit condition, and a survey has been prepared by LBL, working with BED and Northgate Housing to assess tenant satisfaction. Additional work planned by LBL will be to simulate the buildings to estimate the contribution of the individual measures where possible, and to analyze the utility bills to determine the overall energy savings. 


\section{NEW YORK}

The second project is with the New York State Energy Office, and involves monitoring two retrofit strategies in 30 apartment buildings in New York City. The retrofits are the replacements of the central boilers and the installation of new windows. The space-heating energy consumption will be monitored for two years to examine the persistence of savings. In addition, tests will be made periodically to evaluate the durability of the measures.

\section{DEVELOPMENT OF IMPROVED TOOLS}

\section{MULTIFAMILY AUDIT}

A Multifamily Audit was developed under contract to Princeton University. Based on material developed by Princeton and LBL, the audit outlines the steps to evaluate, select, and analyze the performance of the retrofits in a multifamily building. A draft of the audit was prepared in conjunction with the joint Princeton/LBL multifamily diagnostic demonstration and a draft for distribution was made available in 1989. Feedback from users of the audit indicated that the audit was too technical for most practitioners in the field, and a simplified audit was developed in 1990 in conjunction with multifamily offices at HUD.

\section{MULTIFAMILY DIAGNOSTICS}

Diagnostics for energy use in multifamily buildings that have been developed or are currently under development include testing procedures covering: boiler efficiencies, distribution losses, shell and inter-apartment air leakage, and household appliance efficiencies.

Air leakage diagnostics were performed using three different multizone leakage measurement techniques. Rather than starting the tests on an actual apartment building, as was done previously, the experiments were initially performed under controlled conditions in a single-family house that had been divided into two zones with a panel having known leakage characteristics. Two of the techniques tested used blower doors, whereas the third technique was based upon the AC pressurization apparatus. The two blower techniques differed in the way the pressure differences between the two zones were varied, and the manner in which the data was analyzed.

Following the development of these techniques, diagnostic tests were used on a ten-unit apartment building to determine air flows between units and to the outside. Results from these tests showed that the individual apartments were quite leaky to the outside, but had very little leakage between units, in contrast to the older buildings studied previously (Modera, Brunsell, Diamond, 1986). 


\section{RETROFIT MODELING}

Two models have been developed using the data obtained from the Chicago and St. Paul field tests. The first model simulates the air flow through combustion appliances (i.e., heating and hot water systems) that exhaust through a common chimney, a situation that is typical in many multifamily buildings. The model can be used to predict the performance of retrofits such as vent dampers or flow restrictors based upon the physical configuration and operating characteristics of the system (Dumortier and Modera, 1987).

The second model characterizes the seasonal efficiency of multifamily boilers, taking into consideration the venting issues described above, as well as jacket and ground heat losses. The jacket losses from these older brick-set boilers were as high as 12 percent. Newer, steel-case and sheet-metal boilers had jacket losses of $2-4$ percent. More than $80 \%$ of the losses were found to occur in off-cycle. This model should be capable of providing the data necessary to make recommendations for boiler retrofit or replacement. 


\section{COMMERCIAL BUILDINGS}

Commercial buildings account for a major portion of the energy consumed in the United States and if trends continue, are expected to make up a large percentage of future increases in national energy use. As described in the section on The Importance of Existing Buildings, commercial buildings appear to have accounted for retrofit energy savings approximately equal to the residential sector for the period 1972-1986. Because of these factors, reducing energy use in the commercial sector is an important part of improving energy efficiency of the buildings sector in this country. Although many building/business owners recognize that building energy costs represent an important business expense, often only the larger commercial buildings have the devoted staff or other resources necessary to manage and help control their energy requirements. With small- to medium-sized buildings (less than $50,000 \mathrm{sq} \mathrm{ft}$ ) representing more than $96 \%$ of all U.S. commercial buildings and about half of all floor area, continued energy use reductions in the commercial sector will require significant improvements in small- to medium-sized buildings.

An important factor affecting decisions to implement energy-efficiency improvements in small- to medium-sized buildings is the demonstration and documentation of the benefits of attractive technologies. However, measurement of retrofit energy savings in commercial buildings is often more complicated than in residential buildings, and few retrofit projects in the commercial sector benefit from reliable documentation of energy savings results that can be used by others. To address these difficulties, the Existing Building Research program is directing efforts at understanding and developing methods to measure and report results of commercial energy retrofit projects and at obtaining field data on the performance of retrofits.

\section{RETROFIT PERFORMANCE DEMONSTRATIONS}

\section{TENNESSEE}

A field evaluation of a smart thermostat and related temperature control improvements was conducted in a 4,000 sq ft commercial bank building (Fig. TN 1) in Knoxville, Tennessee (Sharp 1990). The building consists primarily of office and open business areas. Space conditioning is accomplished by three split-package air conditioners and one central gas-fired hot water boiler.

The field study had three objectives:

- To demonstrate the energy savings and demand impacts of the installed measures

- To develop a bettcr understanding of how to measure and analyze baseline and improved performance from measured energy use data in small commercial buildings

- To improve knowledge of the data requirements necessary to characterize the energy performance of commercial buildings 
The efficiency improvements consisted of adding timed setback-setup control to the primary heating and cooling system in the building and timed on/off control to two secondary systems.

The upgrades on the three systems were

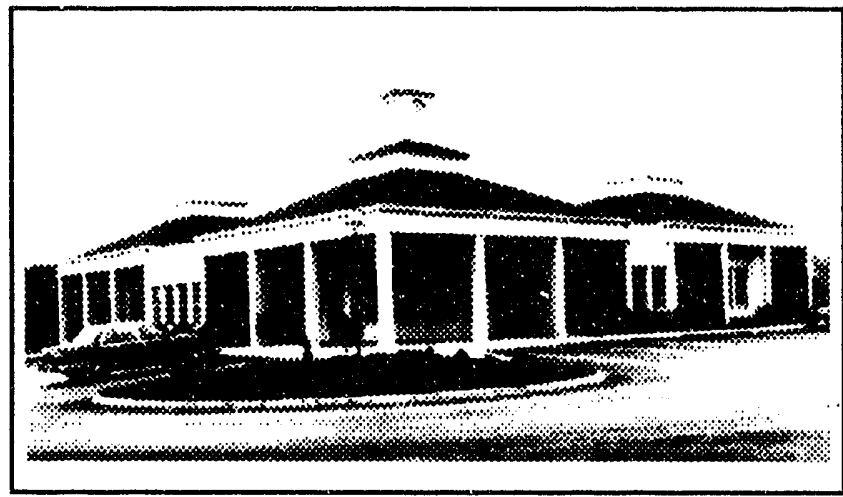

Figure TN1-Outside view of the bank achieved with minimal replacement of existing controls. The primary system received a new programmable thermostat with auxiliary switches that were interfaced to the two secondary systems to provide timed on/off control. This strategy provided more energy efficient control of all three systems while leaving two of the three user-familiar thermostats in place.

Hourly electricity and gas consumption and hourly outdoor temperatures are available for this building for the period of June 17, 1987 to August 30,1988. Approximately $93 \%$ of submetered total energy data and $85 \%$ of end-use data are available for this period. Hourly end use consumption data are available for 38 channels of data, which have been aggregated to heating, cooling, fan, lighting, water heating, and miscellaneous end use totals. Hourly run times are also available for these data channels. Hourly outdoor temperature data were also collected at the site. Monthly utility billing data are available for the period of December 1985 to April 1990. The retrofit was activated March 2, 1988.

Data analyses indicated that the measures were highly effective. Heating energy savings were substantial for both weekdays and weekends. The impact of the new control strategy on the building's heating energy use profile (though not normalized for weather) is illustrated in Fig. TN2. During the building's unoccupied hours, the heating energy use rate after the retrofit is dramatically lower than before. The control changes provided a $33 \%$ reduction in winter heating energy use.

The new control strategy reduced cooling energy requirements by $21 \%$. Unlike heating energy savings, cooling energy savings occurred mostly on weekends, with essentially no savings on weekdays. The results of the cooling energy savings calculations are shown in Table TN1,

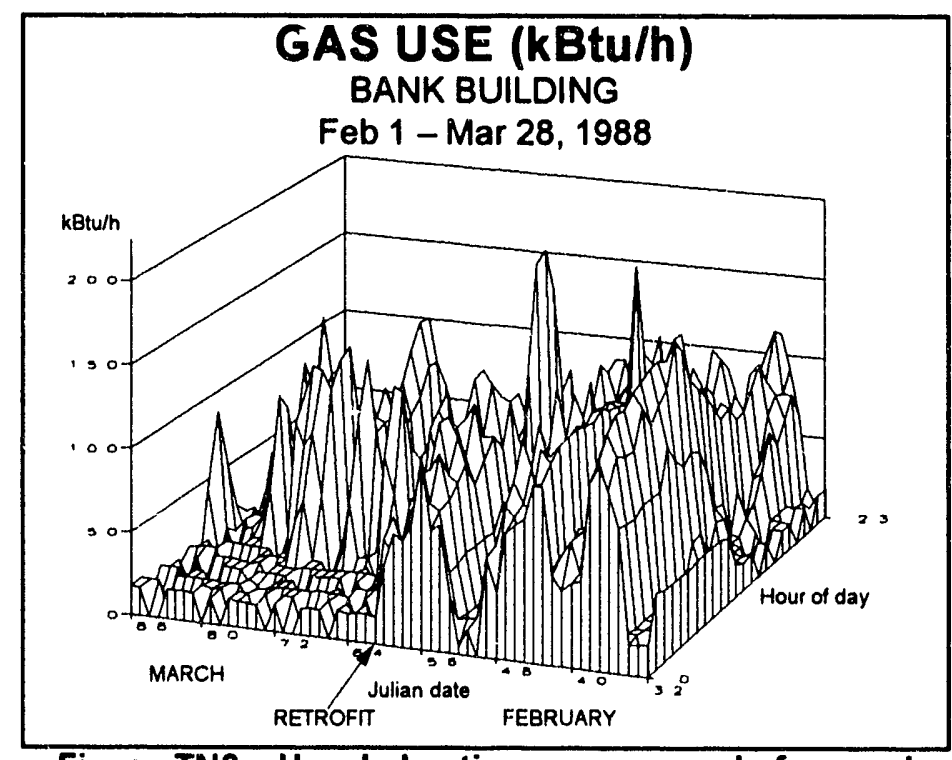

Figure TN2-Hourly heating energy use before and after the retrofit 

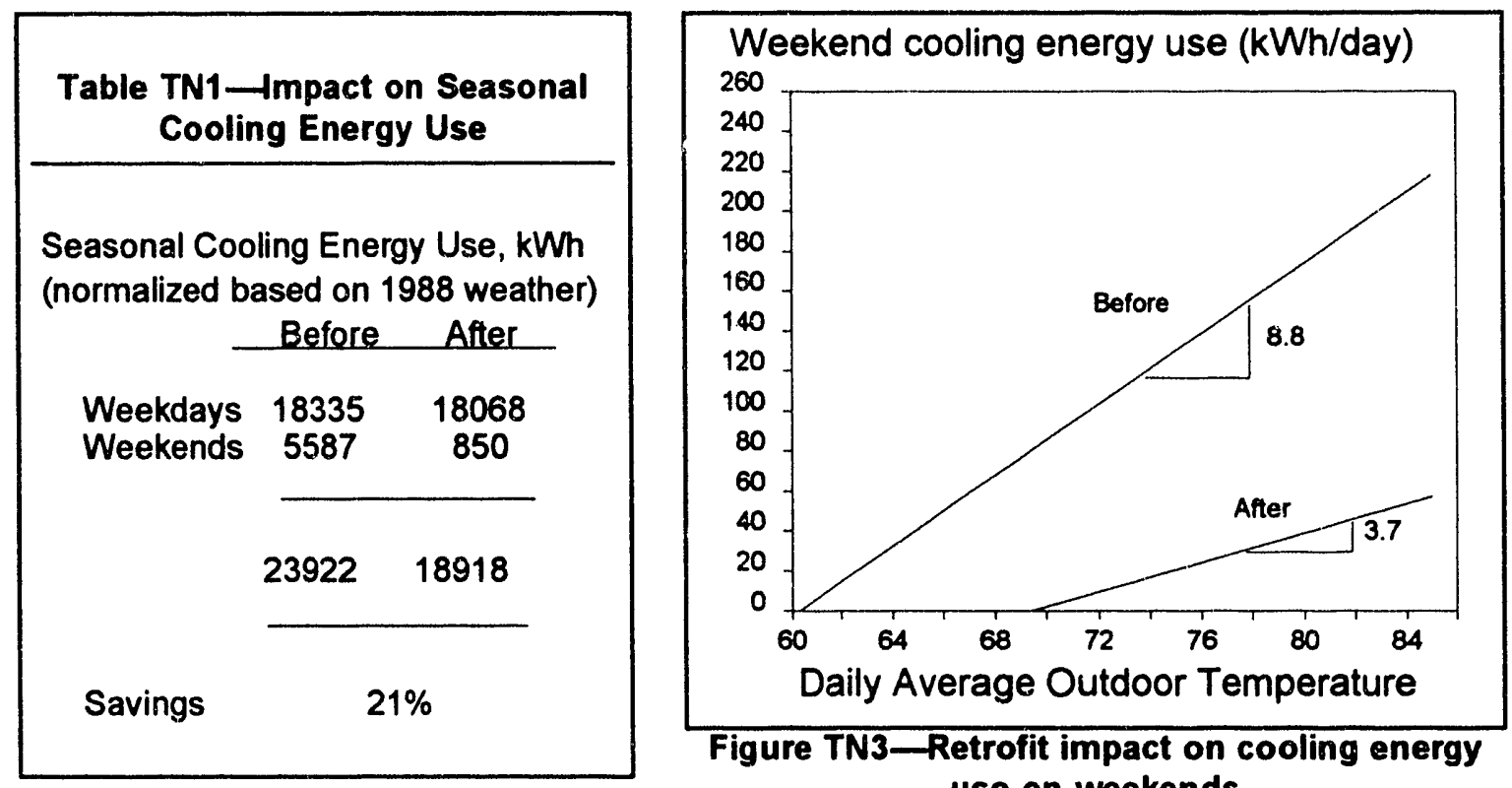

Figure TN3-Retrofit impact on cooling energy use on weekends

normalized to the cooling season weather in 1988 (the pre-retrofit year was 1987). The impact on weekend savings is also shown in Fig. TN3, where the estimated pre- and post-retrofit linear representations of cooling energy as a function of outside temperature show a dramatic shift.

The retrofit was installed by a contractor at a cost of $\$ 600$ in 1988. Total energy savings provided a simple payback of less than one year on the controls upgrade. The new control strategy time-shifted the electric demand pro-

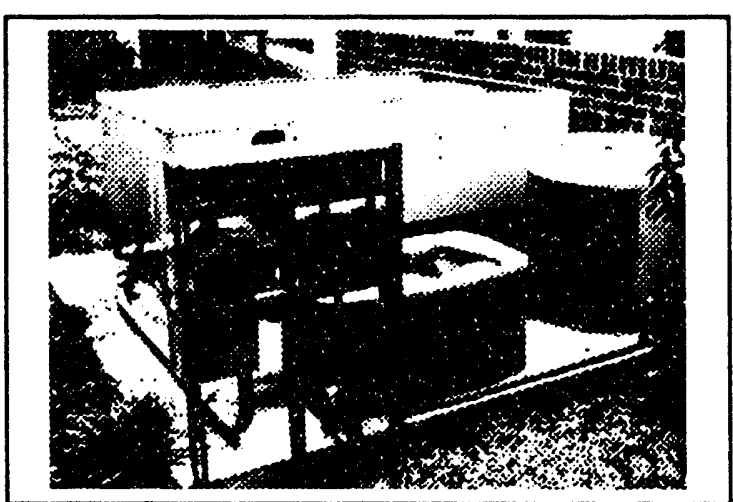

Figure TN4-The bank air conditioning is provided by typical pad-mounted unitary equipment file for the building slightly, and the peak electric load may have increased about $5 \%$. For this building, this peak electric load change was not a concern because typical building loads were well below the $50 \mathrm{~kW}$ level where demand charges begin. In addition to improved energy efficiency, occupants noted a com fort improvement in the area controlled by the programmable system.

Controls upgrades can be done in existing buildings at low cost and with minimal equipment replacement. Upgrades to achieve setback/setup and on/off control can provide dramatic energy savings in buildings where these control schemes are not regularly practiced. Buildings using multiple cooling systems are abundant, and therefore the controls upgrade tested should be applicable to a large number of commercial buildings. Implementation of similar controls upgrades and other promising measures on a wide-scale, where applicable, could contribute significantly to lowered national energy use. 


\section{MASSACHUSETTS}

An electric utility company in the Northeast, Commonwealth Energy Systems, through its two electric utility companies, Commonwealth Electric Co. and Cambridge Electric Light Co. (referred to below as COM/Electric), is currently implementing an innovative, energy conservation program for small commercial buildings in its electric service territories in Massachusetts. Several types of technical assistance are needed, including evaluation of energy savings for this new program. The program is being implemented on a large scale to retrofit existing buildings to obtain energy savings benefits and decrease the need for additional electric generating plants.

The retrofit program is innovative in that the utility is investing in a "conservation power plant" by providing engineering design and installation of retrofit measures (direct installation program) and paying for the installation of those measures. The utility contracts with energy service providers to market the program and install measures. Utility customers are required only to agree to participate. Initially, the primary retrofits will be lighting measures. The program is directed toward reaching most of this customer segment within about five years, at which time COM/Electric expects to go back through this segment to install the technology advances that have occurred in the intervening five years.

COM/Electric is having their contractors survey the energy-using equipment in all buildings covered under the program, in order to develop a data base on this equipment that will help determine future potential retrofits. Procedures for promoting good practices on the part of the contractors are continually reviewed and adjusted as needed. Life cycle cost analyses must be simple to implement in the field, and the approach used is to calculate a present value of avoided future energy use $(\$ / \mathrm{kWh})$ that can be compared directly to the expected annual savings and installed cost of measures. The current present value of this avoided energy use is about $\$ 0.60 / \mathrm{kWh}$, without environmental externalities included. Significant factors affecting their current high costs include their high use of oil for generation and the Seabrook nuclear plant coming on line (now included in the rate base).

Several important program design issues must be addressed in implementing such a program:

- Analytical review of estimates of energy savings benefits

- Development of improved savings estimates where needed

- Identification of additional energy saving measures for use in the program

- Planning of field tests to verify savings from measures

- Evaluation of program benefits and analysis of energy savings results from field tests

- Development of improved methods for providing energy services so these services can move closer to "real time." 
The Existing Buildings Research program authorized Oak Ridge National Laboratory to pursue contract negotiations with COM/Electric under program auspices, and a contract is now in place to provide the types of services described above. An evaluation of program energysaving impacts for the approximately 1,000 buildings served by the program from March through September 1990 was started in 1991.

\section{DISTRICT OF COLUMBIA}

The research work on the energy savings potential of energy management controls in the small bank in Tennessee highlighted the potential benefits of this type of technology - which many commercial buildings now use but many also do not. Also, controls technology continues to evolve, and emerging energy control technologies for commercial buildings offer continuing opportunities to improve commercial building energy efficiency. A field test of improved controls in medium to large commercial buildings in the general location of the District of Columbia is presently being planned. The objective of the project is to provide credible results on the field performance of these new technologies.

Currently, the Potomac Electric Power Company (PEPCO) has expressed interest in participating in such a project to leam more about potential benefits for their demand-side management program. Also, the National Energy Management Institute (NEMI) has agreed in principle to participate as an organization promoting installation of improved controls. NEMI is planning to locate candidate buildings for the field test, and PEPCO may provide incentives for additional retrofits. Negotiations to set up the project continued through 1991, and a plan for the field test will be developed after reasonable progress on the negotiations. The field test is expected to begin in the summer of 1992 .

\section{DEVELOPMENT OF IMPROVED TOOLS}

\section{MONITORING GUIDELINES}

The building energy monitoring protocol for commercial buildings was developed to provide guidance on the most common and basic problems associated with auditing and monitoring, including which building descriptive data are important indicators of energy use and retrofit savings. The monitoring protocol has recommended a set of building characteristic data to collect, but it has not been validated with actual field data. The Texas LoanSTAR program is collecting detailed hourly data on all buildings to measure the energy savings of retrofit measures. Significant experience is being gained under LoanSTAR about the measurement requirements for analyzing the energy savings of certain retrofits in large commercial buildings. A subcontract has been placed with Texas A\&M University to define the data being collected under LoanSTAR to analyze these energy savings. A report describing the data they collect and the comparisons with the current monitoring protocol will be completed this year and should be available in 1992. 


\section{ANALYSIS METHODS}

Initial results from a study of techniques for analyzing metered energy use data to determine baseline energy use and potential energy efficiency improvements in commercial and related buildings were reported in the previous Research Update (MacDonald 1988a). The study was published in 1989 (MacDonald 1989b), and the methods reviewed in the literature indicate that many analysis approaches for metered data of commercial and related buildings are still exploratory. Reasonable results are possible for some buildings using simple measures such as total energy, but the uncertainty of weather variations is still present. Weather adjustments for heating energy use may be possible, but adjustments for cooling are less certain.

The inclusion of specific characteristics of the building and of the activities in the building in a multiple parameter analysis of energy use is an important improvement to analysis methods. Multiple parameter models that analyze effects of occupancy, schedule, special events, and other inputs in addition to weather factors represent an important step forward.

Significant improvements to analysis of metered data for commercial buildings are being tested, and further improvements are needed. These improvements should include continued development of the multiple parameter methods, development of methods for analyzing more detailed (submetered) data (e.g., power signatures), use of macrodynamic methods to generate models with physical significance, and simplification of the methods.

The diversity of methods leads us to conclude that some effort should be made to develop a classification structure to define analysis approaches. Use of this standard structure should be promoted for reporting analyses of commercial building metered data.

In addition to improving the classification and reporting of analysis methods, analysis efforts should be extended to focus on characterizing building types (by appropriate parameters) and the technologies or approaches commonly used to improve efficiency in particular building types. Such an effort is needed to standardize terminology of the types of buildings that are being modified and the nature of the efficiency improvements being made. Improved communication is needed to better explain observed variations between buildings and to more effectively transfer increased knowledge about buildings to more people.

Advanced research on improving the classification and reporting of analysis methods and characterizing building types should be directed at developing relationships between building characteristics and building power signatures (MacDonald 1988b, 1989b). Development of correlations between these two sets of data offers the opportunity to define better models of building energy patterns by identifying and incorporating important causes of variation in power and energy use.

Initial development of advanced comparison methods has been started at PNL, using daily, whole-building electric meter and outdoor temperature data. Data are separated according to day types, such as working days and nonworking days, and then the data are analyzed statistically to obtain fitted parabolic curves of energy use for different day types as functions of 
temperature. The fitted curves indicate the differences in apparent balance point temperature for working and nonworking days, as well as energy use that is not dependent on temperature. Further development of similar methods is expected to continue over time within the program.

\section{AUDIT DEVELOPMENT}

Significant work has been conducted over several years with the American Society of Heating, Cooling, and Refrigerating Engineers (ASHRAE) to assess the energy audit process in commercial buildings. ASHRAE Special Project 56 on the energy audit process produced an assessment of the energy audit process, and as a result of the initial work, a guide was developed on analyzing and reporting building characteristics and energy use in commercial buildings (ASHRAE 1989). The work was managed by PNL. The guide is available through ASHRAE or ORNL.

\section{GAS COOLING TECHNOLOGIES}

A flexible, public domain methodology was developed for estimating financial indicators for altermative HVAC equipment in commercial buildings (McLain 1991). It is based on simulation of the building hourly energy use, and it allows for many economic parameters, among which are detailed utility rate structures, energy escalation rates, inflation rates, and loan expenses. Development of this method was supported by the Gas Research Institute and the Existing Buildings Research program.

Growth in electricity use has reached the point where the availability of electricity in parts of the country is becoming limited until new generating capacity is installed. The commercial sector is estimated to account for over $40 \%$ of the growth in national electricity use from 1972-1986 (DOE 1989). Moreover, the low electrical load factors (high power demand relative to consumption) of commercial buildings combined with the increasing percentage of total electrical consumption used for the buildings sector of the economy have led to decreasing electrical load factors overall.

Space cooling is about one-third of the commercial sector's energy demands and is now the largest single contributor to the electrical utilities summer peak demand (Rabl 1987). Many utilities now include demand and time-of-day charges in their commercial rate structures to reflect the cost of meeting the peak power demands.

There has been considerable activity in recent years to develop alternative technologies that could reduce or levelize building space cooling electrical use. Among these are the development of more efficient electric motor driven chillers, diurnal cool storage, more efficient absorption chillers, desiccant cooling systems, and gas-fired engine driven chillers (GRI 1989). Gas-fired engine-driven chillers were the focus of this development effort. 
The anticipated savings in demand and energy charges for the alternate technologies must be weighed against the possible higher initial costs of these systems, limited choice of equipment, reliability, and maintenance cost concerns of the buyers. The analysis tool that was developed allows economic evaluation of energy cost benefits and expected higher initial and maintenance costs.

A hypothetical $200,000 \mathrm{ft}^{2}, 10$ story office building was selected as the reference building (McLain 1988) for application of the new economic evaluation methodology. Office buildings are a large subsector in the functionally diverse commercial building sector, and the energy consumed by this group is the greatest of any group in this sector (EIA 1989b). They have relatively high peak electrical energy demands and associated demand charges because of the nature of their occupancy schedules. For the office subsector large office buildings (greater than $100,000 \mathrm{ft}^{2}$ ) represent about $42 \%$ of the total floor space and $46 \%$ of the consumed energy. These large buildings consumed $9.2 \%$ of the total energy consumed by commercial buildings overall (EIA 1988, EIA 1989b).

The methodology consists of three steps:

1. Calculate the hourly heating and cooling (HVAC) loads imposed on the central heating and cooling equipment for a selected building (reference building) in a given climate using the DOE-2.1C program. All the other hourly building energy consumption values, such as for lights, domestic hot water, and non-HVAC equipment loads are also calculated using DOE-2.1C.

2. Calculate the hourly and monthly building electricity and natural gas demands for selected chiller technologies using a newly developed personal computer program called Cooling Equipment Simulation Routine (CESR). CESR includes prim ary cooling equipment simulation routines extracted from DOE-2.1C and some new coding to handle new technologies and provide output in the desired format. This step provides hourly values of the building electric and natural gas consumptions using the alternative technologies as well as a base case technology.

3. Calculate the economic results of interest. For this study we focused on the IRR for the selected alternative cooling technologies relative to a base electric centrifugal chiller technology. The IRR values are calculated using the Building Innovations Economic Analysis (BIEA) program (Flanagan 1985), modified slightly to run on a personal computer. BIEA is designed to use hourly or monthly energy consumption data together with the utility rate structures to calculate the building energy consumption charges. It factors in parameters, such as utility demand and time-of-day charges, initial costs, replacement and repair costs, interest, taxes, and inflation rates, in the calculations. The program generates a diverse array of economic results in addition to the IRR values.

The simulations of the various building cooling equipment technologies were performed for the building being located in Chicago, IL, Boston, MA, and San Diego, CA. National Oceanic and Atmospheric Administration Test Reference Year (TRY) weather data were used for the 


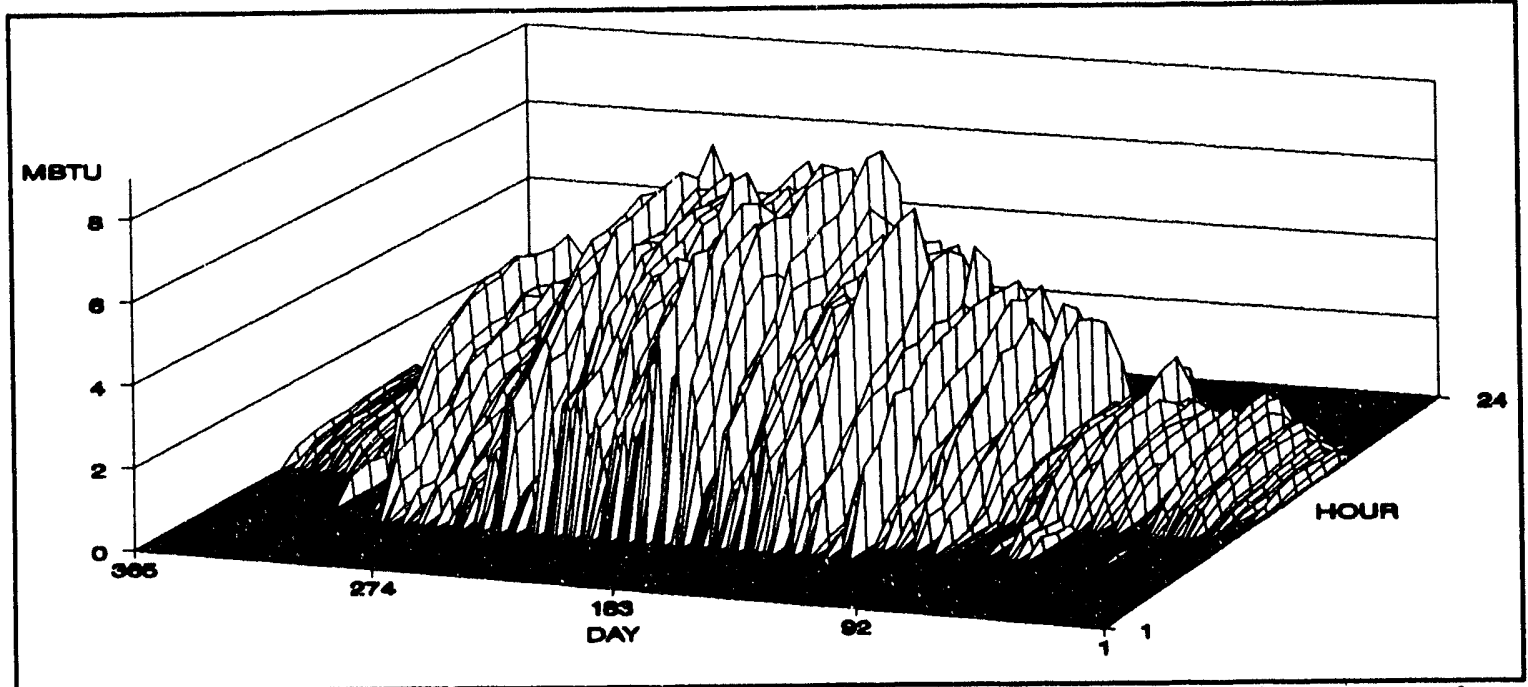

Figure GC1-Total cooling coil load profile for reference building with VAV system in Chicago

simulations. Previous work by Davidson (1986) indicated that engine driven chillers would be competitive in these three cities. The electrical demand charges are relatively high for the Boston and Chicago locations. For San Diego, both the demand charges and the energy rates for electricity are relatively high. Recent studies (Brodrick 1990) also indicated that engine driven chillers would be competitive in regions having relatively high electrical demand charges.

The HVAC systems were assumed to be operated efficiently -only during

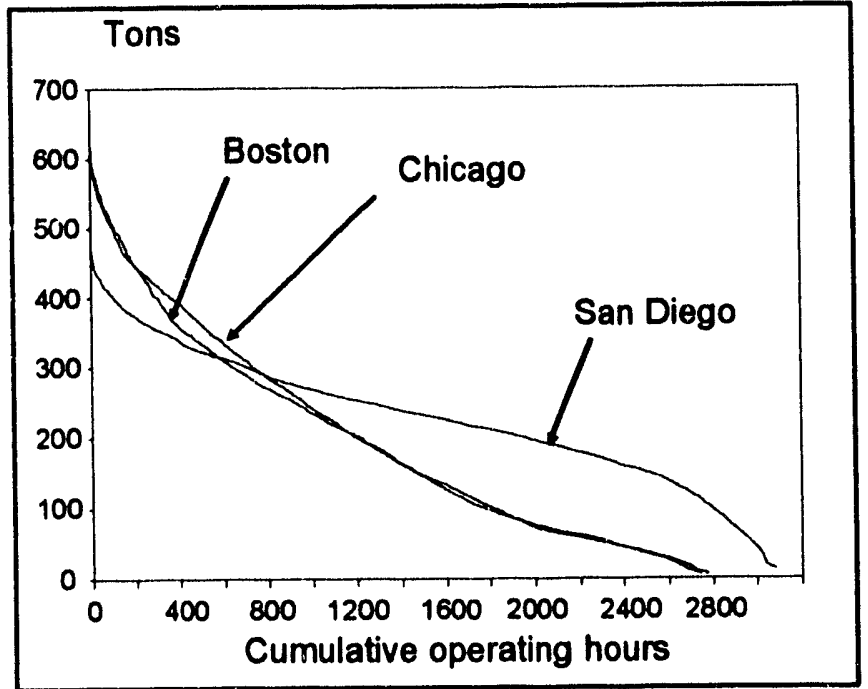

Figure GC2-Chiller load duration curves working hours and when needed for freeze protection during unoccupied hours in severe cold weather. The systems are scheduled to operate from 6:00 a.m. to 6:00 p.m., Monday through Friday, except for holidays.

Figure $\mathrm{GCl}$ is a profile of the cooling loads for the building with the VAV system in Chicago. The profiles reflect the occupancy schedule of the building with the peak loads occurring during late afternoon. For the week, the loads are frequently higher during the first day following the weekend shutdown due to the thermal mass of the building.

Chiller load duration curves for VAV air handling systems, located in different climates are presented in Figure GC2. The curves for Chicago and Boston are close. The one at San Diego is different due to the more uniform weather conditions there. 


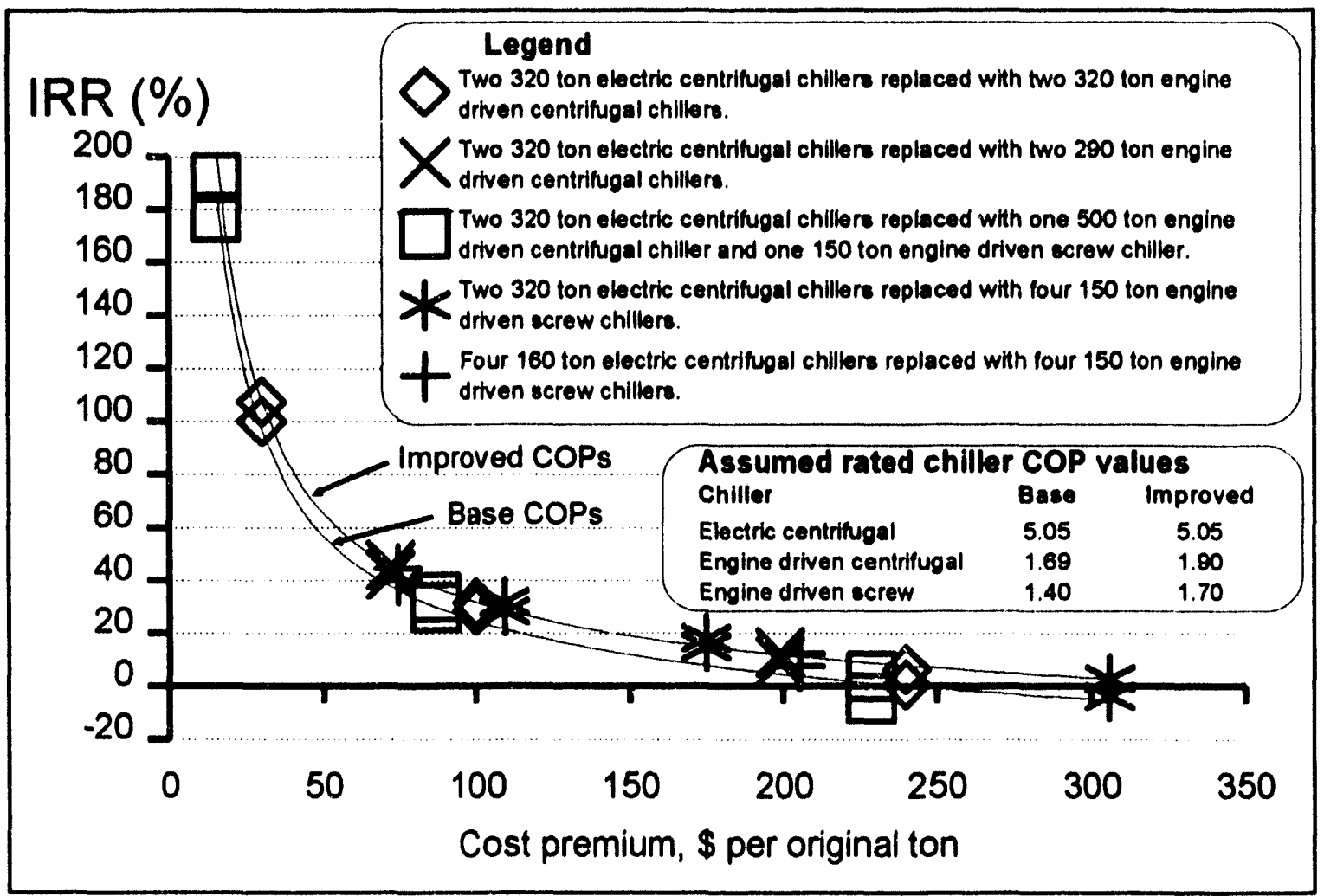

Figure GC3-1nternal rate of return (IRR) values for replacing electric centrifugal chillers with engine driven chiller options, 200,000 $\mathrm{ft}^{2}$ office building with VAV system, Chicago

Figure GC3 shows the IRR values of the engine driven chiller options for the office building located in the Chicago. The results reflect both the climate and the utility rate structure in Chicago. Results were also generated for Boston and San Diego. There is a reasonable correlation between the IRR values and the original cost premiums for the engine-driven chillers. The curves in these plots show the trends of the results.

A single curve can be used to correlate the IRR values, for the selected base COPs or for the selected improved COPs. This appears possible because the average annual efficiencies of the selected engine driven chillers are about the same. Although the rated efficiencies of the centrifugal and the screw chillers are different, the assumptions of constant speed operation for the centrifugal chiller and variable speed operation for the screw chiller led to about the same annual average efficiencies. Engine driven centrifugal chillers probably will be operated as variable speed machines, giving higher average efficiencies and higher IRR values. (This operation mode was not assumed here because of the unavailability of performance data.)

The influence of the cost premiums of the engine driven chillers is very apparent, particularly at premiums of $100 \$ /$ ton or less. At a $100 \$ /$ ton premium, the IRR is about $30 \%$, and at a 150 \$/ton premium, the IRR is in the range of $10 \%$ to $20 \%$. 
The impact of the electrical demand and time-of-day charges on the marginal electricity costs is very pronounced. Calculations were also made to determine the sensitivity of the IRR to the engine nonfuel O\&M cost. The influence of O\&M costs on the IRR is found to be relatively small.

A viable niethodology was developed for estimating financial indicators for HVAC equipment technologies in commercial buildings. The approach described here provides considerable flexibility regarding the capital and energy costs. Among the features in the programs is the ability to specify the energy rate structures having demand and time-of-day charges, energy escalation rates, inflation rates, property and income taxes, tax credits, initial and replacement costs, and loan and mortgage expenses. This allows for the methodology to be used in a wide variety of market scenarios for evaluating altemative technologies.

All the programs used in the methodology are public domain routines. In this investigation, personal computers were used to run the BIEA and CESR programs. These programs are flexible and can be changed relatively easily. The DOE-2.1C program used to generate the building loads can be run on personal computers or minicomputers.

Although this study is directed primarily toward engine driven chillers, the methodology can readily be applied to other technologies. Flexibility results because the routines are modular and can be modified readily to evaluate other technologies.

The analysis indicates that engine driven chillers can have favorable economic indicators in the energy markets evaluated. For the reference office building selected in this study for the three cities, the analysis predicted that an IRR of about $30 \%$ could be realized by the investor if the premium for the engine driven chiller is $100 \$ /$ ton. At a $150 \$ /$ ton premium, the IRR is in the range of $10 \%$ to $20 \%$. 


\section{FUTURE ACTIVITIES}

The new National Energy Strategy (NES) (DOE 1991, p 45) identifies more effective techniques for retrofitting existing residential buildings as an important area of ongoing research that has produced useful results and will continue to receive support. For commercial buildings the NES states a goal of supporting industry, utilities, and government agencies in developing and implementing effective [retrofit] programs ( $p 49$ ). Increasing the energy efficiency of the buildings sector is an important part of the NES.

The Existing Buildings Research program provides a fundamental resource for national efforts to improve the efficiency of the buildings sector of our economy. In addition to conducting R\&D on new technologies needed to specifically address special needs for energy retrofits in buildings, this program bridges the huge gap between technology R\&D and technology use. Within this gap is the large array of activities associated with deployment of technologies within buildings. For deployment to be successful, the technology must meet a need and the barriers to deployment described in the Introduction must be overcome.

Because the buildings sector is so diffuse and diverse, legislators, regulators, govemment planners, and others have difficulty defining the efforts needed to make energy efficiency innovation happen. The primary difficulty is a lack of activities specifically directed at improving deployment of energy technologies in buildings. Hill $(1979, \mathrm{p} 3)$ has stated that innovation involves the use of unique, new, or previously unused ideas or methods. If we accept the idea that technologies must be used to achieve innovation, then deployment of technologies is critical to that use.

As an example of a deployment issue related to a new technology that is not specifically installed in a building, a new residential energy audit procedure was developed under the Existing Buildings program. The new audit was used in a field demonstration of improved deployment of low-income weatherization retrofits, including consideration of mechanical systems retrofit. The field demonstration showed that the new audit was able to increase average energy savings in a DOE Weatherization program from $10 \%$ to $25 \%$ at lower cost. The program Benefit-to-Cost ratio was increased by a factor of three.

If the energy efficiency of the buildings sector in this country is to be dramatically improved over the next 15-30 years, better "deployment" of efficiency technologies is necessary. Improved delivery of measures, improved understanding of how buildings actually perform in the field, and methods for improving operations and maintenance of buildings and energy equipment are all examples of ways to improve the deployment (transfer) of technologies. The Existing Buildings Research program works to meet these needs. Much has been learned about technology deployment in buildings in the first five years of the program, and our future plans will be directed at developing improved retrofit technologies and at significantly improving energy technology deployment results. 


\section{PROGRAM STRATEGY}

Energy efficiency policy continues to be analyzed at many levels to improve understanding of potential benefits and discern reasonable policies for increasing desirable benefits. The evolution of electricity demand side management programs has increased the discussion level. National goals to save energy in buildings can be targeted at new and existing buildings. However, if needed, how can the effectiveness of energy efficiency programs be improved quickly to reach suggested efficiency targets? Our experience indicates clearly that significant near-term improvements are not possible without major efforts directed at assuring deployment of measures in existing buildings. Our vision of the future shows a need for energy management in existing buildings, and we estimate that even with time horizons of 40 years, that at least one-third of efficiency savings achieved 40 years hence must come from improvenents in existing buildings. National efficiency efforts for existing buildings should increase.

Building efficiency programs require a complex set of actions and sometimes a significant amount of building science to function properly and to improve. At the state and local level, all the different types of expertise needed to conduct different levels of evaluations and technology field tests are typicaily not available. Thus, programs are often stymied in certain areas because of a lack of requisite skills. The Existing Buildings program experience has shown that the federal government can provide a unique resource for catalyzing improved programs at the state and local level. The federal government can assume the responsibility for linking together the diverse public and private sector organizations needed to achieve significant program improvements. The end result is improved deployment of technologies.

Our program strategy for the next 5-10 years covers expanding our linkages with public and private sector organizations across the country and moving our program focus away from the low-income residential sector to commercial, industrial, and other residential sectors. We intend to continue to coordinate, conduct, and transfer results of field tests to demonstrate technology performance in buildings, with enhanced credibility of results. Our support of the Texas LoanSTAR program is an example of important support that can be provided. Field tests will only be conducted in cases where other organizations provide significant cost-sharing, indicating an important need for the results. We plan to continue improving methods for deployment of advanced technologies. Our goal is to continue increasing the penetration of efficiency improvements in existing buildings.

The program strategy also calls for new technologies to be developed that: are more cost effective for retrofit, are more technically appropriate for retrofit, allow better identification of retrofits at reduced cost, and improve abilities to assure that expected savings are being achieved.

Over the past several years we have worked with numerous organizations around the country, and the linkages with and among these organizations continues to grow. Many of these organizations are our customers, and an initial matrix has been developed that indicates organizations and building sectors that are appropriate customers for our energy efficiency product (Fig. F1). Primary customers are organizations that directly deliver or install energy 


\begin{tabular}{|c|c|c|c|c|}
\hline \multirow{2}{*}{$\begin{array}{ll}\text { LEGEND: } & \text { PRIMARY CUSTOMER } \\
\text { SECONDARY CUSTOMER }\end{array}$} & \multicolumn{2}{|c|}{ RESIDENTIAL } & \multicolumn{2}{|c|}{ COMMERCIAL } \\
\hline & \multirow{2}{*}{$\begin{array}{l}\text { LOW } \\
\text { INCOME }\end{array}$} & \multirow{2}{*}{ OTHER } & \multirow{2}{*}{ SMALL } & \multirow{2}{*}{$\begin{array}{l}\text { LARGE } \\
\text { PLUS } \\
\text { INST/IND }\end{array}$} \\
\hline CUSTOMER & & & & \\
\hline \multicolumn{5}{|l|}{ DOE. WAP } \\
\hline \multicolumn{5}{|l|}{ HUD } \\
\hline \multicolumn{5}{|l|}{ DOD/FEMP } \\
\hline \multicolumn{5}{|l|}{ STATE GOVERNMENT } \\
\hline \multicolumn{5}{|l|}{ CITY GOVERNMENT } \\
\hline \multicolumn{5}{|l|}{ UTILITIES } \\
\hline \multicolumn{5}{|l|}{ BUILDING SUPPLIERS } \\
\hline \multicolumn{5}{|l|}{ BUILDING OWNER AND STAFF } \\
\hline \multicolumn{5}{|l|}{ BUILDERS, CONTRACTORS } \\
\hline CONSULTANTS, AE FIRMS, ESCOS & & & & \\
\hline
\end{tabular}

Figure F1-Customer categories of the Existing Buildings Program

efficiency measures in buildings. Secondary customers are those that are influenced by or work with our primary customers. Our efforts over the years have provided direct interaction between people from the research and implementation sides of efficiency programs. Through this interaction, distinct improvements in program effectiveness have been produced, where technical improvements are introduced as needed to improve program performance. We will continue to build on the knowledge of technology performance and program performance through expanding linkages with interested organizations.

Our sectoral focus will be changing from low-income residential to other residential and commercial-industrial-institutional. The change reflects the need to address the building sectors where major energy savings can be achieved. Most residential housing is not low income, so some efforts must be directed at the remaining residential stock. Some past efforts have been directed at the commercial/institutional sector, and now our efforts in this sector are beginning to expand. We also plan to begin addressing increased efficiency of energy use in industrial buildings, which together with large commercial/institutional customers, often hold the key to large improvements for utilities with active energy conservation and demand reduction programs. 


\section{CONCLUSION}

Technical leadership appears to be an important ingredient for achieving effective programs. The Existing Buildings program will work to continue providing technical leadership for national efforts to improve the energy efficiency of existing buildings. Efforts will also continue to link together the diverse public and private sector organizations needed to achieve increased efficiency improvements in buildings. Demonstrations and evaluations to establish performance and cost effectiveness of efficiency measures will continue. Work on advanced technologies will increase. The program intends to make an important contribution to building energy efficiency in the United States. 


\section{REFERENCES}

BNL (Brookhaven National Laboratory). (1991). Analysis and Technology Transfer Report, 1989 and 1990, Building Technologies, BNL Report BNL 46559, pp 3-10 to 3-17.

Breton, T. R. (1990). " Options and costs for reducing U.S. $\mathrm{CO}_{2}$ emissions by the year 2010," Proceedings, Energy supply/demand balances: Options and costs, pp 1-5, Washington: Int'l Assoc for Energy Economics.

Brodrick, J.R., and Patel, R. (1990). "Defining th e market for gas cooling," ASHRAE Journal, Vol 32(1), pp 24-31 (January).

Burns, R. and R. E. Hough, (1991). Evaluation of electric demand effects from air conditioner efficiency improvement in single family houses, Oak Ridge National Laboratory report ORNL/Sub/86-SA566/V.

Carlsmith, R. S. et al (1990). Energy efficiency: How far can we go?, Oak Ridge National Laboratory report ORNL/TM-11441.

Cook, J. C., D. W. Yarbrough, and K. E. Wilkes, (1989). "Contamination of reflective foils in horizontal applications and the effect on thermal performance," ASHRAE Transactions, Vol. 95, Part 2.

CSR (CSR, Inc and Meridian Corp) (1989). Weatherization evaluation findings: A comparative analysis, U.S. Dept of Energy report DOE/CE-10530.

Cummings, J. B., J. J. Tooley, and R. Dunsmore, (1990). "Impacts of duct leakage on infiltration rates, space conditioning energy use, and peak electrical demand in Florida homes," Proceedings of the ACEEE 1990 Summer Study on Energy Efficiency in Buildings, V 9, pp 9.65-9.76, Washington: American Council for an Energy Efficient Economy..

Davidson, K., and Brattin, H.D. (1986). "Gas cooling for large commercial buildings," ASHRAE Transactions, Vol 92, Part 1.

DOE (1989). Energy conservation trends, understanding the factors that affect conservation gains in the U.S. economy, U.S. Dept of Energy report DOE/PE-0092.

DOE (1991). National energy strategy (first edition), U.S. Dept of Energy report DOE/S-0082P.

Dumortier, D. and M.P. Modera, A Model for predicting air flow through venting systems for multiple combustion applications, Lawrence Berkeley Laboratory Report LBL-23151.

EIA (1988). NBECS: Characteristics of commercial buildings 1986, Washington, DC: U.S. Department of Energy, Energy Information Administration report DOE/EIA-0246(86).

EIA (1989a). Annual energy review 1988, Washington, DC: U.S. Department of Energy, Energy Information Administration report DOE/EIA-0384(88).

EIA (1989b). NBECS: Commercial buildings consumption and expenditures 1986, Washington, DC: U.S. Department of Energy, Energy Information Administration report DOE/EIA-0318(86).

EPRI (1983). Monitoring methodology handbook for residential HVAC systems, Palo Alto, CA: Electric Power Research Institute, report EPRI EM-3003. 
Flanagan, D.M., D. M. Hamblin, and B. Thomas, Jr (1985). Completion of a public domain life cycle code: Documentation and validation of the building innovations economic analysis (BIEA) code, Oak Ridge National Laboratory report ORNL/TM-8962.

GRI (1989). Gas Research Institute 1990-1994 research and development plan and 1990 research and development program, Chicago, IL: Gas Research Institute.

Hill, C. (1979). "Technological innovation: Agent of change," in C. Hill and J. M. Utterback, Technological Innovation for a Dynamic Economy, Pergamon Press, pp 1-39.

Hughes, P. D. and W. E. Clark (1986). "Plunning and design of field data acquisition and analy sis projects: A case study," Proceedings of the national workshop, Field data acquisition for building and equipment energy-use monitoring, U.S. Dept of Energy report CONF-8510218.

Judkoff, R. et al (1990). "CMFERT: Training and testing of mobile home retrofits," Home Energy, V 7(1) p 23 (January/February).

Judkoff, R. (1991). "Mobile home retrofits revisited: CMFERT phase II," Home Energy, V 8(1) p 21 (January/February).

Levins, W. P., M. A. Karnitz, and J. A. Hall, (1989), Moisture measurements in single-family houses with attics containing radiant barriers, Oak Ridge National Laboratory report ORNL/CON-255.

Levins, W. P., M. A. Karnitz, and J. A. Hall, (1990), Cooling season energy measurements of dust and ventilation effects on radiant barriers, Oak Ringe National Laboratory report ORNL/CON-271.

MacDonald, J. M. et al, (1988a). Research update: Existing building efficiency research, 1987-1988, Oak Ridge National Laboratory report ORNL/CON-268.

MacDonald, J. M. (1988b). "Power signatures as characteristics of commercial buildings." Proceedings of Fifth Annual Symposium on Improving Building Energy Efficiency in Hot and Humid Climates, pp 80-87, College Station, TX: Texas A\&M University.

MacDonald, J. M., T. R. Sharp, and M. B. Gettings, (1989a). A protocol for monitoring energy efficiency improvements in commercial and related buildings, Oak Ridge National Laboratory report ORNL/CON291.

MacDonald, J. M. and D. M. Wasserman, (1989b). Investigation of metered data analysis methods for commercial and related buildings, Oak Ridge National Laboratory report ORNL/CON-279.

Mankiw, N. G. and D. N. Weil, (1989). "The baby boom, the baby bust, and the housing market," Regional Science and Urban Economics, V 19, pp 235-258.

McLain, H.A., J. M. MacDonald, and D. J. Downing (1988). An analytical investigation of energy end-use in commercial office buildings, Oak Ridge National Laboratory report ORNL/CON-250; Chicago: Gas Research Institute, report GRI-87/0318.

McLain, H. A. et al (1991). "Energy and economic benefits of gas cooling options in large office buildings," ASHRAE Transactions, V 97(1).

Miller, W. A. et al (1989). "Motor current signature analysis - A potential diagnostic for air conditioners," ASHRAE Transactions, V 95(1), pp 312-317. 
Modera, M. P., J. T. Brunsell, and R. C. Diamond (1986). “Improving diagnostics and energy analy sis for multi-family buildings: A case study." Proceedings of the ASHRAE/DOE/BTECC Conference, Thermal performance of the exterior envelopes of buildings III, Atlanta: ASHRAE. Lawrence Berkeley Laboratory report LBL-20247.

Proctor, J. (1991). "An ounce of prevention: residential cooling repairs," Home Energy, V 8(3), pp 23-28 (May/June).

NWPPC (1990). Draft 1991 Northwest conservation and electric power plan, V 1, Portland, OR: Northwest Power Planning Council, report 90-18.

Quaid, M. A., and M. O. Anderson (1988). "Measured energy savings from foundation insulation in Minneapolis single family homes," Proceedings of the ACEEE 1988 summer study on energy efficiency in buildings, V 1, pp 118-129, Washington: American Council for an Energy Efficient Economy..

Rabl, V. A. (1987). "Load management: Issues and opportunities," Commercial cool storage, state of the art, Palo Alto, CA: Electric Power Research Institute, report EM-5454-SR, pp 1-1 -1-5.

Robison, D. H., and Lambert, L. A. (1989a). "Effects of ducted forced-air heating systems on residential air leakage and heating energy use." ASHRAE Transactions, Vol. 95, Pt.2, Atlanta: ASHRAE.

Robison, D. H., and Lambert, L. A. (1989b). "Field investigation of residential infiltration and heating duct leakage." ASHRAE Transactions, Vol. 95, Pt.2, Atlanta: ASHRAE.

Robinson, D. A. et al, (1991). Foundation insulation retrofits in single-family houses in Minnesota, Oak Ridge National Laboratory report ORNL/Sub/86-SA711/V.

Schneider, S. H. (1989). "The greenhouse effect: Science and policy," Science, V 243, pp 771-781 (Feb. 10).

Schwengels, P. and W. J. Pepper (1990). "Energy efficiency and greenhouse gas emission reductions: Some international results," Proceedings of the ACEEE 1990 summer study on energy efficiency in buildings, V 4, pp 4.207-4.216, Washington: American Council for an Energy Efficient Economy.

Sharp, T. R., and MacDonald, J. M. (1990). Measurement of energy performance in a small bank building, Oak Ridge National Laboratory report ORNL/CON-297.

Szydlowski, R.F. and R.C. Diamond (1989). Data specification protocol for multifamily buildings, Lawrence Berkeley National Laboratory report LBL-27206.

Ternes, M.P. (1987). Single-family building retrofit performance monitoring protocol: data specification guideline, Oak Ridge National Laboratory report ORNL/CON-196.

Ternes, M. P. et al (1991a). The national fuel end-use efficiency field test: Energy savings and performance of an improved energy conservation measure selection technique, Oak Ridge National Laboratory report ORNL/CON-303.

Ternes, M. P. and W. P. Levins, (1991b). The Oklahoma field test: Space-cooling electricity savings from standard energy conservation measures, radiant barriers, and high-efficiency window air conditioners, Oak Ridge National Laboratory report ORNL/CON-317.

Wall Street Journal (1990). "Commercial Crunch," The Wall Street Journal Reports, Real Estate, p R10, August 10, 1990. 
Wilkes, K. E., (1988). "Modeling of residential attics with radiant barriers," Proceedings of the 5th annual symposium on improving building energy efficiency in hot and humid climates, pp. 161-168, College Station, TX: Texas A\&M University.

Wilkes, K. E., (1989). "Thermal modeling of residential attics with radiant barriers: Comparison with laboratory and field data," Proceedings, Thermal performance of the exterior envelopes of buildings $I V$, Atlanta: ASHRAE, pp. 294-311.

Wilkes, K. E., (1990). "Analysis of annual energy savings due to radiant barriers," Proceedings of the ACEEE 1990 summer study on energy efficiency in buildings, Vol. 1, pp. 235-245, Washington: American Council for an Energy Efficient Economy.

Wilkes, K. E., (1991a). Analysis of annual thermal and moisture performance of radiant barrier systems, Oak Ridge National Laboratory report ORNL/CON-319.

Wilkes, K. E., (1991b). Thermal model of attic systems with radiant barriers, Oak Ridge National Laboratory report ORNL/CON-262.

Wikcox, B., M. O'Kelly, and J. Lutz (1990). "Air tightness and air change rates in typical new Califomia homes," Proceedings of the ACEEE 1990 summer study on energy efficiency in buildings, V 9, pp 9.309-9.316, Washington: American Council for an Energy Efficient Economy. 


\section{BIBLIOGRAPHY}

Burns, R. and R. E. Hough, (1991). Evaluation of electric demand effects from air conditioner efficiency improvement in single family houses, Oak Ridge National Laboratory report ORNL/Sub/86-SA566/V.

Cook, J. C., D. W. Yarbrough, and K. E. Wilkes, (1989). "Contamination of reflective foils in horizontal applications and the effect on thermal performance," ASHRAE Transactions, Vol. 95, Part 2.

Diamond, R. C. and D.J. Dickerhoff, Guidelines for air-leakage measurements in single and multifamily buildings, Lawrence Berkeley Laboratory report LBL-22635, draft.

Diamond, R. C. (1988). "Building managers: the Actors behind the scene," Home Energy, V 5(2) pp 31-34 (March/April).

Dumortier, D. and M.P. Modera (1988). A model for predicting air flow through venting systems for multiple combustion applications, Lawrence Berkeley Laboratory report LBL-23151.

Hough, R. E., and Burns, P. R. (1990). "Effectiveness of an air contitioner replacement program in Austin, Texas." ASHRAE Transactions, Vol. 96, Pt.2, Atlanta: ASHRAE.

Judkoff, R. et al (1988). Mobile home weatherization measures: A study of their effectiveness, Solar Energy Research Institute report SERI/TR-254-3440.

Judkoff, R. et al (1990). "CMFERT: Training and testing of mobile home retrofits," Home Energy, V 7(1) p 23 (January/February).

Judkoff, $R$. et al (1990). Testing the effectiveness of mobile home weatherization measures in a controlled environment: the SERI CMFERT project, Solar Energy Research Institute report SERI/TR-254-3629.

Judkof, R. (1991). "Mobile home retrofits revisited: CMFERT phase II," Home Energy, V 8(1) p 21 (January/February).

Lambert, L. A., and Robison, D. H. (1989). "Effects of ducted forced-air heating systems on residential air leakage and heating energy use." ASHRAE Transactions, Vol. 95, Pt.2, Atlanta: ASHRAE.

Levins, W. P., M. A. Karnitz, and J. A. Hall, (1989), Moisture measurements in single-family houses with attics containing radiant barriers, Oak Ridge National Laboratory report ORNL/CON-255.

Levins, W. P., M. A. Karnitz, and J. A. Hall, (1990), Cooling season energy measurements of dust and ventilation effects on radiant barriers, Oak Ridge National Laboratory report ORNL/CON-271.

MacDonald, J. M. (1988). "Power signatures as characteristics of commercial buildings," Proceedings of Fifth Annual Symposium on Improving Building Energy Efficiency in Hot and Humid Climates, College Station, TX: Texas A\&M University.

MacDonald, J. M., T. R. Sharp, and M. B. Gettings, (1989). A protocol for monitoring energy efficiency improvements in commercial and related buildings, Oak Ridge National Laboratory report ORNL/CON291.

MacDonald, J. M. and D. M. Wasserman, (1989). Investigation of metered data analysis methods for commercial and related buildings, Oak Ridge National Laboratory report ORNL/CON-279. 
MacDonald, J. M., and Sharp, T. R. (1989). "Load impacts of energy management hardware, " End-use load information and application conference for customer and utility communication. Syracuse, NY: The Fleming Group.

McLain, H.A.; MacDonald, J.M.; and Downing, D.J. (1988). An analytical investigation of energy end-use in commercial office buildings, Oak Ridge National Laboratory report ORNL/CON-250; Chicago: Gas Research Institute, report GRI-87/0318.

Miller, W. A. et al (1989). "Motor current signature analysis - A potential diagnostic for air conditioners," ASHRAE Transactions, V 95(1), pp 312-317.

Robinson, D. A. et al, (1991). Foundation insulation retrofits in single-family houses in Minnesota, Oak Ridge National Laboratory report ORNL/Sub/86-SA711/V.

Robinson, D. A., et al, (1990). "Cold climate foundation insulation retrofit performance." ASHRAE Transactions, Vol. 96, Pt.2, Atlanta: ASHRAE.

Robison, D. H., and Lambert, L. A. (1989a). "Effects of ducted forced-air heating systems on residential air leakage and heating energy use." ASHRAE Transactions, Vol. 95, Pt.2, Atlanta: ASHRAE.

Robison, D. H., and Lambert, L. A. (1989b). "Field investigation of residential infiltration and heating duct leakage." ASHRAE Transactions, Vol. 95, Pt.2, Atlanta: ASHRAE.

Sharp, T. R., and MacDonald, J. M. (1990). Measurement of energy performance in a small bank building, Oak Ridge National Laboratory report ORNL/CON-297.

Sharp, T. R., and MacDonald, J. M. (1990). "Effective, low-cost HVAC controls upgrade in a small bank building." ASHRAE Transactions, Vol. 96, Pt.1, Atlanta: ASHRAE.

Sharp, T. R. and M. P. Ternes, (1990). The North Carolina field test: Experimental plan, Oak Ridge National Laboratory report ORNL/TM-11339.

Szydlowski, R.F. and R.C. Diamond (1989). Data specification protocol for multifamily buildings, Lawrence Eerkeley National Laboratory report LBL-27206.

Ternes, M.P. (1987). Single-family building retrofit performance monitoring protocol: data specification guideline, Oak Ridge National Laboratory report ORNL/CON-196.

Ternes, M.P., (1990). “Energy savings and performance of an improved energy efficiency measure selection technique." ASHRAE Transactions, Vol. 96, Pt.2, Atlanta: ASHRAE.

Ternes, M. P. et al (1991). The national fuel end-use efficiency field test: Energy savings and performance of an improved energy conservation measure selection technique, Oak Ridge National Laboratory report ORNL/CON-303.

Ternes, M. P. and W. P. Levins, (1991). The Oklahoma field test: Space-cooling electricity savings from standard energy conservation measures, radiant barriers, and high-efficiency window air conditioners, Oak Ridge National Laboratory report ORNL/CON-317.

Ternes, M. P. and P. S. Hu, (1989). The Oklahoma cooling retrofit field test: Experimental plan, Oak Ridge National Laboratory report ORNL/TM-10761.

Ternes, M. P. and W. P. Levins, (1990). "Measured space-cooling electricity savings from standard energy conservation measures, radiant barriers, and high-efficiency window air conditioners," ACEEE 1990 
Summer Study on Energy Efficiency in Buildings, V. 9, pp. 9.299-308, Washington: American Council for an Energy Efficient Economy.

Ternes, M. P. and P. S. Hu, (1988). The national fuel gas end-use efficiency field test: Experimental plan, Oak Ridge National Laboratory report ORNL/TM-10760.

Ternes, M.P. (1990). " Energy savings and performance of an improved energy efficiency measure selection technique," ASHRAE Transactions, V. 96, Pt. 2, pp. 598-605.

Ternes, M. P. et al (1991). The national fuel end-use efficiency field test: Energy savings and performance of an improved energy conservation measure selection technique, Oak Ridge National Laboratory report ORNL/CON-303.

Wilkes, K. E., (1989). "Thermal modeling of residential attics with radiant barriers: Comparison with laboratory and field data," Proceedings, Thermal performance of the exterior envelopes of buildings $I V$, pp. 294-311, Atlanta: ASHRAE.

Wilkes, K. E., (1990). "Analysis of annual energy savings due to radiant barriers," Proceedings of the ACEEE 1990 summer study on energy efficiency in buildings, Vol. 1, pp. 235-245, Washington: American Council for an Energy Efficient Economy.

Wilkes, K. E., (1991). Analysis of annual thermal and moisture performance of radiant barrier systems, Oak Ridge National Laboratory report ORNL/CON-319.

Wilkes, K. E., (1991). Thermal model of attic systems with radiant barriers, Oak Ridge National Laboratory report ORNL/CON-262. 


\section{INTERNAL DISTRIBUTION}

$\begin{aligned} \text { 1. } & \text { J. M. MacDonald } \\ \text { 2. } & \text { M. P. Ternes } \\ \text { 3. } & \text { W. R. Mixon } \\ \text { 4. } & \text { T. R. Sharp } \\ \text { 5. } & \text { J. O. Kolb } \\ \text { 6. } & \text { K. E. Wilkes } \\ \text { 7. } & \text { D. C. Bauer } \\ \text { 8. } & \text { V. D. Baxter } \\ \text { 9. } & \text { L. G. Berry } \\ \text { 10. } & \text { M. A. Broders } \\ \text { 11. } & \text { M. A. Brown } \\ \text { 12. } & \text { J. B. Cannon } \\ \text { 13. } & \text { R. S. Carlsmith } \\ \text { 14. } & \text { J. E. Christian } \\ \text { 15. } & \text { G. E. Courville } \\ \text { 16. } & \text { F. A. Creswick } \\ \text { 17. } & \text { A. O. Desjarlais } \\ \text { 18. } & \text { P. D. Fairchild } \\ \text { 19. } & \text { W. Fulkerson }\end{aligned}$

20. M. B. Gettings

21. P. J. Hughes

22. M. A. Kuliasha

23. W. P. Levins

24. H. A. McLain

25. A. C. Schaffhauser

26. R. B. Shelton

27. J. J. Tomlinson

28. D. L. White

29. T. J. Wilbanks

30-228. Energy Conservation Dist., Building 3147, MS-6070

229-230. Central Research Library

231. Document Reference Section

232. Laboratory Records-RC

233. Laboratory Records

234. ORNL Patent Office

235. ORNL Laboratory Protection Division

236. ORNL Public Relations Division

\section{EXTERNAL DISTRIBUTION}

237-246. R. Anderson, 1617 Cole Blvd., Solar Energy Research Institute, Golden, CO 80401

247. B. Howard, Alliance to Save Energy, 1725 K St., N.W., Suite 914, Washington, DC 20006-1401

248-320. E. C. Freeman, CE-421, U.S. Department of Energy, 1000 Independence Ave., Washington, DC 20585

321. H. M. Ingram, Director, Udall Center for Studies in Public Policy, The University of Arizona, 803/811 East First St, Tucson, AZ 85719

322. C. D. MacCracken, Calmac Manufacturing Corp., P.O. Box 710, Englewood, NJ 07631

323. P. E. Mihlmester, Aspen Systems Corp., Fairbanks Plaza, 575 Oak Ridge Tumpike, Oak Ridge, TN 37830

324-350. M. P. Modera, B 90-3074, Lawrence Berkeley Laboratory, Berkeley, CA 94720

351-371. R. Pratt, Pacific Northwest Laboratory, P.O. Box 999, Richland, WA 99352

372. R. L. Ritschard, B90-4000, Lawrence Berkeley Laboratory, Berkeley, CA 94720

373. J. B. Shrago, Director, Office of Technology Transfer, 405 Kirkland Hall, Vanderbilt University, Nashville, TN 37240

374 Office of the Assistant Manager for Energy Research and Development, U.S. Department of Energy, P.O. Box 2001, Oak Ridge, TN 37831-8600

375-384. Office of Scientific and Technical Information, U.S. Department of Energy, P.O. Box 62, Oak Ridge, TN 37831 
DATE FILMED $6 / 21 / 93$ 
